\title{
Molecular Strategies to Modulate the Electrochemical Properties of P-Type Si(111) Surfaces Covalently Functionalized with Ferrocene and Naphthalene Diimide
}

Arindam Mukhopadhyay, ${ }^{\mathrm{a}}$ Brianna Bernard, ${ }^{\mathrm{a}}$ Kaixuan Liu, ${ }^{\mathrm{a}}$ Victor Paulino, ${ }^{\mathrm{a}}$ Chuan Liu, ${ }^{\mathrm{a}}$ Carrie Donley, ${ }^{\mathrm{b}}$ and Jean-Hubert Olivier ${ }^{\mathrm{a}^{*}}$

a Department of Chemistry, University of Miami, Cox Science Center, 1301 Memorial Drive, Coral Gables, FL 33146

${ }^{\mathrm{b}}$ Chapel Hill Analytical and Nanofabrication Laboratory, Department of Applied Physical Sciences, University of North Carolina, 243 Chapman Hall, Chapel Hill, NC 27599

*Corresponding Author; E-mail: jh.olivier@miami.edu

\section{Table of Contents}

1. General Aspects, Materials and Instrumentation

S2

2. Synthetic Procedures and Characterization Data S3-S7

3. Tapping Mode AFM Images and Surface Roughness Data

S8-S14

4. XPS Characterization Data

5. Electrochemical Characterization of Functionalized Si Surfaces: Various S29-S33 Cyclic Voltammograms and Related Plots

6. Calculation of Surface Coverage of Immobilized Ferrocene in Si-Fc@1-4

7. Determination of the Rate of Electrochemical Oxidation of Organo-Iron S43-S44

8. Electrochemical Properties of Si-NDI@5 and Calculation of Surface Coverage of Immobilized NDI

9. IR, NMR and ESI-Mass Spectra

10. Key Abbreviations/Acronyms/Symbols Used 


\section{General Aspects, Materials and Instrumentation}

Air sensitive materials were handled inside a Braun Labmaster DP glove box. Standard Schlenk techniques were used to carry out reactions that are air-sensitive. Unless otherwise mentioned, all the chemicals were used as received from commercial sources. For instance, tetrabutylammonium fluoride, i.e., TBAF, in the form of $1 \mathrm{M}$ solution in THF (SigmaAldrich), ferrocenecarboxylic acid (Chem-Impex), 4-ethynylbenzyl alcohol (Santa Cruz Biotechnology), $N$-ethyl- $N$ '-(3-dimethylaminopropyl)carbodiimide hydrochloride, i.e., EDCI (Chem-Impex), $N, N, N^{\prime}, N^{\prime}$-tetramethyl-O-(1H-benzotriazol-1-yl)uronium hexafluorophosphate, i.e., HBTU (TCI Chemicals), 4-(dimethylamino)pyridine (ChemImpex), tetramethylfluoroformamidinium hexafluorophosphate, i.e., TFFH (TCI Chemicals), 1,7-octadiyne (TCI Chemicals), 2-azidoethanol (Toronto Research Chemicals), anhyd $\mathrm{CuSO}_{4}$ (Acros Organics), sodium L-ascorbate (TCI Chemicals), etc. were used as received without any further purification whatsoever. Conc. $\mathrm{H}_{2} \mathrm{SO}_{4}$ and $30 \% \mathrm{H}_{2} \mathrm{O}_{2}$ were purchased from VWR. Hydrofluoric acid (48 wt $\%$ in $\mathrm{H}_{2} \mathrm{O},>99.99 \%$ trace metals basis) was obtained from SigmaAldrich. All of the organic solvents (HPLC grade) employed for synthesis and purification via column chromatography were purchased from VWR; they were, namely, n-hexane, ethyl acetate, toluene, tetrahydrofuran (THF), dichloromethane (DCM), N,N-dimethylformamide $(\mathrm{DMF})$, acetonitrile $(\mathrm{MeCN})$, methanol $(\mathrm{MeOH})$, ethanol $(\mathrm{EtOH})$, water, etc. Anhyd THF was prepared by distillation over Na/benzophenone under Ar. Toluene, DCM, DMF, MeCN and $N, N$-diisopropylethylamine, i.e., Hünig's base (Sigma-Aldrich) were dehydrated by distillation over anhyd calcium hydride (Strem Chemicals) under Ar and stored over activated molecular sieves in Schlenk round bottom flasks prior to using. Column chromatography was carried out on the bench top using silica gel (VWR, 70-90 $\mu \mathrm{m}$ ). Solution-state photolysis reactions were carried out using a Rayonet photochemical reactor (Model: RMR-600; Southern New England Ultraviolet Company) fitted with 8 (each of $35 \mathrm{~W}$ ) UV lamps ( $\lambda=$ $254 \mathrm{~nm}$ ). IR spectra were obtained on a Perkin Elmer Frontier FTIR instrument. NMR spectra were recorded on an Advance Bruker $400 \mathrm{MHz}$ spectrometer using $\mathrm{CDCl}_{3}$ as the solvent (Cambridge Isotope Laboratories, Inc.) and referenced in ppm with respect to TMS using the residual $\mathrm{CDCl}_{3}$ signal as the internal reference. Mass spectra were recorded on a MicroQTOF ESI mass spectrometer. Room temperature (rt) refers to $25{ }^{\circ} \mathrm{C}$. The synthesis of 1,2diazidoethane $^{1}$ and bis(2-(N,N-dimethylamino)ethyl)-substituted NDI (4) $)^{2}$ was accomplished according to the literature-reported procedures. 


\section{Synthetic Procedures and Characterization Data}

\section{Synthesis of ((4-Ethynylbenzyl)oxy)triisopropylsilane (1)}

This compound was synthesized according to the literature-reported procedure in three steps as described below. ${ }^{3}$

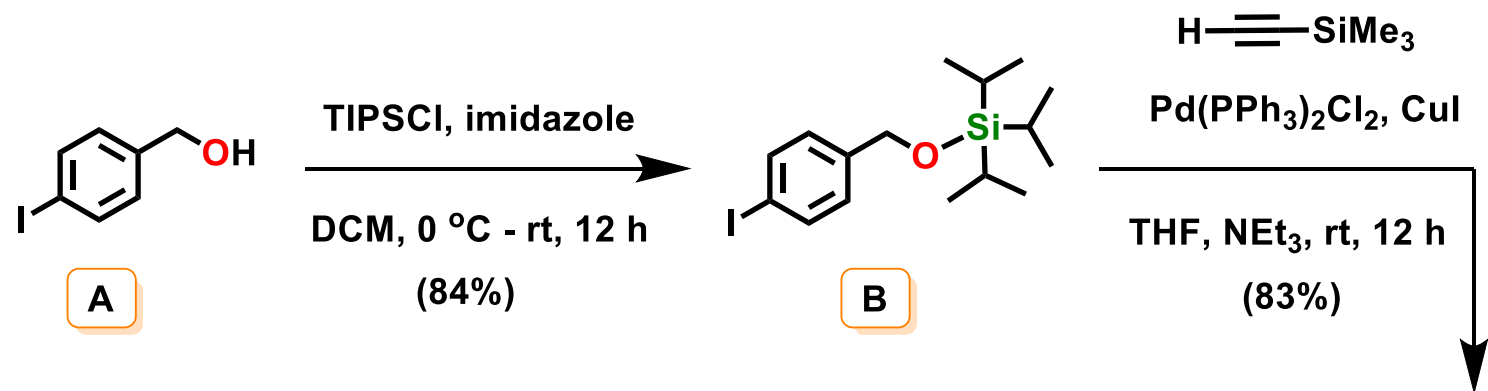

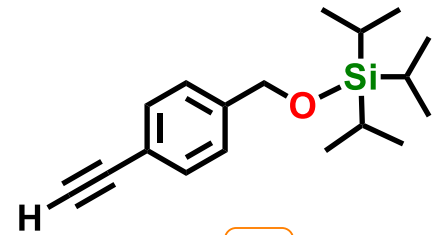

1

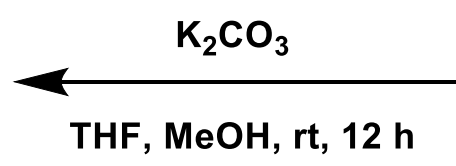

$(97 \%)$

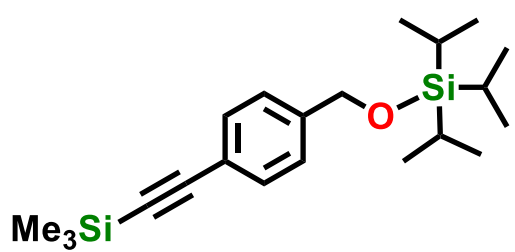

C

Step 1: Synthesis of ((4-Iodobenzyl)oxy)triisopropylsilane (B). ${ }^{3}$ The synthesis of $\mathbf{B}$ was accomplished by silylation of 4-iodobenzyl alcohol (A) with triisopropylsilyl chloride (TIPSCl) in the presence of imidazole.

In a typical procedure, a mixture of $\mathbf{A}(5.0 \mathrm{~g}, 21.36 \mathrm{mmol})$ and imidazole $(1.745 \mathrm{~g}, 25.63$ $\mathrm{mmol})$ in dry DCM $(200 \mathrm{~mL})$ was stirred under Ar gas atmosphere at $0{ }^{\circ} \mathrm{C}$. To this stirred reaction mixture, TIPSCl (4.94 g, $5.5 \mathrm{~mL}, 25.63 \mathrm{mmol})$ was added dropwise to give a milky white suspension. The contents were then stirred at $\mathrm{rt}$ for $12 \mathrm{~h}$ and subsequently quenched with water. The organic layer was extracted with DCM $(3 \times 60 \mathrm{~mL})$, dried over anhyd $\mathrm{Na}_{2} \mathrm{SO}_{4}$, filtered, and evaporated under reduced pressure to obtain crude product as a colorless oil. Crude purification using silica gel column chromatography (short-pad filtration column, 10\% DCM in hexane as the mobile phase) afforded the pure product as a colorless oil in 84\% yield (7.0 g). ${ }^{1} \mathrm{H}$ NMR (400 MHz, $\left.\mathrm{CDCl}_{3}\right) \delta 1.08-1.14(\mathrm{~m}, 21 \mathrm{H}), 4.80(\mathrm{~s}, 2 \mathrm{H})$, $7.13(\mathrm{~d}, J=8.0 \mathrm{~Hz}, 2 \mathrm{H}), 7.67(\mathrm{~d}, 2 \mathrm{H}, J=8.0 \mathrm{~Hz})$. 
Step 2: Synthesis of Triisopropyl((4-((trimethylsilyl)ethynyl)benzyl)oxy)silane (C). ${ }^{3}$ This compound was accessed by the Sonogashira cross coupling of $\mathbf{B}$ with trimethylsilylacetylene under $\mathrm{Pd}(\mathrm{II})$-catalyzed condition. A representative synthetic procedure is described below.

To a mixture of $\mathbf{B}(0.79 \mathrm{~g}, 2.02 \mathrm{mmol}), \mathrm{Pd}\left(\mathrm{PPh}_{3}\right)_{2} \mathrm{Cl}_{2}(0.142 \mathrm{~g}, 0.202 \mathrm{mmol})$ and $\mathrm{CuI}(0.038$ g, $0.202 \mathrm{mmol})$ contained in a Schlenk tube $(100 \mathrm{~mL})$, dry and deoxygenated THF $(20 \mathrm{~mL})$ and $\mathrm{NEt}_{3}(20 \mathrm{~mL})$ was added via cannulation under Ar gas atmosphere. To this stirred reaction mixture, trimethylsilylacetylene $(0.396 \mathrm{~g}, 0.56 \mathrm{~mL}, 4.04 \mathrm{mmol})$ was added dropwise at $\mathrm{rt}$ and stirred at $\mathrm{rt}$ under Ar for $12 \mathrm{~h}$, exhibiting a color change of orange-yellow to red and eventually to brownish-black. The reaction mixture was filtered through a short pad of celite and the black precipitate was washed with ethyl acetate $(10 \mathrm{~mL})$. The combined, filtered organic layer was evaporated under reduced pressure to obtain a crude material which, upon subjection to silica gel column chromatography (5\% DCM in hexane as the mobile phase), yielded the pure product as a colorless oil in $83 \%$ yield $(0.605 \mathrm{~g}) .{ }^{1} \mathrm{H}$ NMR $(400 \mathrm{MHz}$, $\left.\mathrm{CDCl}_{3}\right) \delta 0.26(\mathrm{~s}, 9 \mathrm{H}), 1.08-1.22(\mathrm{~m}, 21 \mathrm{H}), 4.83(\mathrm{~s}, 2 \mathrm{H}), 7.29(\mathrm{~d}, J=8.0 \mathrm{~Hz}, 2 \mathrm{H}), 7.44(\mathrm{~d}, J$ $=8.0 \mathrm{~Hz}, 2 \mathrm{H})$. ESI-MS ${ }^{+} \mathrm{m} / \mathrm{z}$ Calcd for $\mathrm{C}_{21} \mathrm{H}_{36} \mathrm{OSi}_{2} \mathrm{Na} 383.2202[\mathrm{M}+\mathrm{Na}]^{+}$, found 383.2201.

Step 3: Synthesis of ((4-Ethynylbenzyl)oxy)triisopropylsilane (1). ${ }^{3}$ Synthesis of 1 was accomplished by deprotection of the trimethylsilyl moiety in $\mathbf{B}$ under mild basic condition.

In a typical procedure, to a solution of $\mathbf{B}(0.35 \mathrm{~g}, 0.97 \mathrm{mmol})$ in a solvent mixture $(30 \mathrm{~mL})$ of $\mathrm{THF} / \mathrm{MeOH}(1: 9, \mathrm{v} / \mathrm{v})$, solid $\mathrm{K}_{2} \mathrm{CO}_{3}(6.7 \mathrm{~g}, 48.52 \mathrm{mmol})$ was added and the reaction mixture was stirred at $\mathrm{rt}$ for $12 \mathrm{~h}$, before solvent evaporation under reduced pressure. The dried contents were extracted with $100 \mathrm{~mL}$ of water with DCM $(3 \times 15 \mathrm{~mL})$, dried over anhyd $\mathrm{Na}_{2} \mathrm{SO}_{4}$, filtered, and evaporated under reduced pressure to give the crude product as a colorless oil. The oil was purified by silica gel column chromatography (short-pad filtration column, hexane as the mobile phase), giving the pure product as a colorless oil (0.272 $\mathrm{g}$, 97\%). ${ }^{1} \mathrm{H}$ NMR (400 MHz, $\mathrm{CDCl}_{3}$ ) $\delta 1.16-1.27$ (m, $\left.21 \mathrm{H}\right), 3.07$ (s, 1H), 4.89 (s, 2H), 7.37 (d, $J=8.0 \mathrm{~Hz}, 2 \mathrm{H}), 7.52(\mathrm{~d}, J=8.0 \mathrm{~Hz}, 2 \mathrm{H}) . \mathrm{ESI}_{-} \mathrm{MS}^{+} \mathrm{m} / \mathrm{z}$ Calcd for $\mathrm{C}_{18} \mathrm{H}_{28} \mathrm{OSiNa} 311.1807$ $[\mathrm{M}+\mathrm{Na}]^{+}$, found 311.1813 . 


\section{Synthesis of 4-Ethynylbenzyl Ferrocene Carboxylate (2)}

This ester was synthesized by the esterification of ferrocene carboxylic acid $\left(\mathrm{Fc}-\mathrm{CO}_{2} \mathrm{H}\right)$ with 4-ethynylbenzyl alcohol (EBA) in the presence of $N$-ethyl- $N$ '-(3dimethylaminopropyl)carbodiimide hydrochloride (EDCI) as the esterifying agent and 4(dimethylamino)pyridine (DMAP) as the base, according to the route shown below.
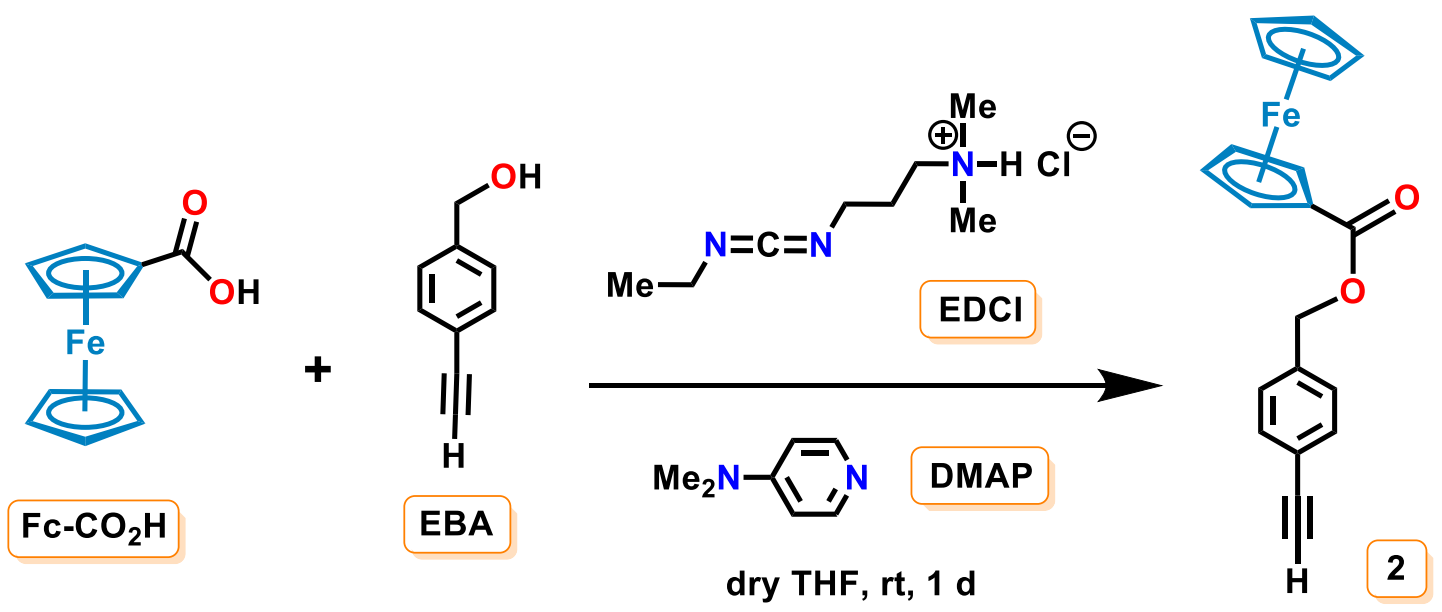

$(96 \%)$

In a typical procedure, a mixture of $\mathrm{Fc}-\mathrm{CO}_{2} \mathrm{H}(0.870 \mathrm{~g}, 3.78 \mathrm{mmol})$, EDCI $(1.451 \mathrm{~g}, 7.57$ mmol) and DMAP (2.31 g, $18.90 \mathrm{mmol})$ in dry THF $(40 \mathrm{~mL})$ was stirred at rt under Ar gas atmosphere for $1 \mathrm{~h}$. Subsequently, a solution of EBA $(0.5 \mathrm{~g}, 3.78 \mathrm{mmol})$ in dry THF $(15 \mathrm{~mL})$ was added dropwise and the resulting mixture was stirred at $\mathrm{rt}$ under Ar for $1 \mathrm{~d}$ and gave a white precipitate. The precipitate was removed after filtration and washing with THF and the resulting filtrate was dried to give an orange residue which was dissolved in DCM (30 mL). Subsequently, this DCM solution was washed with water and the organic layer was extracted with DCM $(3 \times 15 \mathrm{~mL})$. The combined organic layer was dried over anhyd $\mathrm{Na}_{2} \mathrm{SO}_{4}$, filtered, and evaporated under reduced pressure to obtain a crude orange solid. The latter was purified by silica gel column chromatography ( $8 \%$ ethyl acetate in hexane as the mobile phase) to give rise to the pure product as a crystalline orange-yellow solid in quantitative yield $(1.25 \mathrm{~g}$, 96\%). IR (neat solid) $\mathrm{cm}^{-1} 3268,1695,1461,1270,1128 ;{ }^{1} \mathrm{H} \mathrm{NMR}\left(400 \mathrm{MHz}, \mathrm{CDCl}_{3}\right) \delta 3.08$ (s, 1H), 4.12 (s, 5H), 4.40 (s, 2H), 4.83 (s, 2H), 5.25 (s, 2H), 7.42 (d, J=8.0 Hz, 2H), 7.52 (d, $J=8.0 \mathrm{~Hz}, \quad 2 \mathrm{H}) ; \quad{ }^{13} \mathrm{C} \quad \mathrm{NMR} \quad\left(101 \quad \mathrm{MHz}, \quad \mathrm{CDCl}_{3}\right) \quad \delta 65.22, \quad 69.68, \quad 70.15$, 71.40, 77.60, 83.26, 121.91,128.04, 132.26, 137.31, 171.39; ESI-MS ${ }^{+} \quad \mathrm{m} / \mathrm{z} \quad$ Calcd for $\mathrm{C}_{20} \mathrm{H}_{16} \mathrm{O}_{2} \mathrm{FeNa} 367.0397[\mathrm{M}+\mathrm{Na}]^{+}$, found 367.0382 . 


\section{Synthesis of 2-Azidoethyl Ferrocene Carboxylate (3)}

This ester was synthesized by the esterification of ferrocene carboxylic acid $\left(\mathrm{Fc}-\mathrm{CO}_{2} \mathrm{H}\right)$ with 2-azidoethanol (Az-EtOH) in the presence of $N$-ethyl- $N$ '-(3dimethylaminopropyl)carbodiimide hydrochloride (EDCI) as the esterifying agent and 4(dimethylamino)pyridine (DMAP) as the base, according to the route shown below.
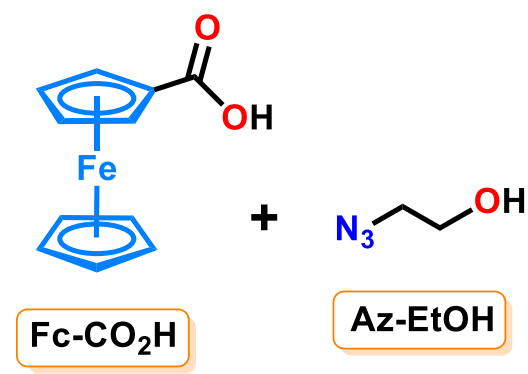

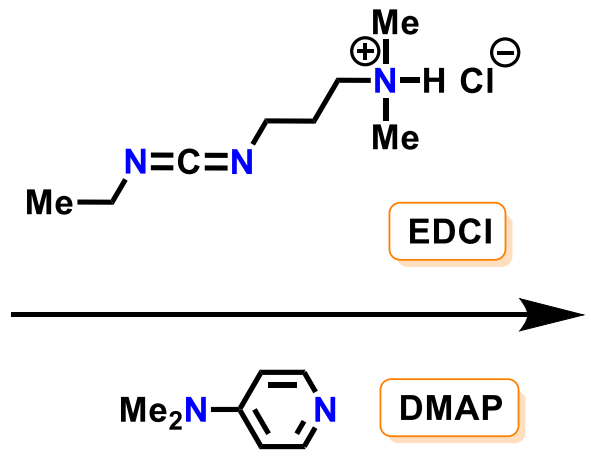

dry THF, rt, 1 d

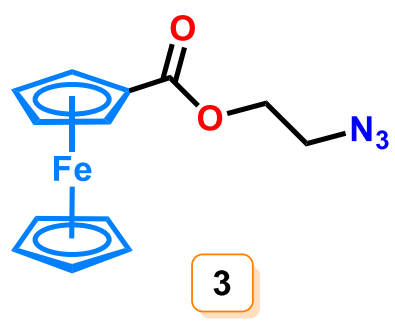

$(94 \%)$

The synthetic procedure was carried out in the same manner as that of 2 . In a typical

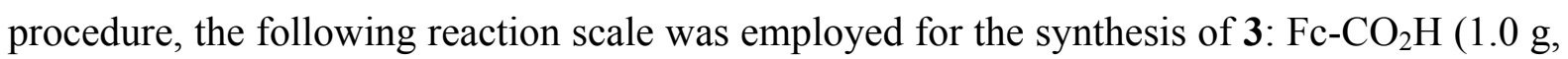
$4.35 \mathrm{mmol}$ ), EDCI (1.67 g, 8.70 mmol), DMAP (2.66 g, $21.75 \mathrm{mmol})$, Az-EtOH (0.379 g, $0.33 \mathrm{~mL}, 4.35 \mathrm{mmol})$ and dry THF (50 mL). Usual work up, as mentioned above, followed by purification of the crude material using silica gel column chromatography ( $8 \%$ ethyl acetate in hexane as the mobile phase) led to the pure product as crystalline orange-yellow solid in nearly quantitative yield (1.22 g, 94\%). IR (neat solid) $\mathrm{cm}^{-1} 2100,1704,1456,1260$, 1132; ${ }^{1} \mathrm{H}$ NMR (400 MHz, $\left.\mathrm{CDCl}_{3}\right) \delta 3.54(\mathrm{t}, J=4.0 \mathrm{~Hz}, 2 \mathrm{H}), 4.23(\mathrm{~s}, 5 \mathrm{H}), 4.40(\mathrm{t}, J=4.0$ $\mathrm{Hz}, 2 \mathrm{H}), 4.42$ (s, 2H), $4.84(\mathrm{~s}, 2 \mathrm{H}) ;{ }^{13} \mathrm{C} \mathrm{NMR}\left(101 \mathrm{MHz}, \mathrm{CDCl}_{3}\right) \delta 50.08,62.99,69.83$, 70.25, 71.56, 171.48; ESI-MS ${ }^{+} \mathrm{m} / \mathrm{z}$ Calcd for $\mathrm{C}_{13} \mathrm{H}_{13} \mathrm{O}_{2} \mathrm{~N}_{3} \mathrm{Fe} 299.0357$ [M] $]^{+}$, found 299.0378. 


\section{Synthesis of Alkyne-Substituted NDI (5)}

The alkyne-substituted NDI 5 was synthesized by mono-quaternization of the bis $(2-(\mathrm{N}, \mathrm{N}$ dimethylamino)ethyl)-substituted NDI 4 with propargyl chloride according to the route shown below. NDI 4 was prepared by a literature-reported procedure. ${ }^{2}$
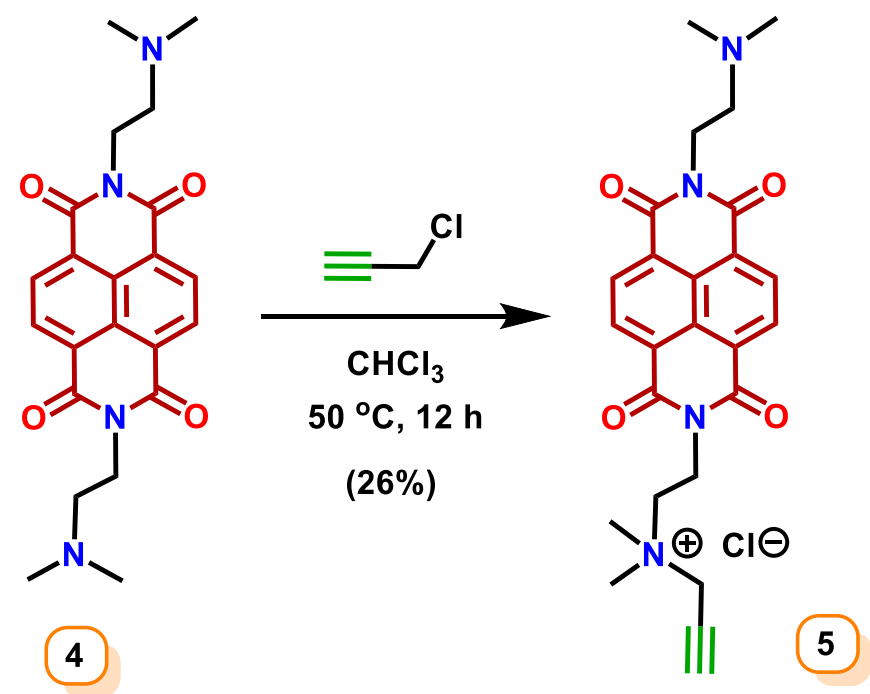

In a typical experiment, $4(3.0 \mathrm{~g}, 7.35 \mathrm{mmol})$ was dissolved in $90 \mathrm{~mL}$ of anhydrous $\mathrm{CHCl}_{3}$ under Ar gas atmosphere. To this solution, propargyl chloride $(0.48 \mathrm{~mL}, 6.61 \mathrm{mmol})$ was added and the reaction mixture was stirred at $50{ }^{\circ} \mathrm{C}$ overnight under Ar. Subsequently, the reaction mixture was cooled to $\mathrm{rt}$ and the resulting precipitate was filtered and washed with DCM. This crude product was purified by dissolving in DMF and re-precipitating using diethyl ether. The precipitate was then filtered and dried under vacuum to give rise to pure $\mathbf{5}$ as a dark yellow solid in $26 \%$ yield $(0.84 \mathrm{~g})$. IR (neat solid) $\mathrm{cm}^{-1} 3230,1700,1658,1583$, 1455, 1332, 1250, 1160, 1048; ${ }^{1} \mathrm{H}$ NMR (400 MHz, $\left.\mathrm{CD}_{3} \mathrm{OD}\right) \delta 0.86(\mathrm{~s}, 6 \mathrm{H}), 1.23(\mathrm{t}, J=6.6$ $\mathrm{Hz}, 2 \mathrm{H}), 1.78-1.80(\mathrm{~m}, 2 \mathrm{H}), 1.88(\mathrm{~s}, 6 \mathrm{H}), 2.33$ (t, $J=7.2 \mathrm{~Hz}, 2 \mathrm{H}), 2.83(\mathrm{t}, J=6.6 \mathrm{~Hz}, 2 \mathrm{H})$, $3.01(\mathrm{~s}, 1 \mathrm{H}), 3.16(\mathrm{t}, J=7.0 \mathrm{~Hz}, 2 \mathrm{H}), 7.19-7.28(\mathrm{~m}, 4 \mathrm{H}) ;{ }^{13} \mathrm{C} \mathrm{NMR}\left(101 \mathrm{MHz}, \mathrm{CD}_{3} \mathrm{OD}\right)$ $\delta 35.37,39.21,45.93,51.71,55.93,57.79,61.82,71.86,72.30,83.76,127.52,128.03$, 128.44, 131.80, 132.18, 164.36, 164.43; ESI-MS ${ }^{+} \mathrm{m} / \mathrm{z}$ Calcd for $\mathrm{C}_{25} \mathrm{H}_{27} \mathrm{~N}_{4} \mathrm{O}_{4} 447.2032[\mathrm{M}]^{+}$, found 447.2064 . 


\section{Tapping Mode AFM Images and Surface Roughness Data}

The tapping mode AFM images were recorded for all functionalized $\mathrm{Si}$ surfaces using a Digital Instruments Dimension 3100 microscope (located at the Dr. John T. Macdonald Foundation BioNIUM Institute in the University of Miami). The microscope was operated with 'Nanoscope 6' controller. The AFM images were collected under air at rt using tapping mode silicon tips (n-type, tip radius $<10 \mathrm{~nm}, f=43-81 \mathrm{kHz}, k=0.6-3.7 \mathrm{~N} / \mathrm{m}$ ) obtained from AppNano (FORTA-10). Typical scan rate was $0.8 \mathrm{~Hz}$. The data were analyzed using Gwyddion software (version 2.51).
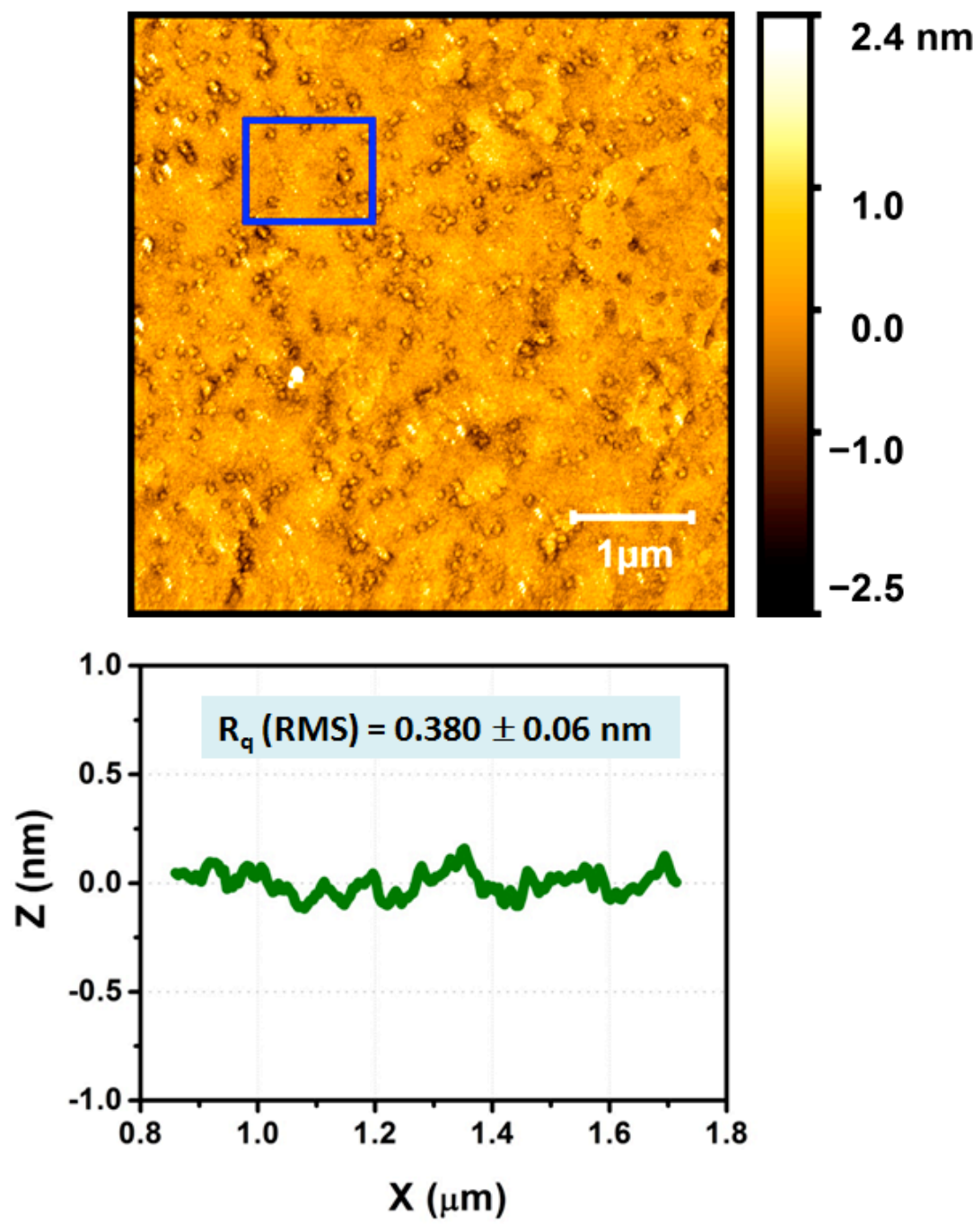

Figure S1. Tapping mode AFM image of the Si-BnE surface. The area on the AFM image marked with the blue square was probed to analyze the cross-section profile of the surface which is shown at the bottom. The $\mathrm{R}_{\mathrm{q}}(\mathrm{RMS})$ calculated for the cross-section profile is also shown in the profile; the standard deviation for the $\mathrm{R}_{\mathrm{q}}(\mathrm{RMS})$ data is based on at least 3 independent measurements. 

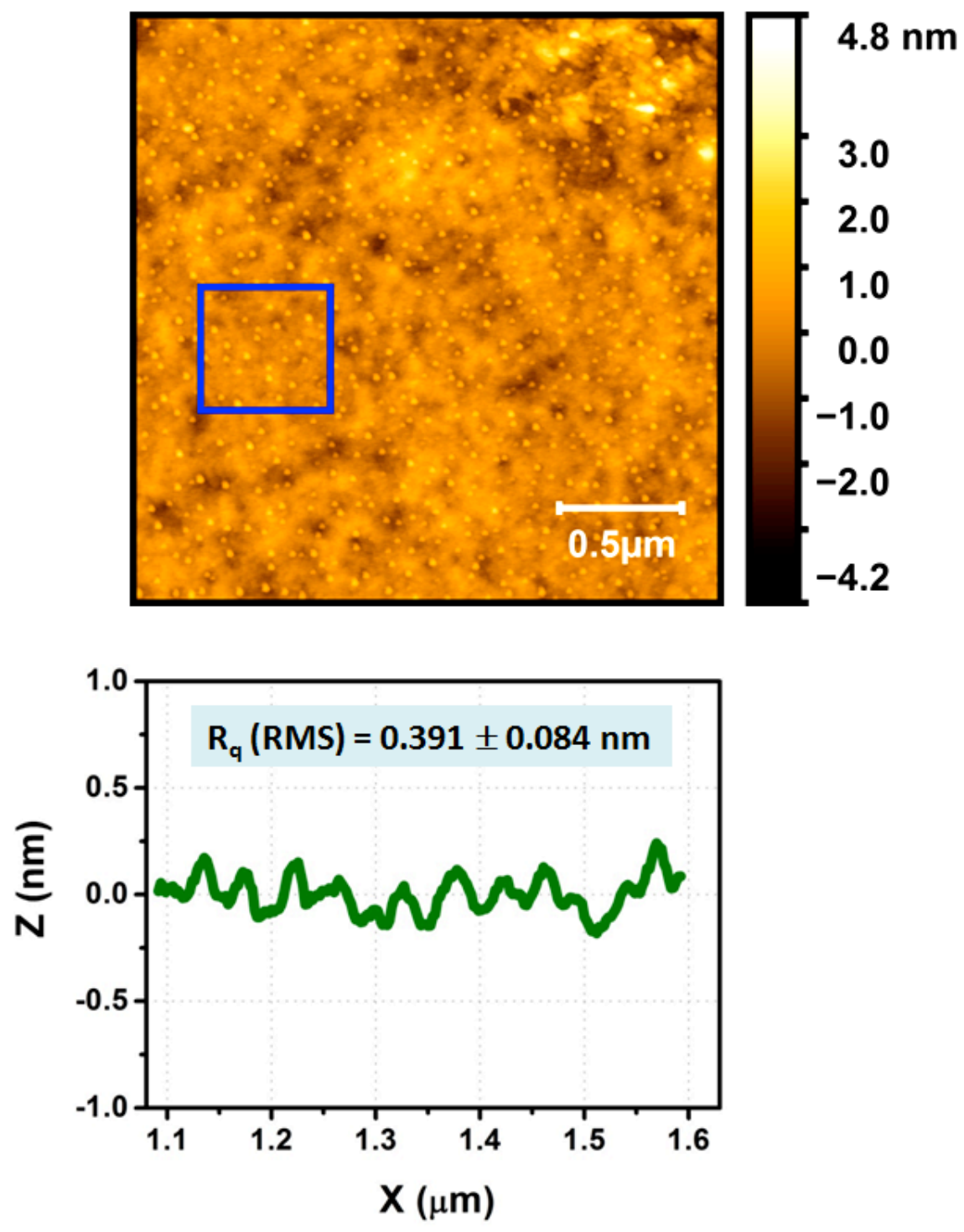

Figure S2. Tapping mode AFM image of the Si-BnA surface. The area on the AFM image marked with the blue square was probed to analyze the cross-section profile of the surface which is shown at the bottom. The $\mathrm{R}_{\mathrm{q}}(\mathrm{RMS})$ calculated for the cross-section profile is also shown in the profile; the standard deviation for the $\mathrm{R}_{\mathrm{q}}(\mathrm{RMS})$ data is based on at least 3 independent measurements. 

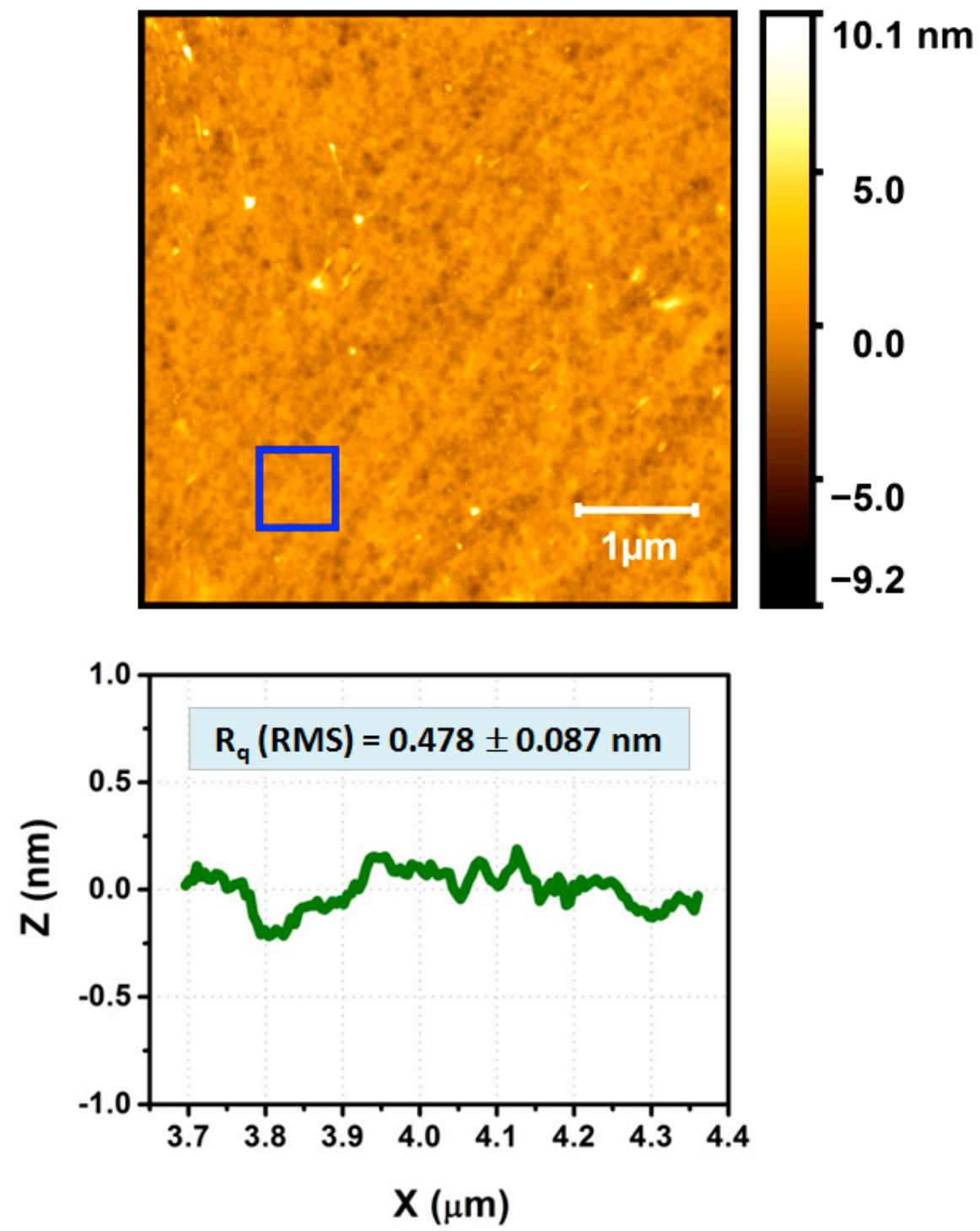

Figure S3. Tapping mode AFM image of the Si-Fc@2 surface. The area on the AFM image marked with the blue square was probed to analyze the cross-section profile of the surface which is shown at the bottom. The $\mathrm{R}_{\mathrm{q}}(\mathrm{RMS})$ calculated for the cross-section profile is also shown in the profile; the standard deviation for the $\mathrm{R}_{\mathrm{q}}(\mathrm{RMS})$ data is based on at least 3 independent measurements. 

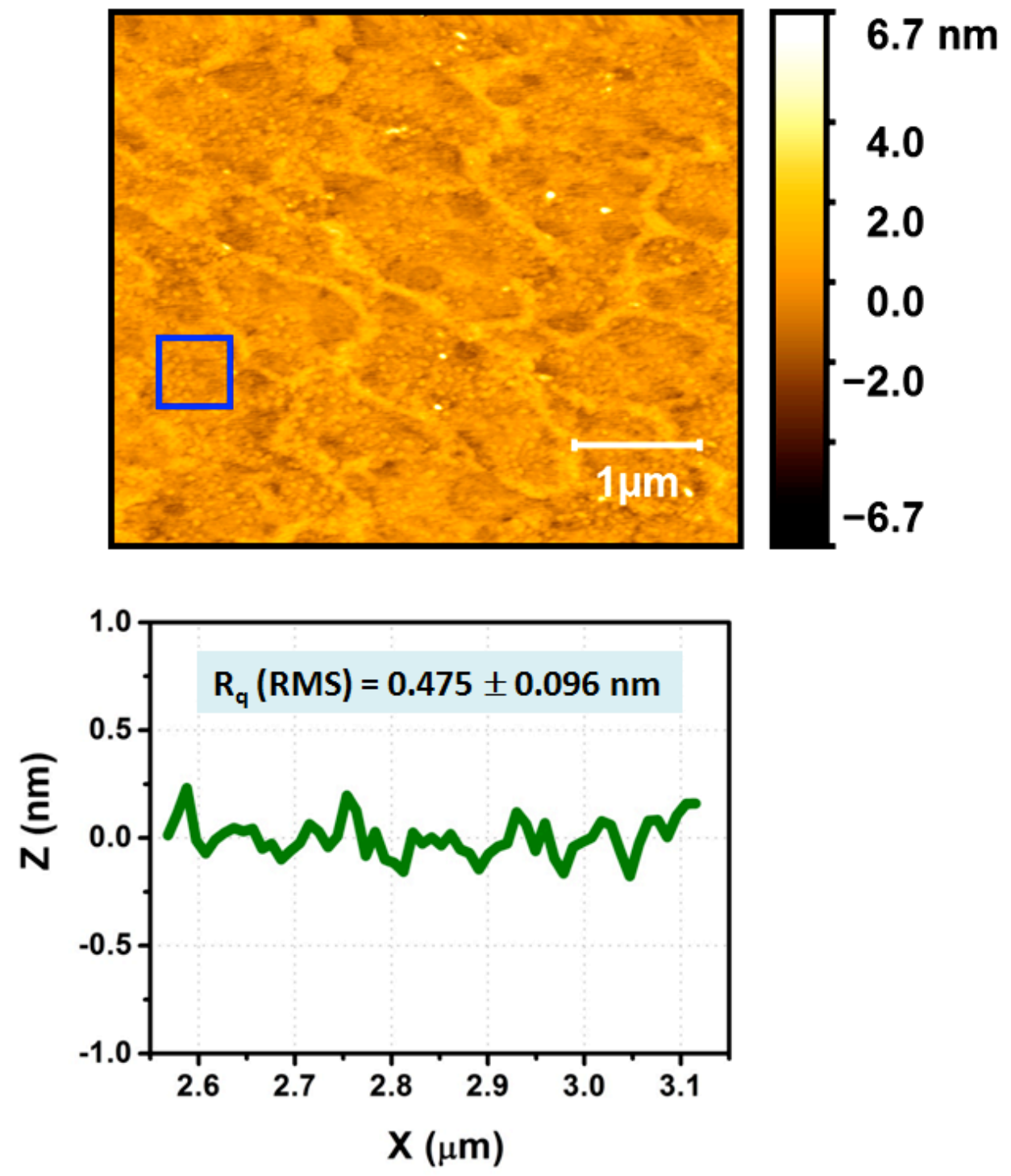

Figure S4. Tapping mode AFM image of the Si-Oct surface. The area on the AFM image marked with the blue square was probed to analyze the cross-section profile of the surface which is shown at the bottom. The $\mathrm{R}_{\mathrm{q}}(\mathrm{RMS})$ calculated for the cross-section profile is also shown in the profile; the standard deviation for the $\mathrm{R}_{\mathrm{q}}(\mathrm{RMS})$ data is based on at least 3 independent measurements. 

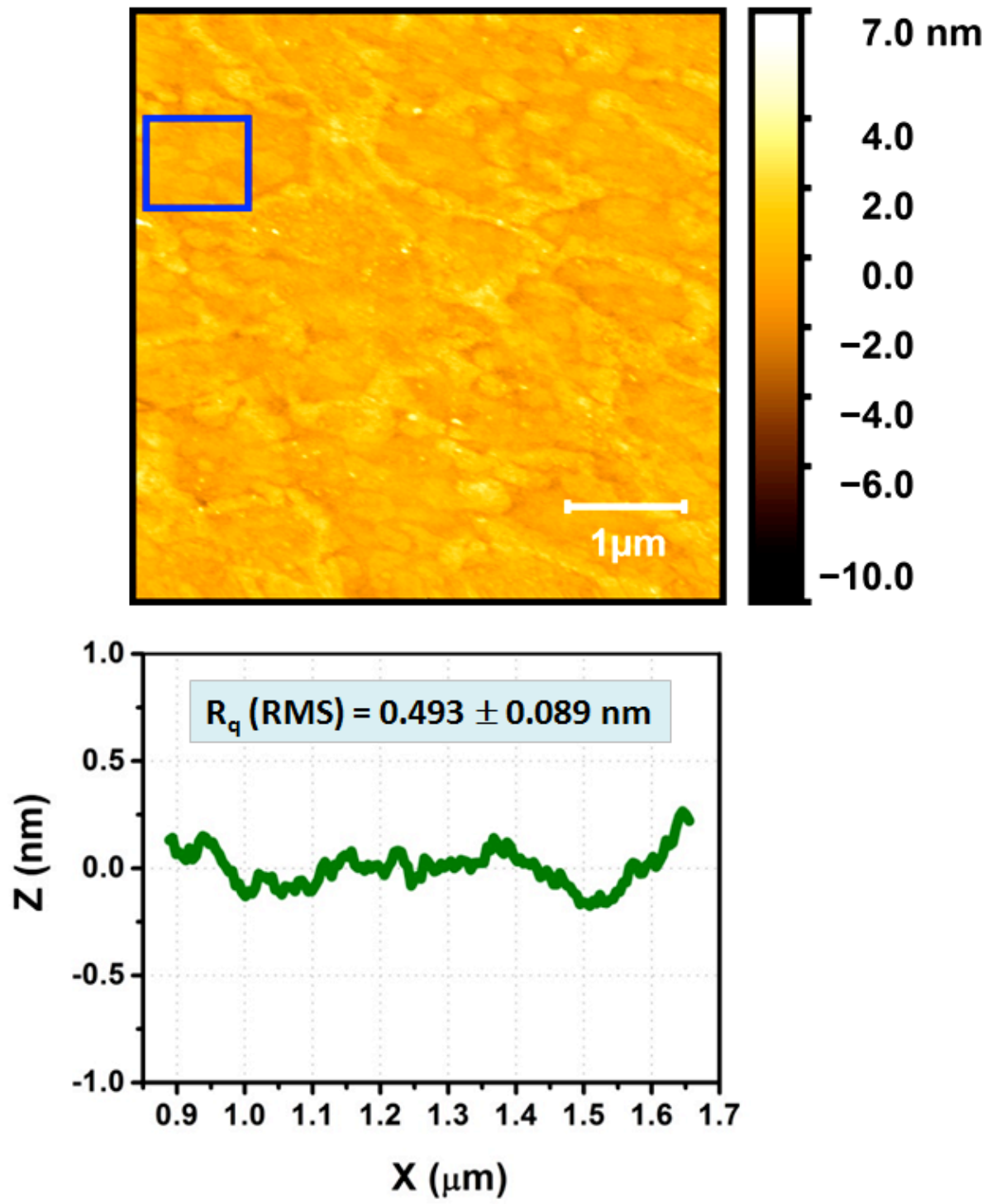

Figure S5. Tapping mode AFM image of the Si-Fc@4 surface. The area on the AFM image marked with the blue square was probed to analyze the cross-section profile of the surface which is shown at the bottom. The $\mathrm{R}_{\mathrm{q}}(\mathrm{RMS})$ calculated for the cross-section profile is also shown in the profile; the standard deviation for the $\mathrm{R}_{\mathrm{q}}(\mathrm{RMS})$ data is based on at least 3 independent measurements. 

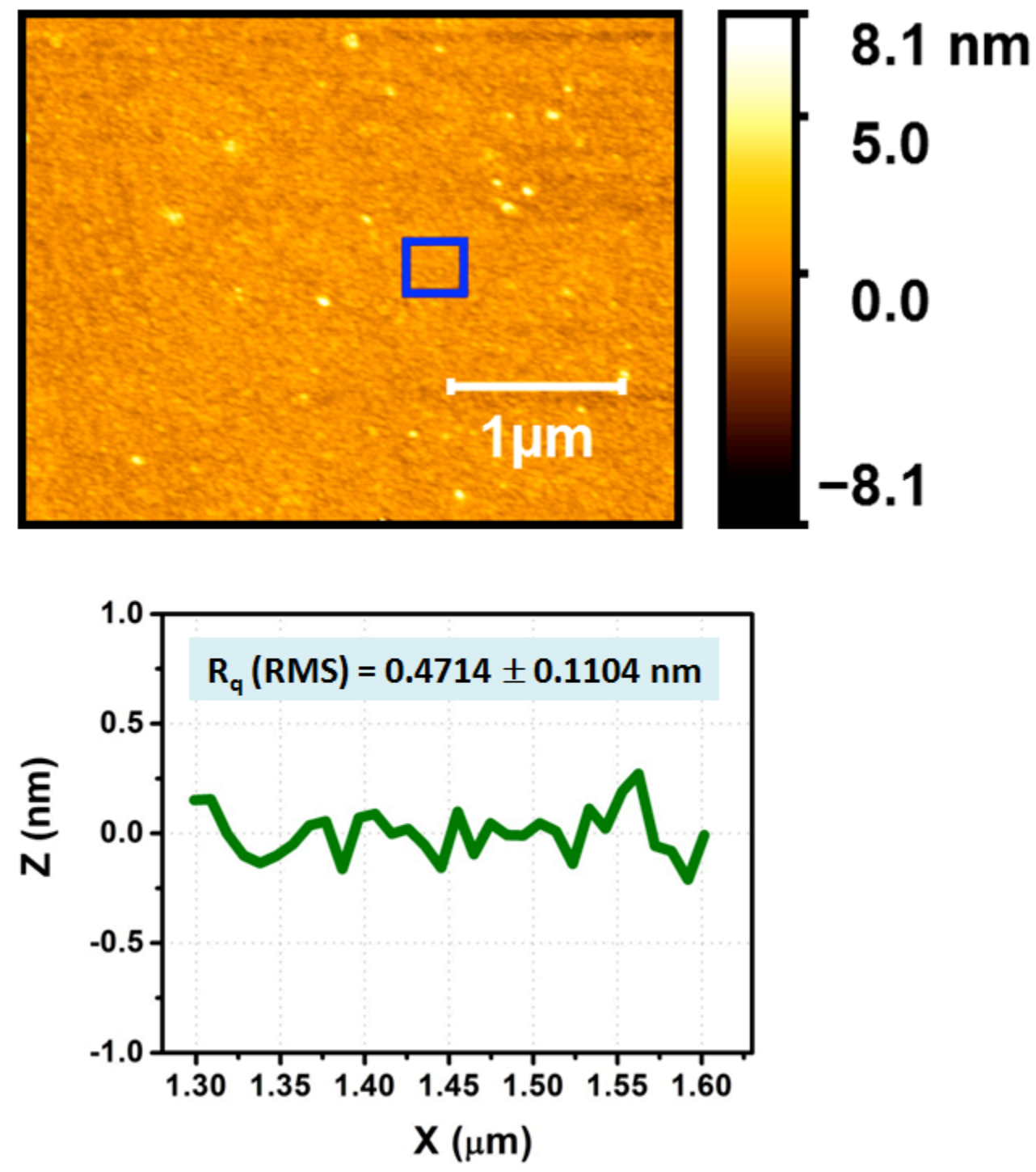

Figure S6. Tapping mode AFM image of the Si-Az surface. The area on the AFM image marked with the blue square was probed to analyze the cross-section profile of the surface which is shown at the bottom. The $\mathrm{R}_{\mathrm{q}}(\mathrm{RMS})$ calculated for the cross-section profile is also shown in the profile; the standard deviation for the $\mathrm{R}_{\mathrm{q}}(\mathrm{RMS})$ data is based on at least 3 independent measurements. 

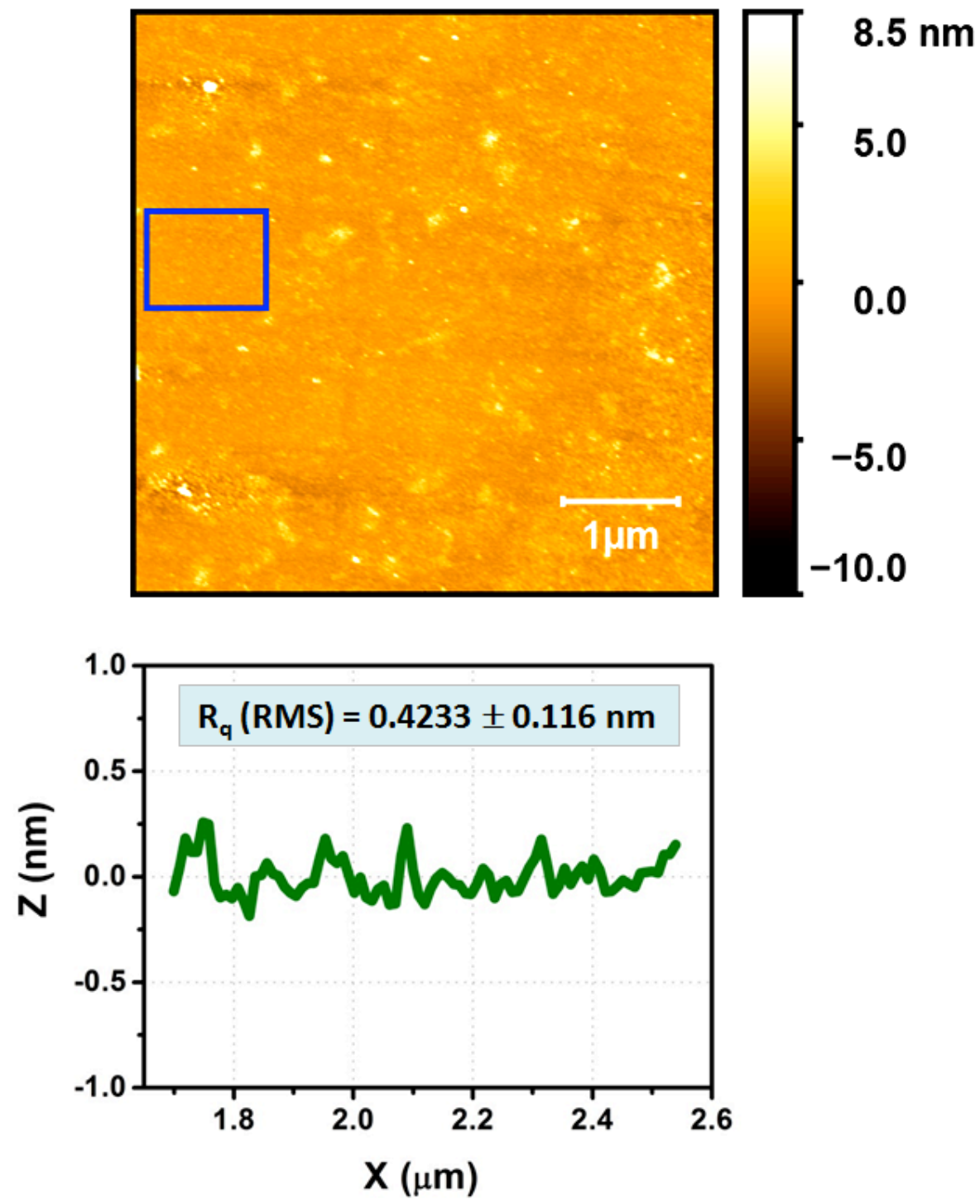

Figure S7. Tapping mode AFM image of the Si-NDI@5 surface. The area on the AFM image marked with the blue square was probed to analyze the cross-section profile of the surface which is shown at the bottom. The $\mathrm{R}_{\mathrm{q}}(\mathrm{RMS})$ calculated for the cross-section profile is also shown in the profile; the standard deviation for the $\mathrm{R}_{\mathrm{q}}(\mathrm{RMS})$ data is based on at least 3 independent measurements. 


\section{XPS Characterization Data}

XPS data was collected on a Kratos Axis Ultra DLD system with a monochromatic Al Ka source and a base pressure of ca. $6^{* 10^{\wedge-9}}$ torr. Survey and high resolutions scans were obtained at pass energies of 80 and $20 \mathrm{eV}$, respectively. A charge neutralizer was used for charge compensation, and all data was corrected to the $\mathrm{C} 1 \mathrm{~s}$ peak at $284.6 \mathrm{eV}$. 


\subsection{Representative High Resolution XPS Spectra}

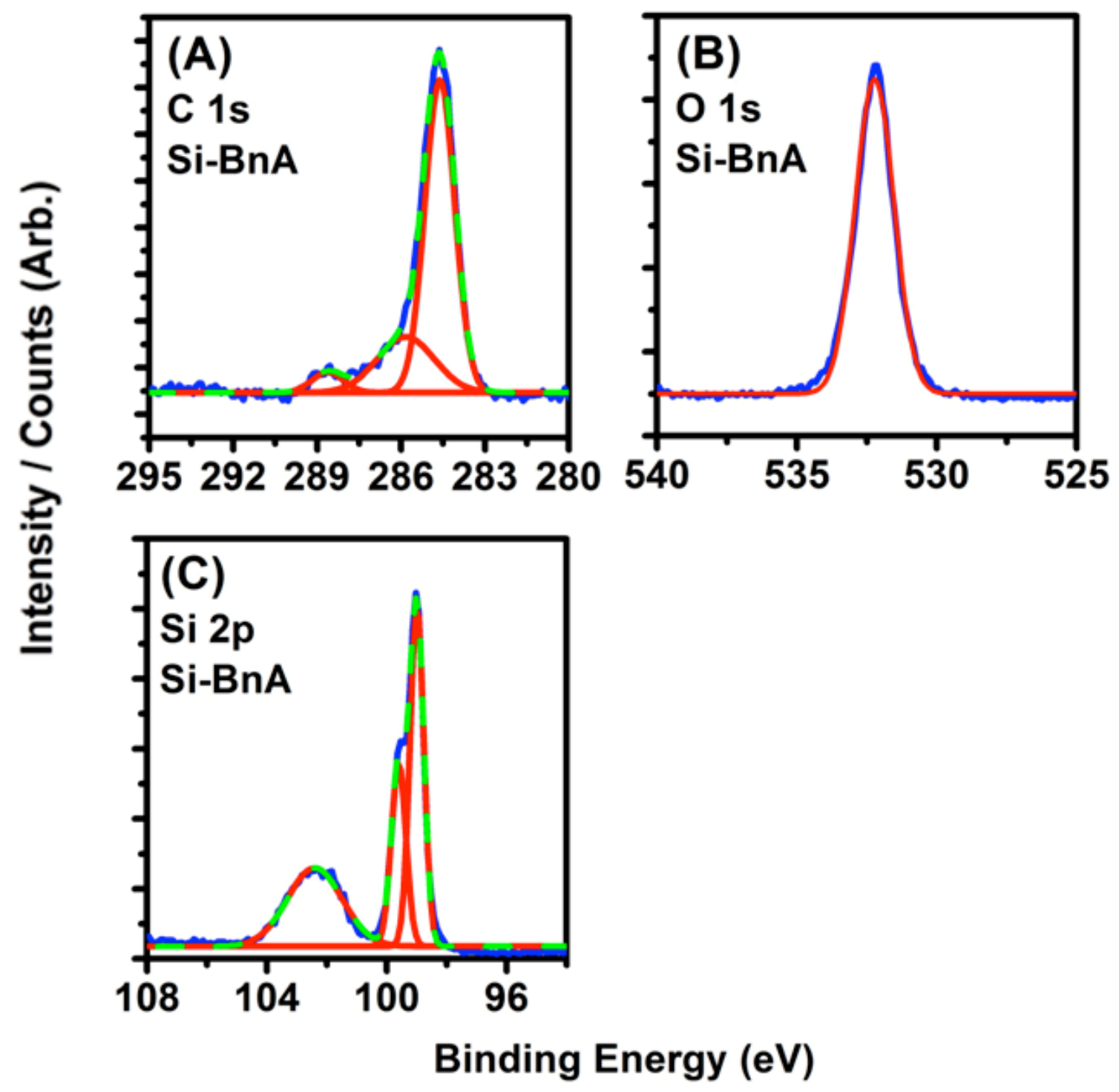

Figure S8. High resolution XPS spectra (blue), deconvoluted spectra (red), and sum (dashed green) of the pre-functionalized Si surface Si-BnA. (A) C 1s area. The high-energy peak centered at $288.6 \mathrm{eV}$ is assigned to $\mathrm{C}=\mathrm{O}$ bonds formed by the oxidation of benzylic alcohol. The contributions at $286.0 \mathrm{eV}$ and $284.6 \mathrm{eV}$ are ascribed to $\mathrm{C}-\mathrm{O}$ and $\mathrm{C}-\mathrm{C}$ bonds, respectively. (B) $\mathrm{O} 1 \mathrm{~s}$ area. (C) $\mathrm{Si} 2 \mathrm{p}$ area that underscores the formation of $\mathrm{SiO}_{\mathrm{x}}$ as evidenced by the peak centered at $102.5 \mathrm{eV}$. 

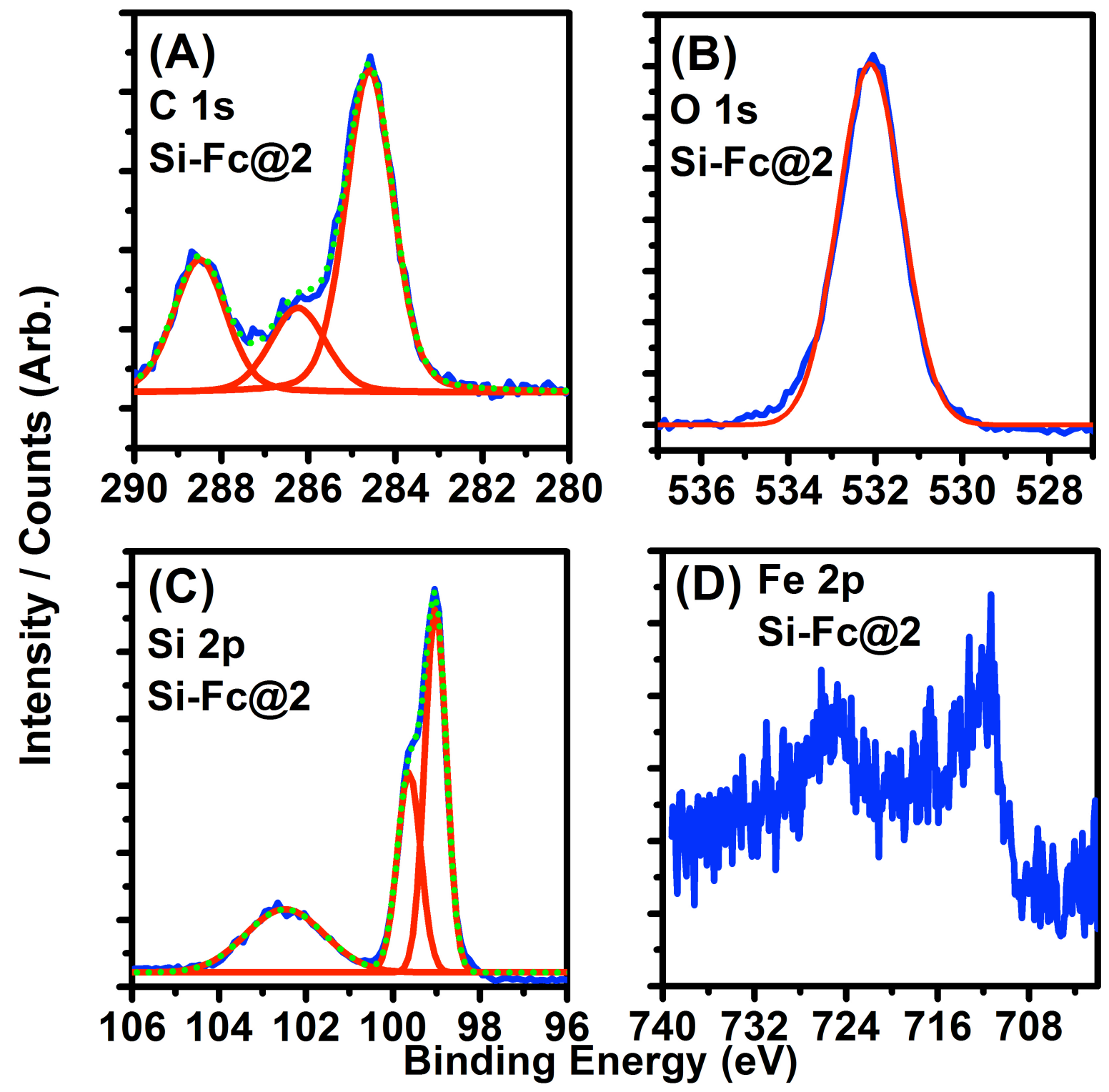

Figure S9. High resolution XPS spectra (blue), deconvoluted spectra (red), and sum (dashed green) of the Fc-functionalized surface Si-Fc@2: (A) C 1s area; the high-energy peak centered at $288.5 \mathrm{eV}$ is assigned to $\mathrm{C}=\mathrm{O}$ bonds, the contributions at $286.24 \mathrm{eV}$, and $284.6 \mathrm{eV}$ are ascribed to C-O, and C-C bond, respectively. (B) O 1s area. (C) Si 2p area of Si-Fc@2 that underscores the formation of $\mathrm{SiO}_{\mathrm{x}}$ as evidenced by the peak centered at $102.5 \mathrm{eV}$. (D) $\mathrm{Fe}$ $2 p$ area of Si-Fc@2 that shows two spin-orbit split components 1/2 and 3/2 centered at 725.8 $\mathrm{eV}$ and $711.7 \mathrm{eV}$, respectively. 


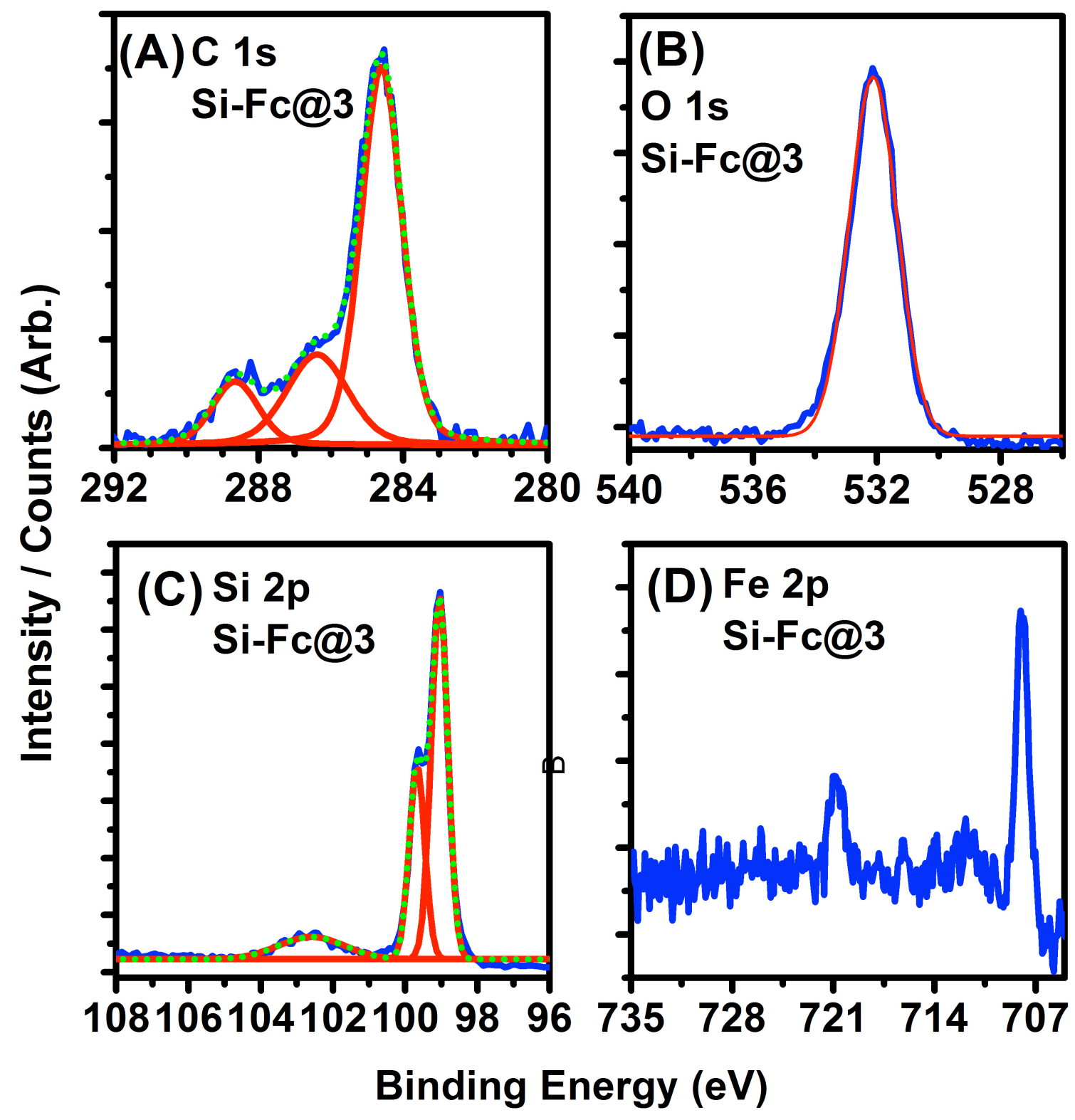

Figure S10. High resolution XPS spectra (blue), deconvoluted spectra (red), and sum (dashed green) of the Fc-functionalized surface Si-Fc@3: (A) C 1s area; the high-energy peak centered at $288.6 \mathrm{eV}$ is assigned to $\mathrm{C}=\mathrm{O}$ bonds, the contributions at $286.4 \mathrm{eV}$, and $284.7 \mathrm{eV}$ are ascribed to $\mathrm{C}-\mathrm{O}$, and $\mathrm{C}-\mathrm{C}$ bond, respectively. (B) $\mathrm{N} 1 \mathrm{~s}$ area. The deconvolution into two Gaussian functions centered at $401.9 \mathrm{eV}$ and $400.1 \mathrm{eV}$ confirms the presence of two chemically distinct nitrogen atoms. (B) O 1s area. (C) Si 2p area of Si-Fc@3 that underscores modest formation of $\mathrm{SiO}_{\mathrm{x}}$ as evidenced by the peak centered at $102.5 \mathrm{eV}$. (D) Fe $2 \mathrm{p}$ area of Si-Fc@3 that shows two spin-orbit split components $1 / 2$ and $3 / 2$ centered at $720.1 \mathrm{eV}$ and $707.7 \mathrm{eV}$, respectively. 


\subsection{Qualitative Elemental Analysis}

Exploiting the high-resolution XPS spectra shown in Section 4.1 and applying a relative sensitivity factor (RSF), the ratio of $\mathrm{Fe}$ and $\underline{\mathrm{C}}=\mathrm{O}$ was estimated for $\mathbf{S i - F c @ 1 - 4 . ~ T h e ~ a t o m i c ~}$ concentration of $\underline{\mathrm{C}}=\mathrm{O}$ was calculated using the area of the deconvoluted spectra centered at $288.6 \mathrm{eV}$ and the total atomic concentration of $\mathrm{C} 1 \mathrm{~s}$ can be found in the table below summarizing the atomic concentration (corrected with relative sensitivity factor RSF) for relevant atoms. For example, using the deconvolution curves shown in Figure 2B, one can estimate the area of the $\underline{\mathrm{C}}=\mathrm{O}(288.6 \mathrm{eV}$, area $=811), \mathrm{C}-\mathrm{O}(286.4 \mathrm{eV}$, area $=869)$, and C-C $(284.6 \mathrm{eV}$, area $=3371)$ curves. The area of the carbon double bond oxygen peak is $16.05 \%$ of the total $\mathrm{C} 1 \mathrm{~s}$ peak area, resulting in an atomic concentration of $\mathrm{C}=\mathrm{O}$ of $4.6 \%$ in the table below. Comparing the atomic concentration of $\mathrm{C}=\mathrm{O}$ with that of $\mathrm{Fe}$ provides a means to estimate the ratio of $\mathrm{Fe}: \underline{\mathrm{C}}=\mathrm{O}$. This procedure has been applied to surfaces $\mathbf{S i - F c} @ \mathbf{1}-\mathbf{4}$.

\section{Analysis for Si-Fc@1:}

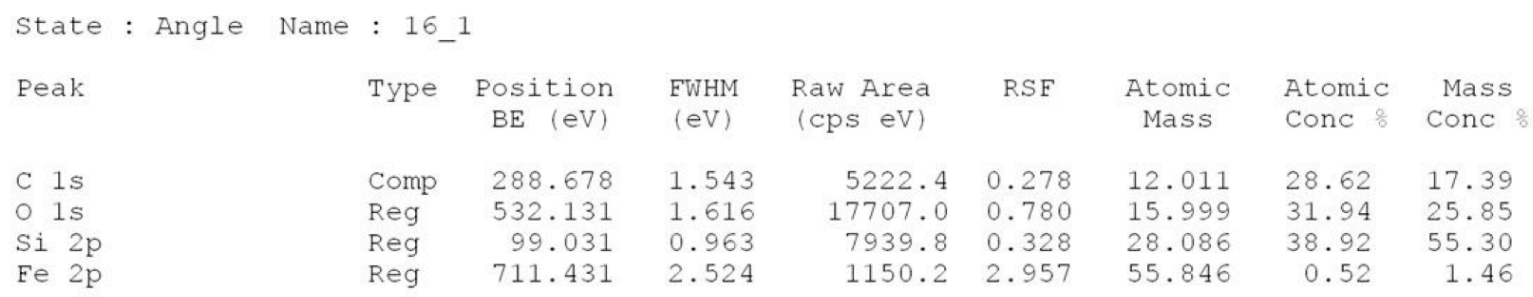

Considering that the atomic concentration of $\mathrm{C}=\mathrm{O}$ is $4.6 \%$, an estimated ratio of $1: 9$ for $\mathrm{Fe}: \underline{\mathrm{C}}=\mathrm{O}$ characterizes $\mathbf{S i - F c} @ \mathbf{1}$. It is fair to assume that the overestimation of $\mathrm{C}=\mathrm{O}$ may stem from adsorption of carbon-derived contaminants on the surface such as $\mathrm{CO}_{2}$.

\section{Analysis for Si-Fc@2:}

\begin{tabular}{|c|c|c|c|c|c|c|c|c|}
\hline Peak & Type & $\begin{array}{c}\text { Position } \\
\text { BE (eV) }\end{array}$ & $\begin{array}{l}\text { EWHM } \\
(\mathrm{eV})\end{array}$ & $\begin{array}{l}\text { Raw Area } \\
\text { (cps eV) }\end{array}$ & RSE & $\begin{array}{c}\text { Atomic } \\
\text { Mass }\end{array}$ & $\begin{array}{l}\text { Atomic } \\
\text { Conc \% }\end{array}$ & $\begin{array}{l}\text { Mass } \\
\text { Conc }\end{array}$ \\
\hline C $1 \mathrm{~s}$ & Comp & 288.501 & 1.537 & 4540.6 & 0.278 & 12.011 & 26.66 & 15.91 \\
\hline $01 \mathrm{~s}$ & Reg & 532.238 & 1.593 & 16287.4 & 0.780 & 15.999 & 31.47 & 25.02 \\
\hline Si $2 p$ & Reg & 99.138 & 0.932 & 7889.9 & 0.328 & 28.086 & 41.42 & 57.82 \\
\hline $\mathrm{Fe} 2 \mathrm{p}$ & Reg & 711.438 & 1.510 & 941.3 & 2.957 & 55.846 & 0.45 & 1.26 \\
\hline
\end{tabular}

Considering that the atomic concentration of $\mathrm{C}=\mathrm{O}$ is $4.8 \%$, an estimated ratio of $1: 11$ for $\mathrm{Fe}: \underline{\mathrm{C}}=\mathrm{O}$ characterizes $\mathbf{S i - F} @ \mathbf{c}$. It is fair to assume that the overestimation of $\mathrm{C}=\mathrm{O}$ may stem from adsorption of carbon-derived contaminants on the surface such as $\mathrm{CO}_{2}$. 


\section{Analysis for Si-Fc@3:}

\begin{tabular}{|c|c|c|c|c|c|c|c|c|}
\hline Peak & Type & $\begin{array}{c}\text { Position } \\
\text { BE (ev) }\end{array}$ & $\begin{array}{c}\text { EWHM } \\
(\mathrm{eV})\end{array}$ & $\begin{array}{c}\text { Raw Area } \\
\text { (cps eV) }\end{array}$ & RSF & $\begin{array}{c}\text { Atomic } \\
\text { Mass }\end{array}$ & $\begin{array}{l}\text { Atomic } \\
\text { Conc : }\end{array}$ & $\begin{array}{l}\text { Mass } \\
\text { Conc }\end{array}$ \\
\hline C $1 \mathrm{~s}$ & Comp & 288.431 & 1.776 & 3749.2 & 0.278 & 12.011 & 26.56 & 15.52 \\
\hline $01 \mathrm{~s}$ & Reg & 532.032 & 1.669 & 11951.2 & 0.780 & 15.999 & 27.86 & 21.69 \\
\hline Si $2 p$ & Reg & 99.032 & 0.958 & 7135.6 & 0.328 & 28.086 & 45.21 & 61.79 \\
\hline $\mathrm{Fe} 2 \mathrm{p}$ & Reg & 711.132 & 1.074 & 630.7 & 2.957 & 55.846 & 0.37 & 0.99 \\
\hline
\end{tabular}

Considering that the atomic concentration of $\mathrm{C}=\mathrm{O}$ is $3.1 \%$, an estimated ratio of $1: 8$ for $\mathrm{Fe}: \underline{\mathrm{C}}=\mathrm{O}$ characterizes $\mathbf{S i}-\mathbf{F c} @ 3$. It is fair to assume that the overestimation of $\mathrm{C}=\mathrm{O}$ may stem from adsorption of carbon-derived contaminants on the surface such as $\mathrm{CO}_{2}$..

\section{Analysis for Si-Fc@4:}

\begin{tabular}{|c|c|c|c|c|c|c|c|c|}
\hline Peak & Type & $\begin{array}{c}\text { Position } \\
B E(e V)\end{array}$ & $\begin{array}{l}\text { EWHM } \\
(\mathrm{eV})\end{array}$ & $\begin{array}{l}\text { Raw Area } \\
\text { (cps eV) }\end{array}$ & RSE & $\begin{array}{c}\text { Atomic } \\
\text { Mass }\end{array}$ & $\begin{array}{l}\text { Atomic } \\
\text { Conc }\end{array}$ & $\begin{array}{l}\text { Mass } \\
\text { Conc }\end{array}$ \\
\hline C $1 \mathrm{~s}$ & Comp & 288.496 & 1.622 & 5764.5 & 0.278 & 12.011 & 31.96 & 19.65 \\
\hline$N$ is & Reg & 399.957 & 0.867 & 455.5 & 0.477 & 14.007 & 1.42 & 1.02 \\
\hline $\mathrm{si} 2 \mathrm{p}$ & Reg & 98.957 & 0.984 & 7827.9 & 0.328 & 28.086 & 38.82 & 55.81 \\
\hline $\mathrm{Fe} 2 \mathrm{p}$ & Reg & 711.057 & 2.577 & 798.5 & 2.957 & 55.846 & 0.36 & 1.04 \\
\hline
\end{tabular}

Considering that the atomic concentration of $\mathrm{C}=\mathrm{O}$ is $4.2 \%$, an estimated ratio of $1: 12$ for $\mathrm{Fe}: \underline{\mathrm{C}}=\mathrm{O}$ characterizes $\mathrm{Si}-\mathbf{F c} @ \mathbf{4}$. It is fair to assume that the overestimation of $\mathrm{C}=\mathrm{O}$ may stem from adsorption of $\mathrm{CO}_{2}$ on the surface. In contrast, it is interesting to compare the atomic concentration ratio $\mathrm{N}: \mathrm{Fe}$. As can be seen from the table above, a ratio of 1:3.99 Fe: $\mathrm{N}$ can be calculated and matches the theoretical 1:3 ratio expected for Si-Fc@4.

\section{Analysis for Si-NDI@5:}

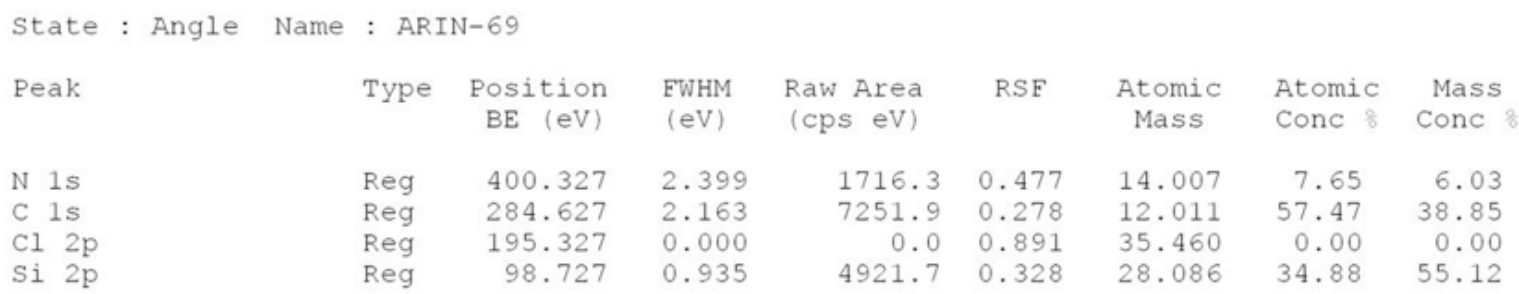




\subsection{Representative XPS Survey (Full) Spectra}

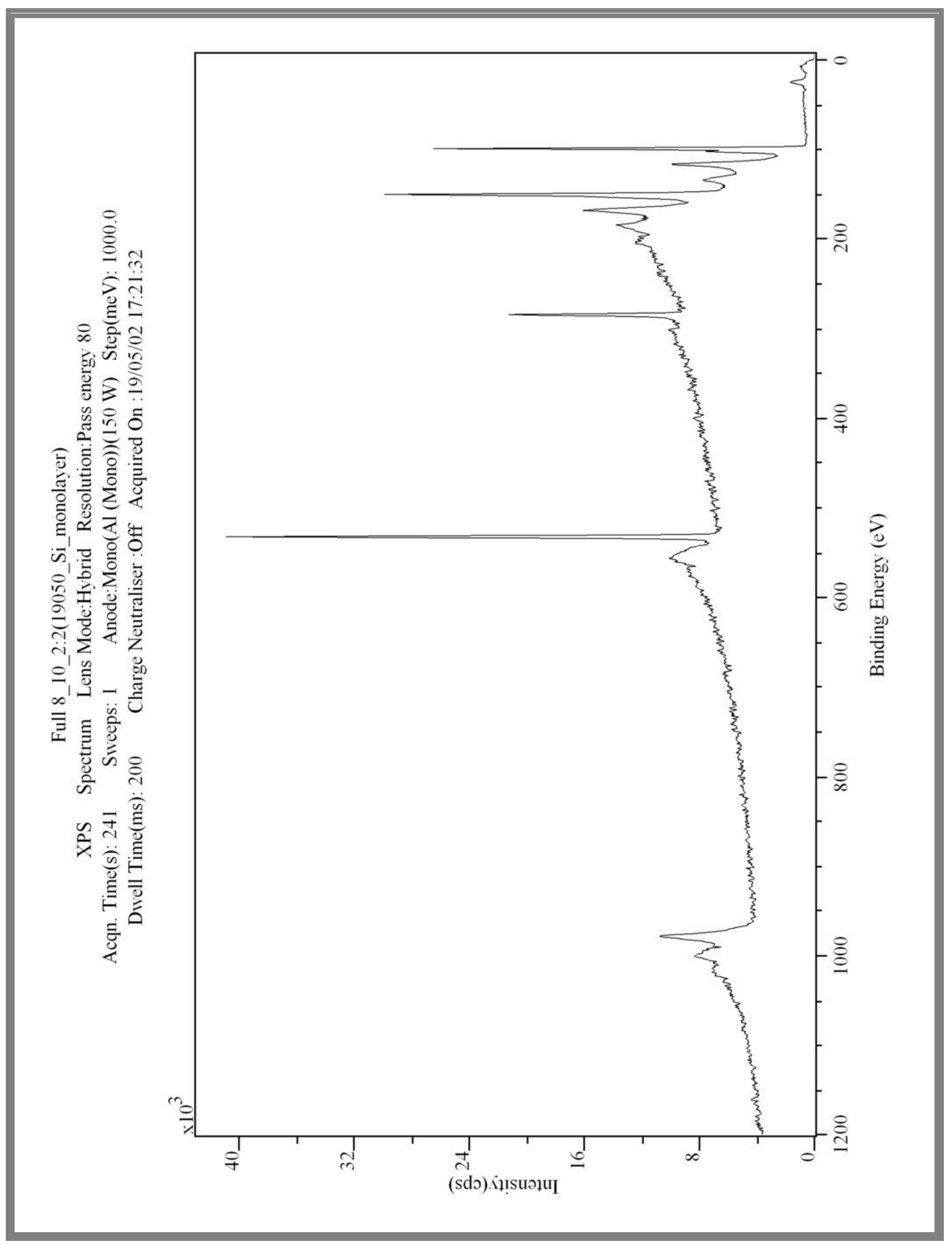

Figure S11. XPS survey spectrum (full) recorded for Si-BnE. 


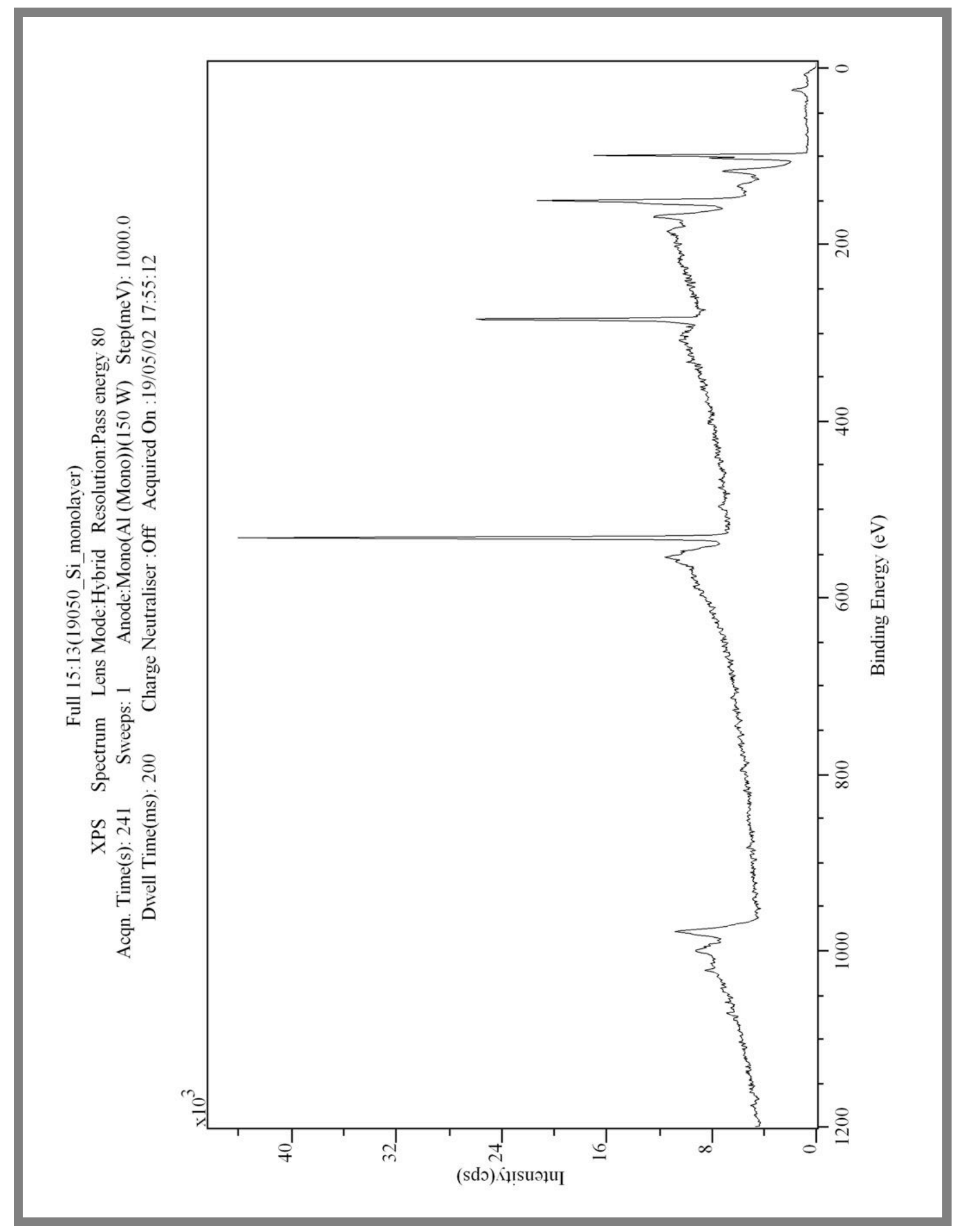

Figure S12. XPS survey spectrum (full) recorded for Si-BnA. 


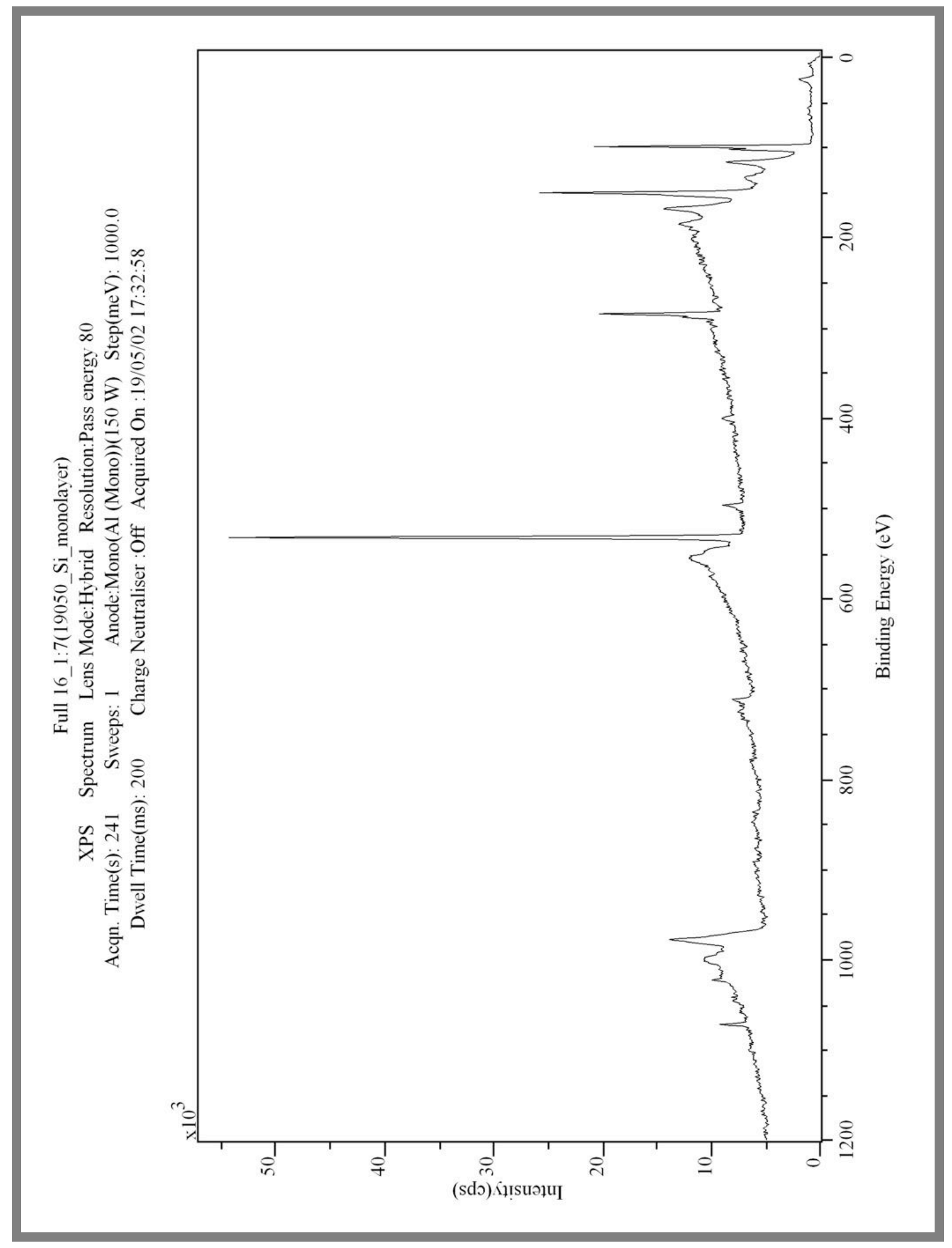

Figure S13. XPS survey spectrum (full) recorded for Si-Fc@1. 


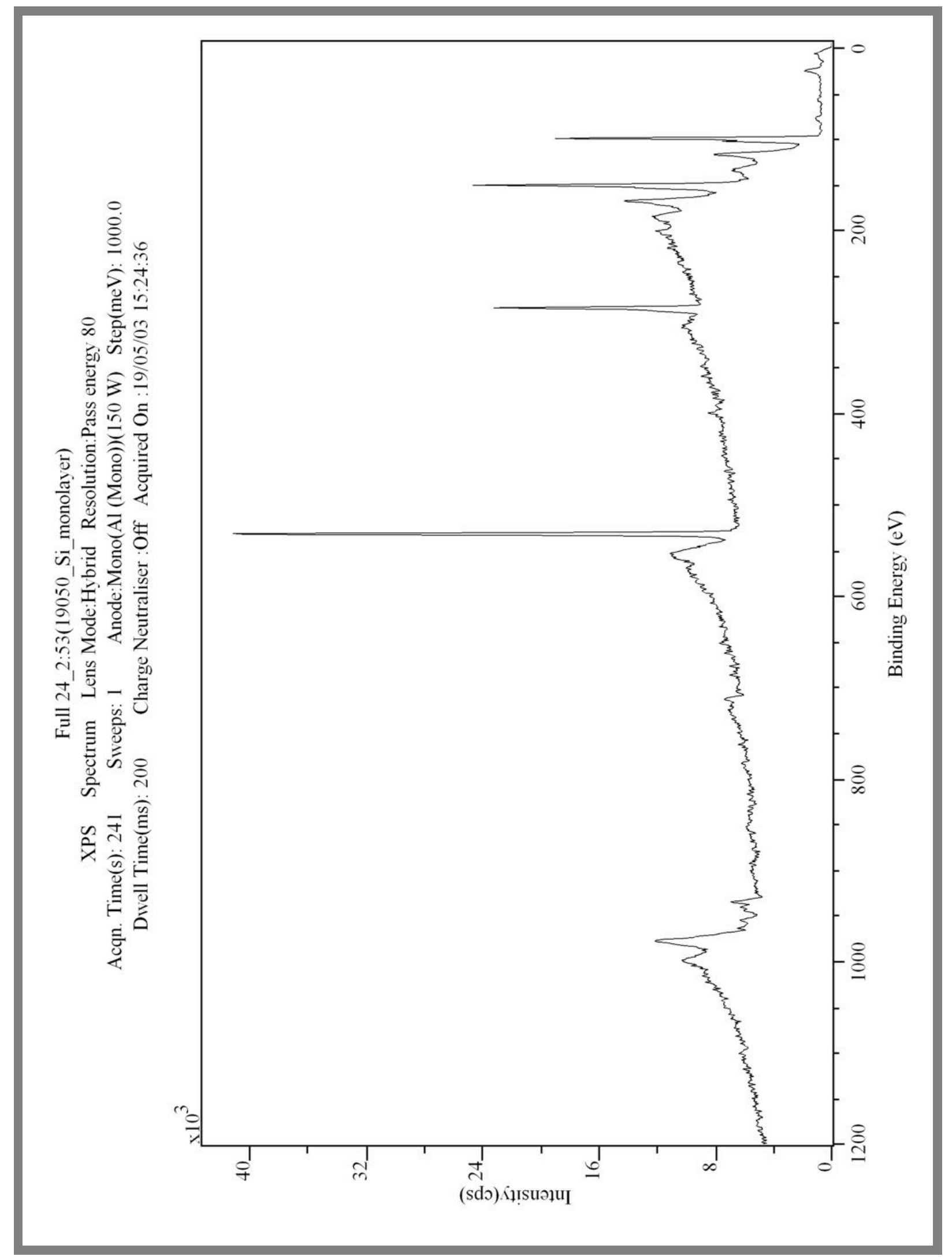

Figure S14. XPS survey spectrum (full) recorded for Si-Fc@2. 


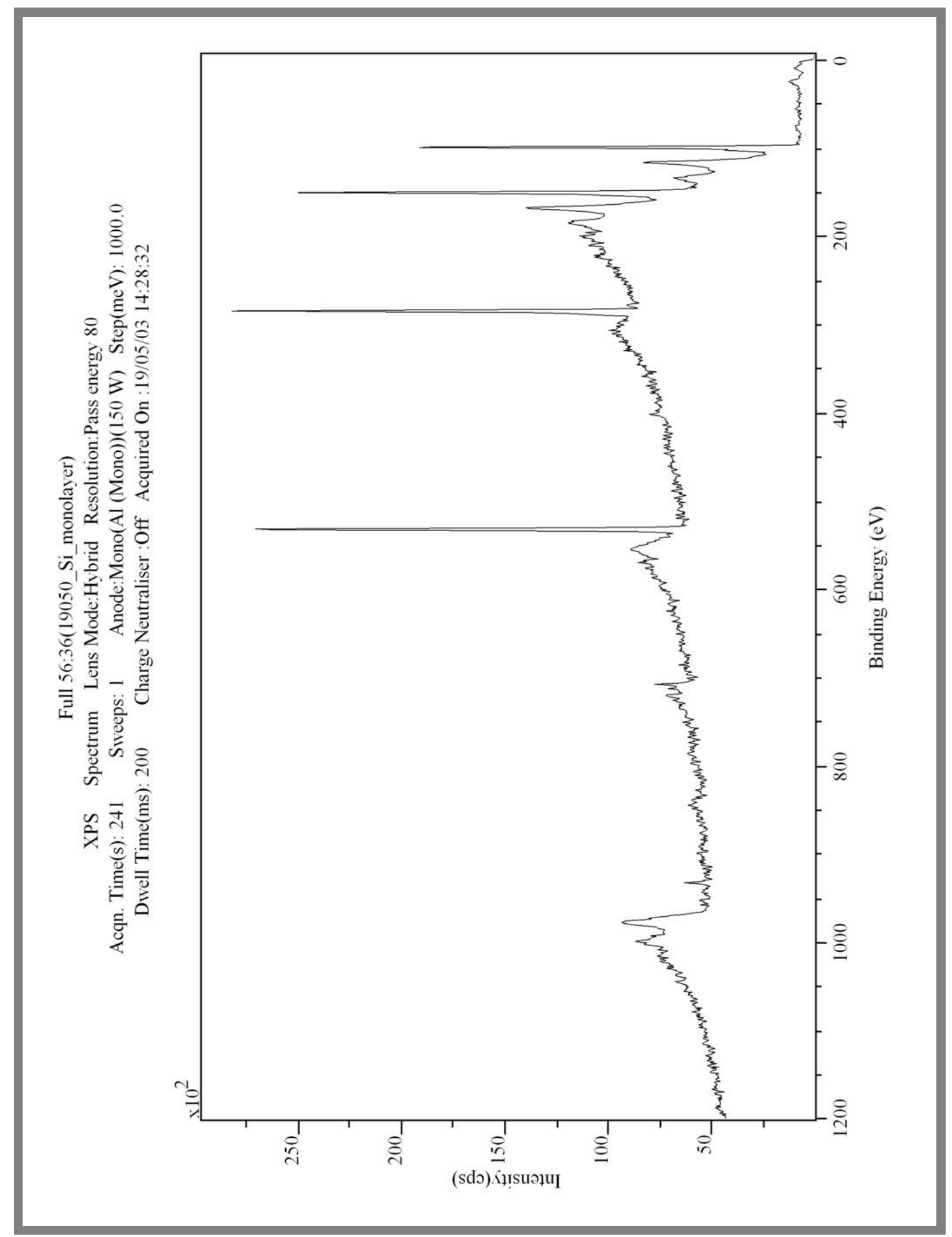

Figure S15. XPS survey spectrum (full) recorded for Si-Fe@3. 


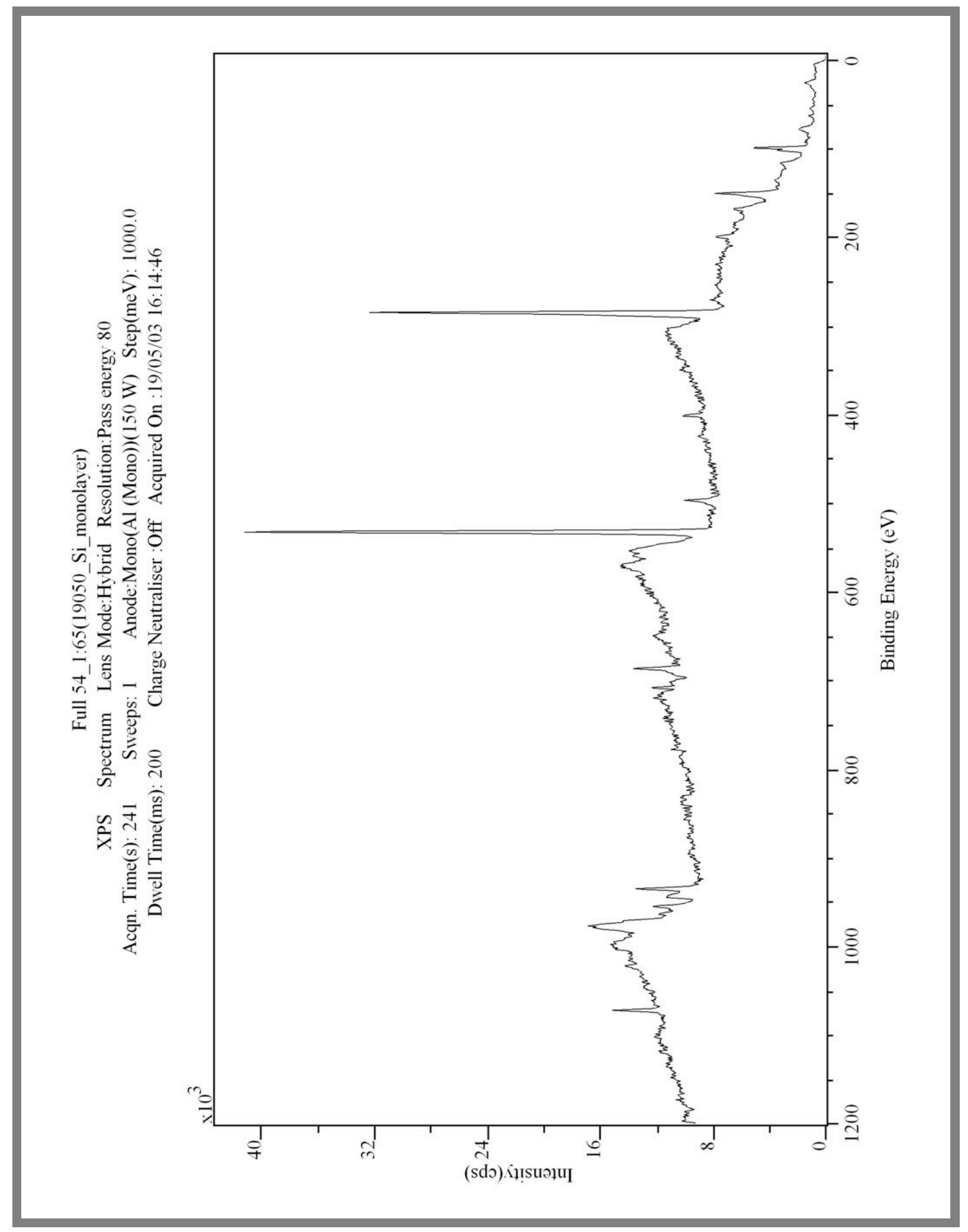

Figure S16. XPS survey spectrum (full) recorded for Si-Fc@4. 


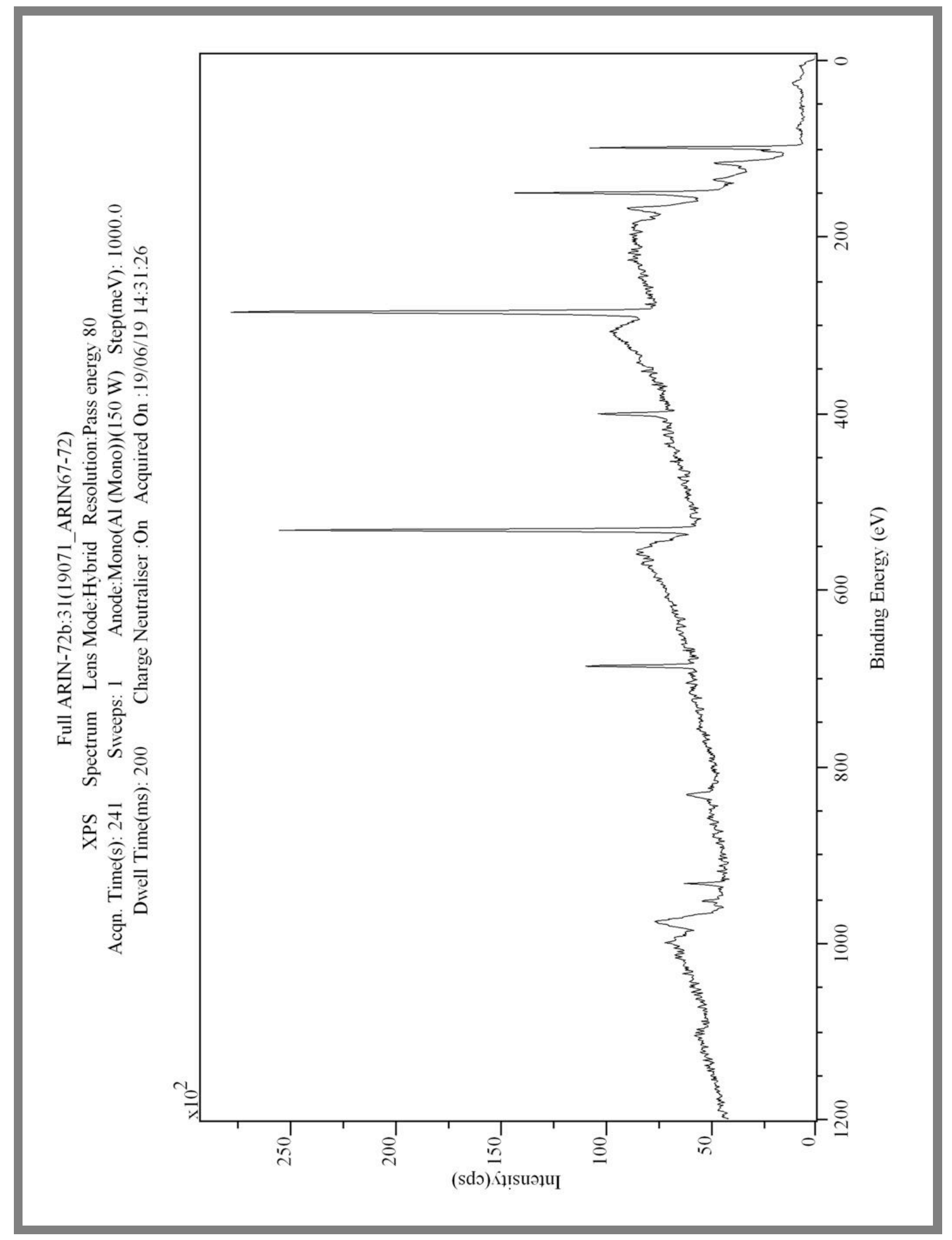

Figure S17. XPS survey spectrum (full) recorded for Si-Az. 


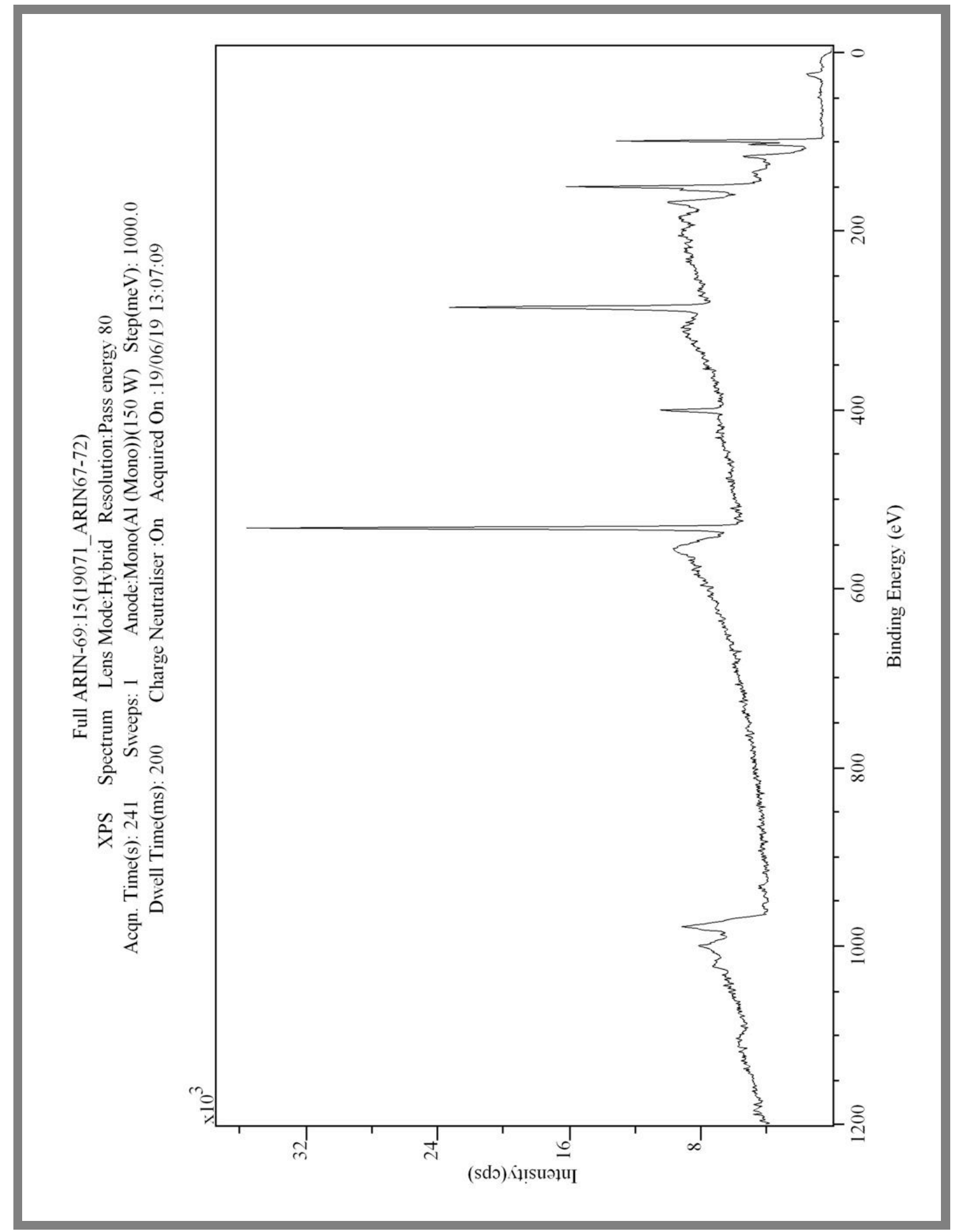

Figure S18. XPS survey spectrum (full) recorded for Si-NDI@5. 


\section{Electrochemical Characterization of Functionalized Si Surfaces: Various Cyclic Voltammograms and Related Plots}

Cyclic voltammetry (CV) measurements were carried out on a PARSTAT 3000A potentiostat/galvanostat/EIS analyzer (Ametek Scientific Instruments) using a self-designed and customized three-electrode Teflon cell under Ar. The ferrocene- and NDI-functionalized $\operatorname{Si}(111)$ surfaces were used as the working electrodes. In a typical setup, the unpolished rear side of the Si substrate was mechanically scratched (removal of native oxide layer) to expose the atomic Si surface and an Ohmic contact was immediately made with a copper conductive tape (Electron Microscopy Sciences; electrical resistance $=0.032 \mathrm{ohm} / \mathrm{cm}$ ) by applying a drop $(\sim 0.3 \mathrm{~mL})$ of gallium-indium eutectic (Sigma-Aldrich). The top functionalized surface of the Si substrate was then pressed against an opening at the Teflon cell bottom via the usage of a customized O-ring seal; the inner diameter of the latter was $0.8 \mathrm{~cm}$. Given that only the surface under the O-ring was subjected to electrochemical measurements, the effective electro-active surface area (AESA) was calculated to be $0.5026 \mathrm{~cm}^{2}$. The counter electrode was a Pt wire and the reference electrode was $\mathrm{Ag} / \mathrm{AgCl}(3 \mathrm{M} \mathrm{NaCl})$. A solution $(0.1 \mathrm{M})$ of tetra-nbutylammonium hexafluorophosphate $\left(\mathrm{n}-\mathrm{Bu}_{4} \mathrm{NPF}_{6}\right.$, Sigma-Aldrich) in dry and degassed $\mathrm{MeCN}$ was used as the supporting electrolyte. About $15 \mathrm{~mL}$ of this electrolyte solution (dried further on activated molecular sieves) was transferred to the Teflon cell by passing through a Whatman syringe filter (PTFE, pore size $=0.2 \mu \mathrm{m}$, GE Healthcare Life Sciences) and subsequently purged with Ar bubbling for 10 min prior to the experiment. All measurements were carried out at $\mathrm{rt}$. All the reported potentials are referenced to $\mathrm{Ag} / \mathrm{AgCl}$ electrode. 

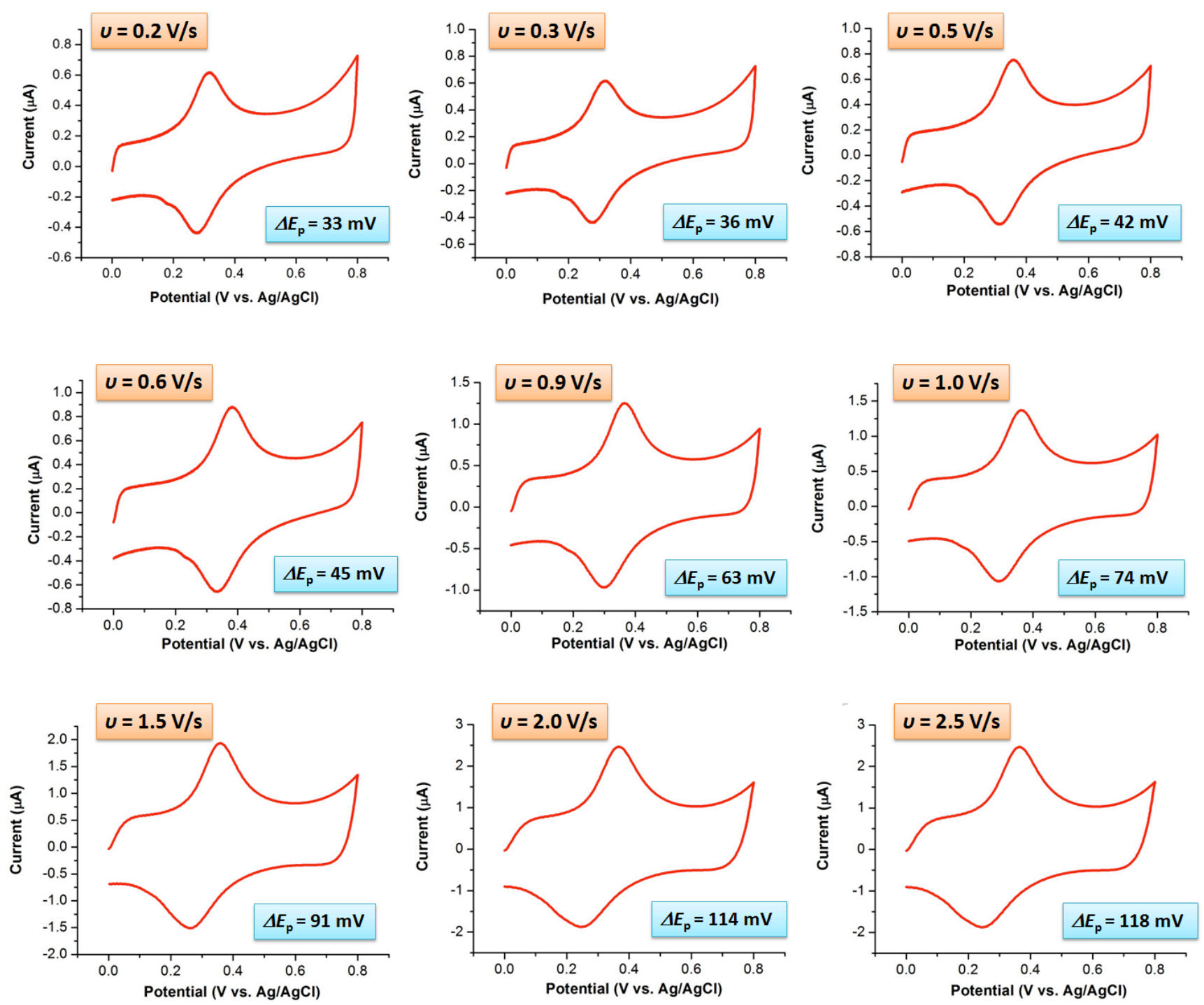

Figure S19. Representative cyclic voltammograms of Si-Fc@1 at different scan rates (v). All the voltammetric experiments were carried out under argon gas atmosphere at $25{ }^{\circ} \mathrm{C}$ in dry acetonitrile using $0.1 \mathrm{Mn}-\mathrm{Bu}_{4} \mathrm{NPF}_{6}$ as the supporting electrolyte, the Si-Fc surface as working electrode, $\mathrm{Ag} / \mathrm{AgCl}(3 \mathrm{M} \mathrm{NaCl})$ as the reference electrode and $\mathrm{Pt}$ as the counter electrode. The $\Delta E_{\mathrm{p}}$ is shown in the blue box in each case. Notice the increase in $\Delta E_{\mathrm{p}}$ with increasing scan rate. 


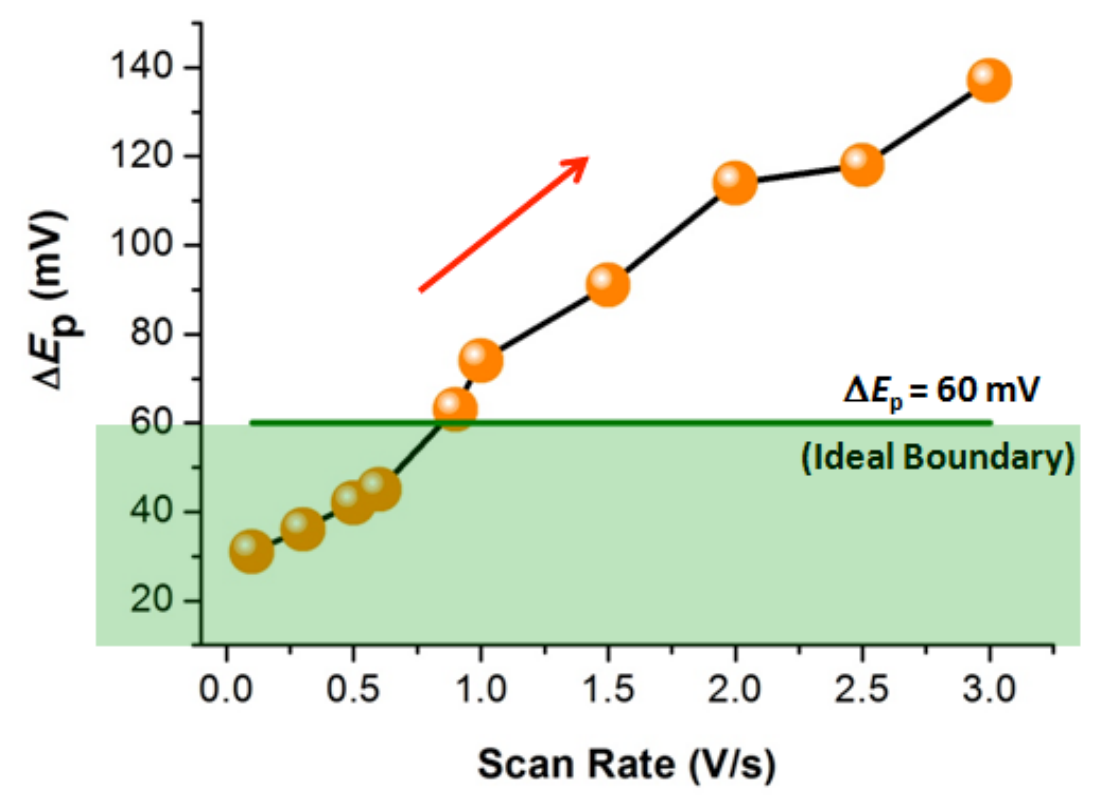

Figure S20. A plot that shows a regular increase in $\Delta E_{\mathrm{p}}$ with increasing scan rate in the case of Si-Fc@1. The ideal boundary (considering one-electron redox system) of $\Delta E_{\mathrm{p}}=60 \mathrm{mV}$ is shown with a green line/shadow.

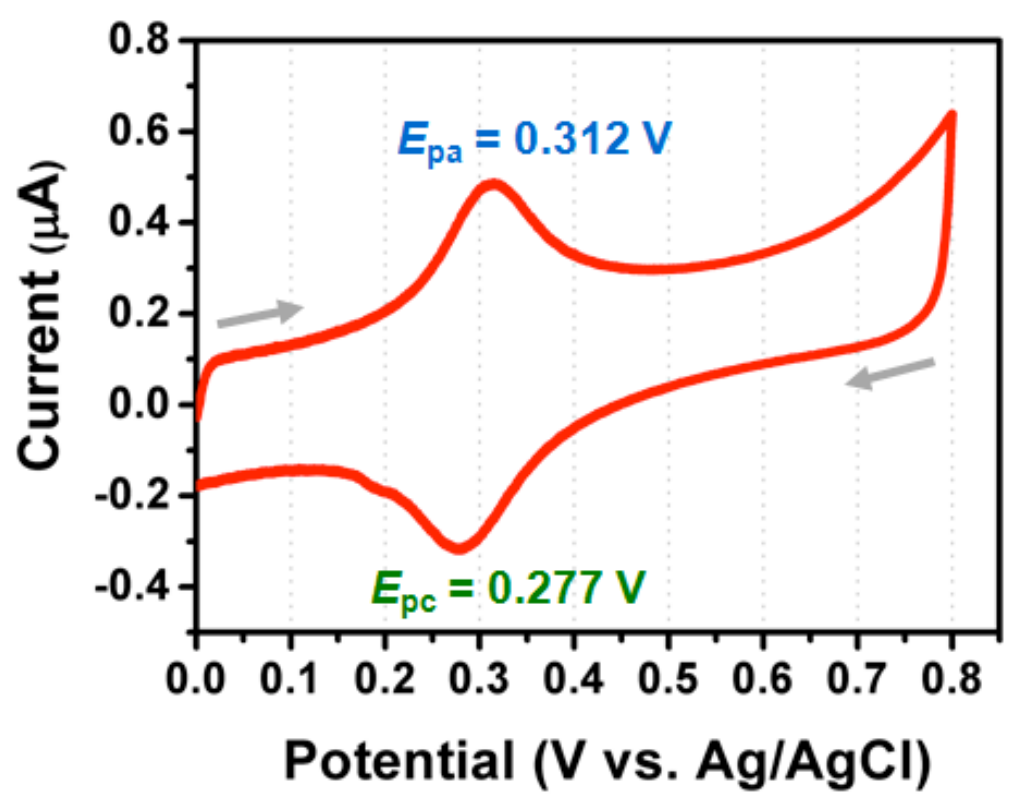

Figure S21. Representative cyclic voltammogram of Si-Fc@2 at the scan rate of $0.1 \mathrm{~V} / \mathrm{s}$. The voltammetric experiment was carried out under argon gas atmosphere at $25{ }^{\circ} \mathrm{C}$ in dry acetonitrile using $0.1 \mathrm{M} \mathrm{n}-\mathrm{Bu}_{4} \mathrm{NPF}_{6}$ as the supporting electrolyte, the $\mathbf{S i - F c}$ surface as working electrode, $\mathrm{Ag} / \mathrm{AgCl}(3 \mathrm{M} \mathrm{NaCl})$ as the reference electrode and $\mathrm{Pt}$ as the counter electrode. 

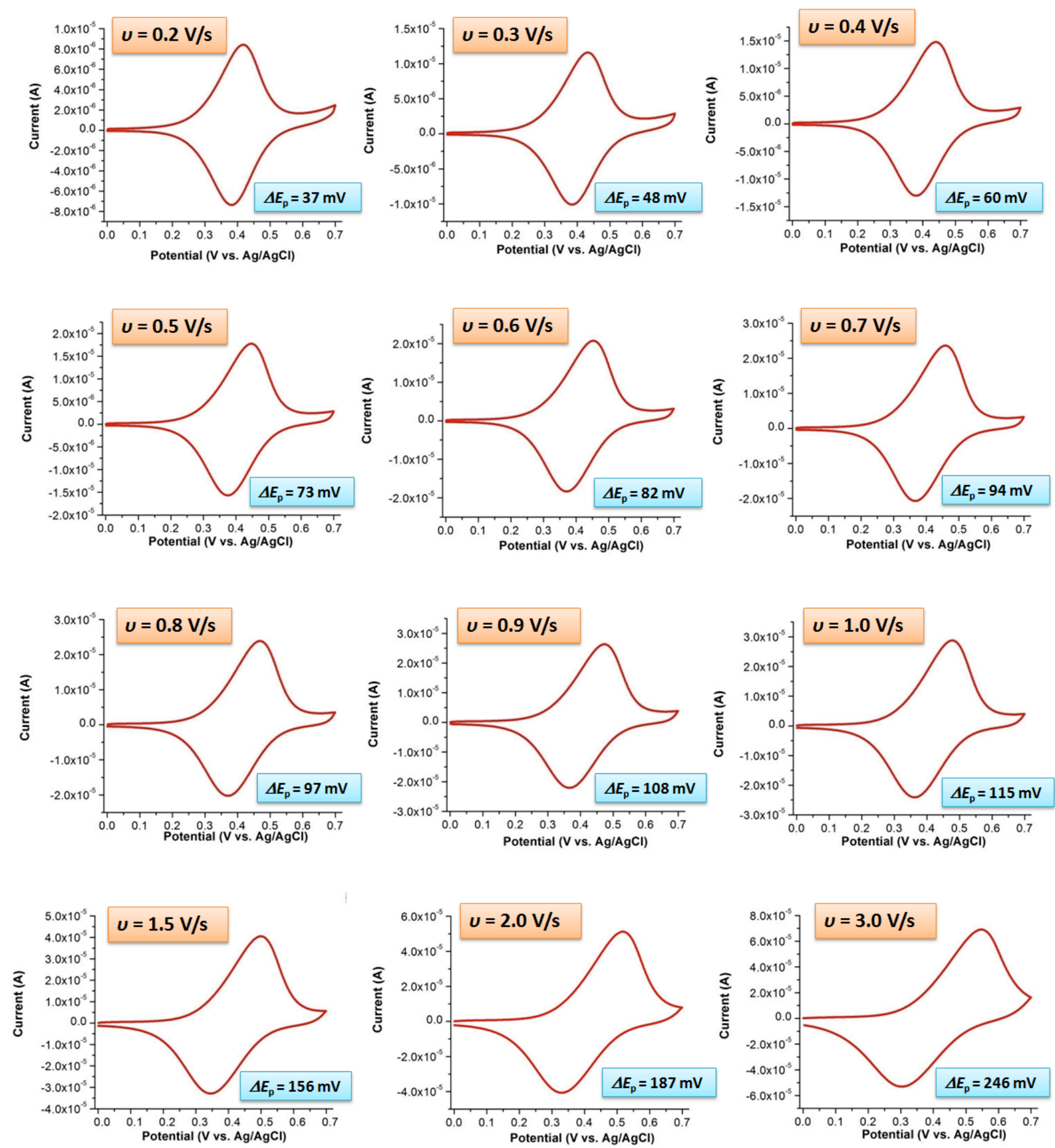

Figure S22. Representative cyclic voltammograms of Si-Fc@3 at different scan rates (v). All the voltammetric experiments were carried out under argon gas atmosphere at $25{ }^{\circ} \mathrm{C}$ in dry acetonitrile using $0.1 \mathrm{Mn}-\mathrm{Bu}_{4} \mathrm{NPF}_{6}$ as the supporting electrolyte, the Si-Fc surface as working electrode, $\mathrm{Ag} / \mathrm{AgCl}(3 \mathrm{M} \mathrm{NaCl})$ as the reference electrode and $\mathrm{Pt}$ as the counter electrode. The $\Delta E_{\mathrm{p}}$ is shown in the blue box in each case. Notice the increase in $\Delta E_{\mathrm{p}}$ with increasing scan rate. 

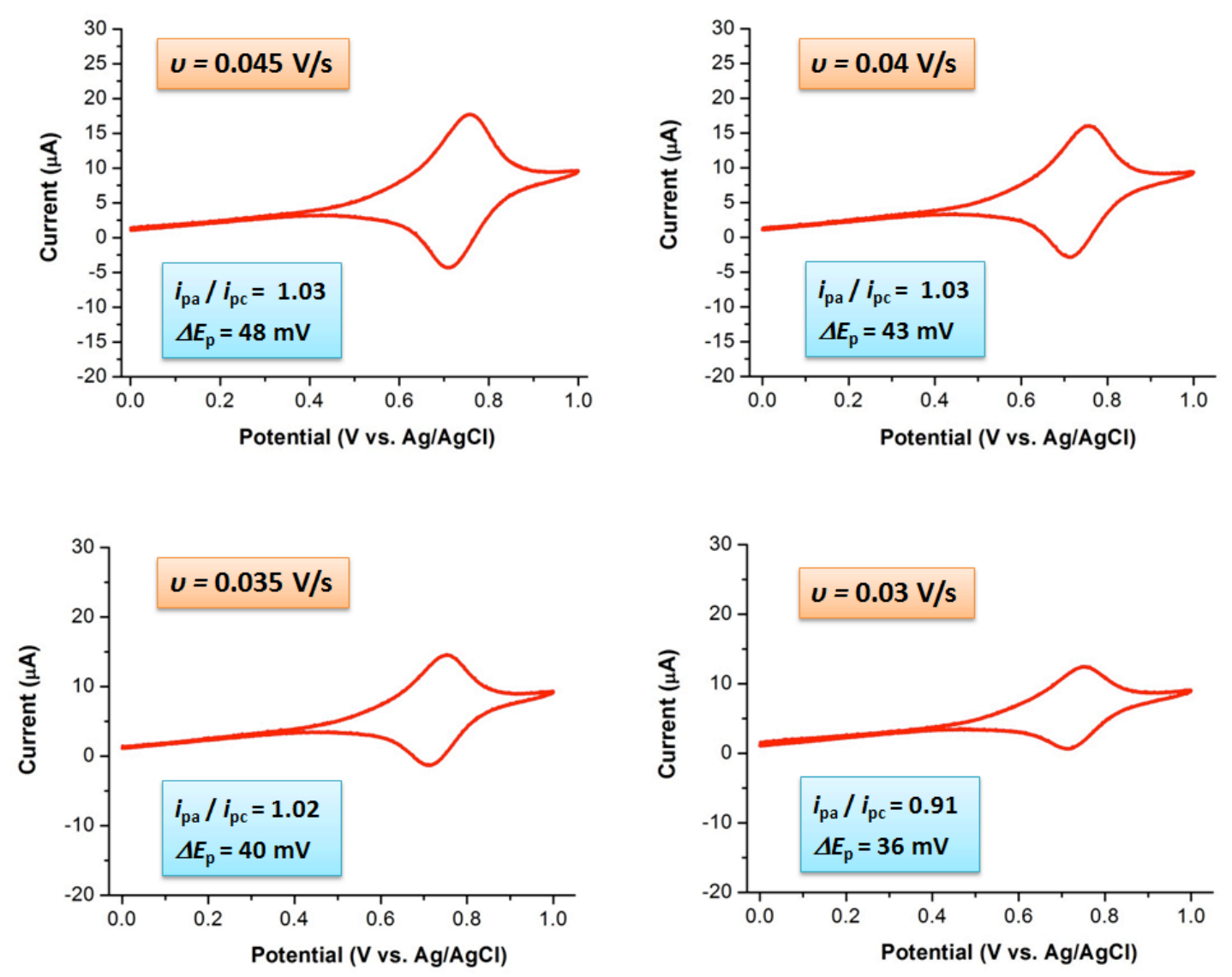

Figure S23. Representative cyclic voltammograms of Si-Fc@4 at different scan rates $(v)$. All the voltammetric experiments were carried out under argon gas atmosphere at $25{ }^{\circ} \mathrm{C}$ in dry acetonitrile using $0.1 \mathrm{M} \mathrm{n}-\mathrm{Bu}_{4} \mathrm{NPF}_{6}$ as the supporting electrolyte, the Si-Fc surface as working electrode, $\mathrm{Ag} / \mathrm{AgCl}(3 \mathrm{M} \mathrm{NaCl})$ as the reference electrode and $\mathrm{Pt}$ as the counter electrode. The ratio of anodic and cathodic currents and the $\Delta E_{\mathrm{p}}$ are shown within the blue box in each case. Notice the increase in $\Delta E_{\mathrm{p}}$ with increasing scan rate.

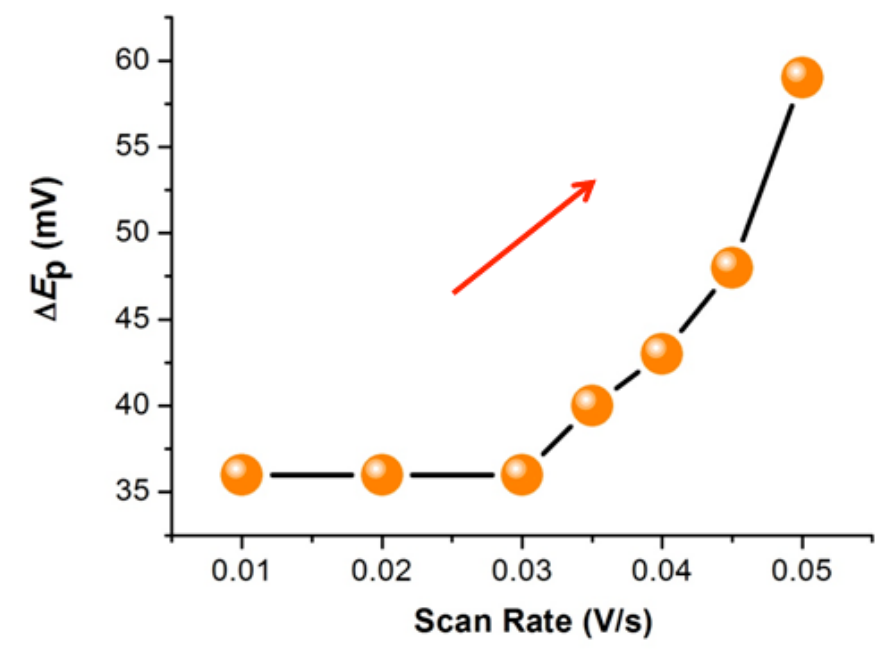

Figure S24. A plot showing increase in $\Delta E_{\mathrm{p}}$ with increasing scan rate in the case of $\mathbf{S i - F \mathbf { c }} \mathbf{4}$. 


\section{Calculation of Surface Coverage of Immobilized Ferrocene in Si-Fe@1-4}

The calculation of the total surface coverage of immobilized ferrocene on the Si-Fc@1-4 surfaces was performed by following several steps as discussed below.

1. To begin, cyclic voltammograms were recorded at a low scan rate to make sure that $\Delta E_{\mathrm{p}} \leq 60 \mathrm{mV}$.

2. From the entire voltammogram, the capacitive current-corrected anodic cycle (i.e., oxidation wave) was selected.

3. The actual mathematical area ' $\mathrm{A}_{1}$ ' (unit $=\mathrm{AV}$ ) under the anodic peak was calculated from the integration using 'Origin 8 ' software.

4. The amount of charge passed ' $Q$ ' (unit = A.s or Coulomb) was calculated from the formula:

$$
\mathrm{Q}(\text { Coulomb })=\mathrm{A}_{1}(\mathrm{AV}) / \text { scan rate }(\mathrm{V} / \mathrm{s})
$$

5. Surface coverage ' $\Gamma$ ' (unit $=\mathrm{mol} / \mathrm{cm}^{2}$ ) was calculated from the following equation: ${ }^{4}$

$$
\Gamma=\mathrm{Q} / \mathrm{nFA} \mathrm{ESA}
$$

where, ' $\mathrm{n}$ ' is the number of electrons exchanged, ' $\mathrm{F}$ ' is the Faraday constant ( $\mathrm{F}=$ $96485.3329 \mathrm{Coulomb} / \mathrm{mol}$ ) and 'A $\mathrm{E}_{\mathrm{ESA}}$ ' is the electro-active surface area (also known as geometric surface area), i.e., inner area of the O-ring which is exposed to the surface.

For the present investigation: $\mathrm{n}=1$ and $\mathrm{A}_{\mathrm{ESA}}=0.5026 \mathrm{~cm}^{2}$.

Shown below are the details of the calculation for each of the surfaces. 
Selected only anodic cycle

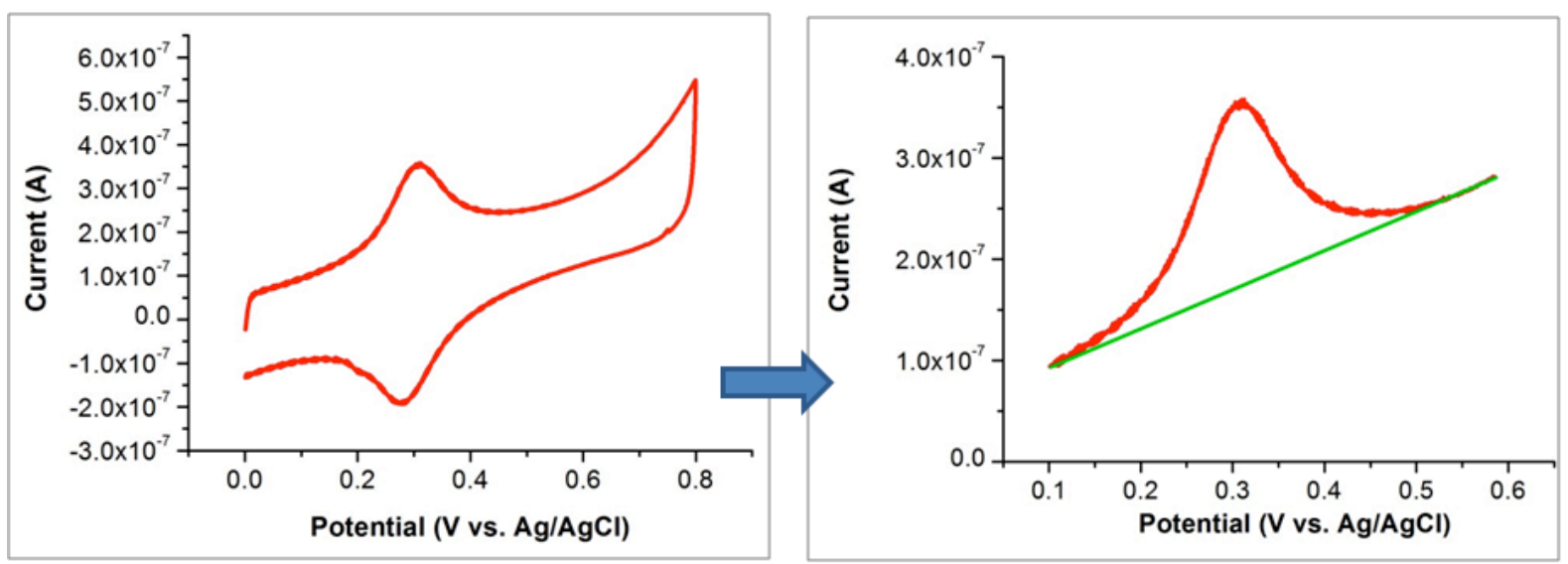

Correct area is under the curve \& bound by the tangent!

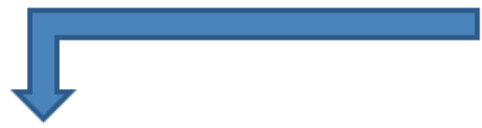

bound by the tangent!

Integration: Total Area under the Curve

Correction Employed

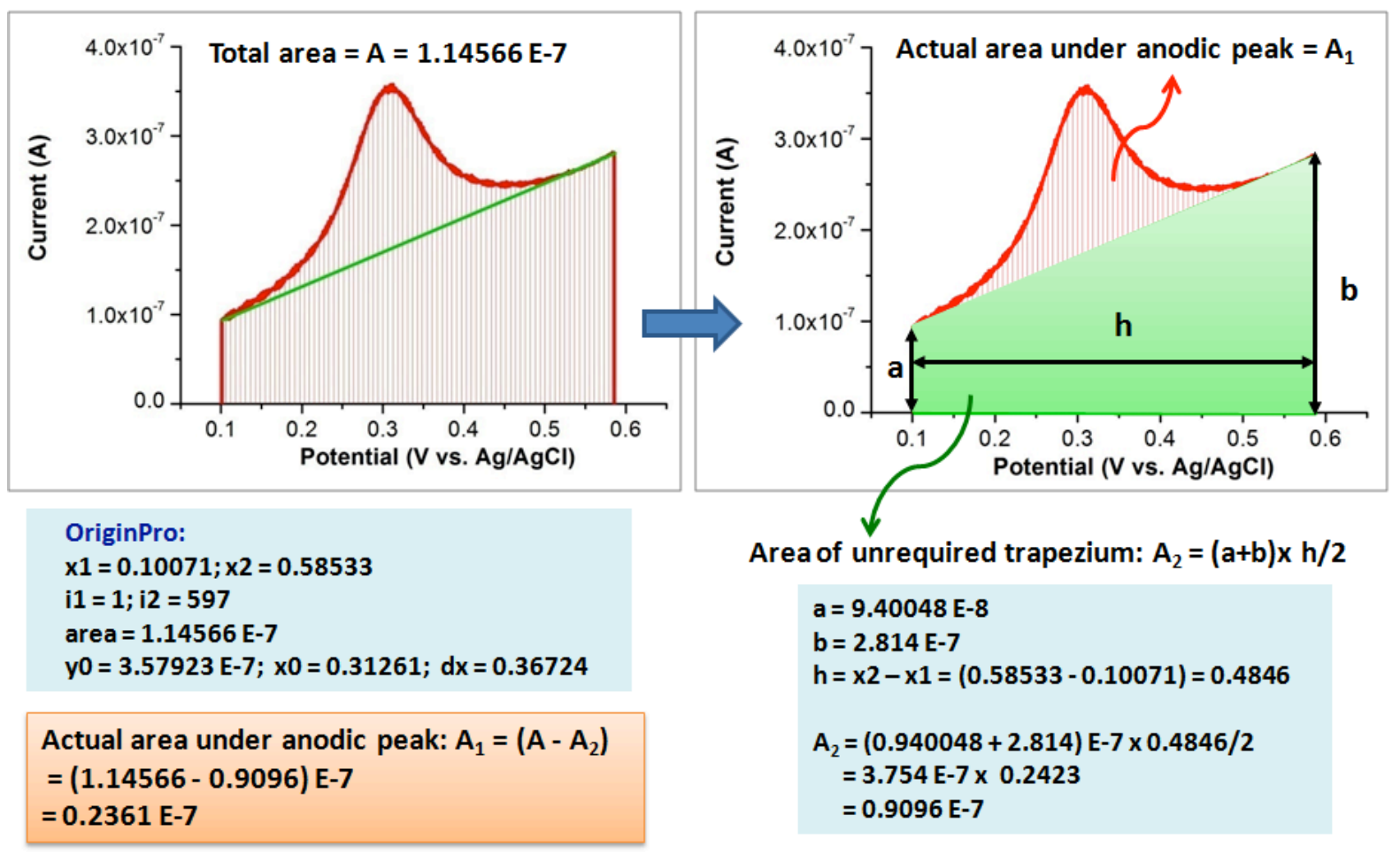

Figure S25. Calculation of area under the anodic peak for Si-Fe@1 (scan rate $=0.1 \mathrm{~V} / \mathrm{s})$. 
From above calculation, $\mathrm{A}_{1}=0.2361 \times 10^{-7} \mathrm{AV}$

Therefore, $\mathrm{Q}=\mathrm{A}_{1} /$ scan rate

$$
\begin{aligned}
& =0.2361 \times 10^{-7} \mathrm{AV} / 0.1 \mathrm{~V} / \mathrm{s} \\
& =0.2361 \times 10^{-6} \mathrm{As} \\
& =0.2361 \times 10^{-6} \text { Coulomb }
\end{aligned}
$$

Hence, surface coverage $\left(\mathrm{mol} / \mathrm{cm}^{2}\right)$ can be determined as:

$$
\begin{aligned}
\Gamma & =\mathrm{Q} / \mathrm{nFA}_{\mathrm{ESA}} \\
& =\left(0.2361 \times 10^{-6} \text { Coulomb }\right) /\left\{(96485.3329 \text { Coulomb } / \mathrm{mol}) \times\left(0.5026 \mathrm{~cm}^{2}\right)\right\} \\
& =4.87 \times 10^{-12} \mathrm{~mol} / \mathrm{cm}^{2}
\end{aligned}
$$

Surface coverage (molecules $/ \mathrm{cm}^{2}$ ) can also be expressed as following:

$$
\begin{aligned}
\Gamma & =4.87 \times 10^{-12} \mathrm{~mol} / \mathrm{cm}^{2} \\
& =4.87 \times 10^{-12} \times 6.023 \times 10^{23} \text { molecules } / \mathrm{cm}^{2} \\
& =29.33 \times 10^{11} \text { molecules } / \mathrm{cm}^{2}
\end{aligned}
$$

Thus, the area on the $\mathrm{Si}(111)$ surface which contains one organo-iron unit should be:

$$
\begin{aligned}
\mathrm{A}_{\mathrm{s}} & =\left\{1 /\left(29.33 \times 10^{11}\right)\right\} \mathrm{cm}^{2} \\
& =\left\{10^{14} /\left(29.33 \times 10^{11}\right)\right\} \mathrm{nm}^{2} \\
& =34.09 \mathrm{~nm}^{2}
\end{aligned}
$$

The ratio of Si atoms and organo-iron units on the surface considering the atomic density of $\mathrm{Si}(111)^{5}$ to be $7.8 \times 10^{14}$ atoms $/ \mathrm{cm}^{2}$ should be:

$$
\begin{aligned}
\mathrm{R}_{\mathrm{Si} / \mathrm{Fe}} & =\left(7.8 \times 10^{14}\right) /\left(29.33 \times 10^{11}\right) \\
& =265.9
\end{aligned}
$$

This means that a single organo-iron unit is present per 266 atoms of Si on the surface. 
Selected only anodic cycle

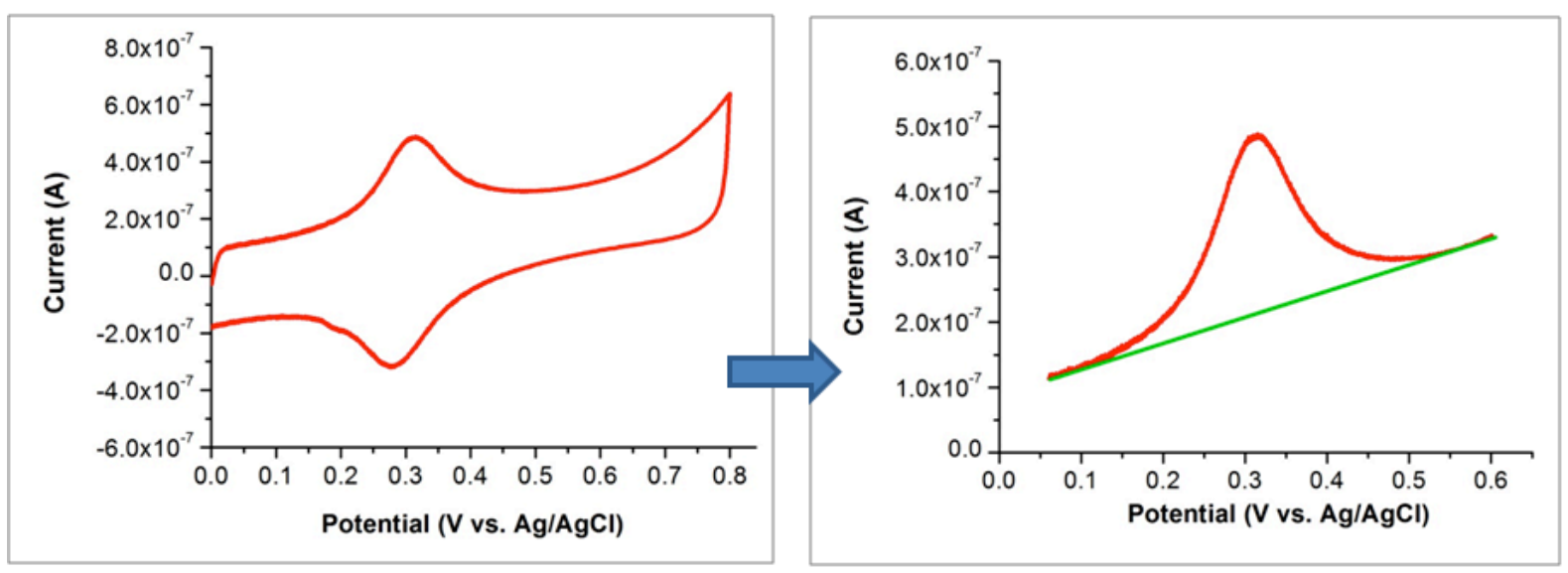

Correct area is under the curve $\&$ bound by the tangent!
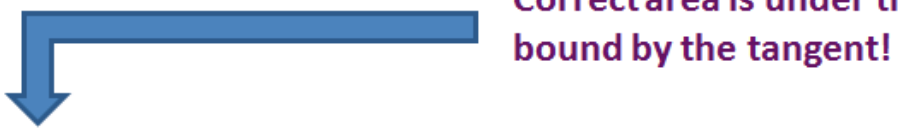

Integration: Total Area under the Curve

Correction Employed

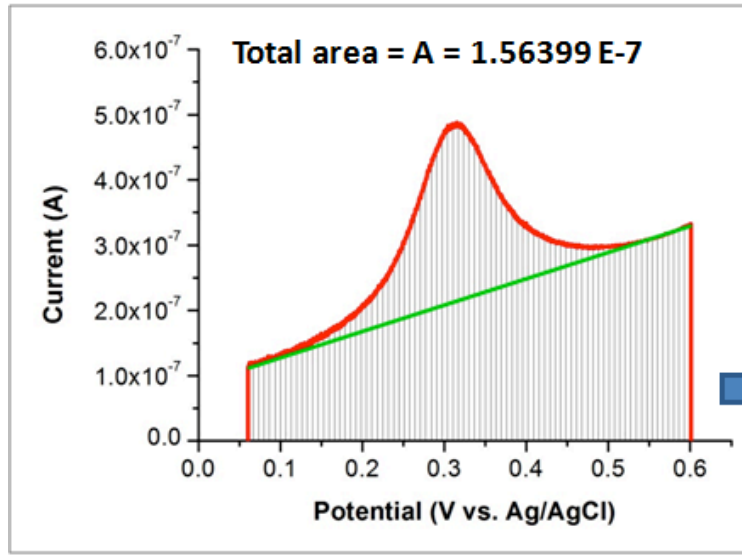

OriginPro:

$\mathrm{x} 1=0.06068 ; \mathrm{x} 2=0.60069$

i1 $=1 ;$ i $2=676$

area $=1.56399 \mathrm{E}-7$

y0 $=4.88118 E-7 ; x 0=0.31495 ; d x=0.37537$

Actual area under anodic peak: $A_{1}=\left(A-A_{2}\right)$

$=(1.56399-1.205) \mathrm{E}-7$

$=0.359 \mathrm{E}-7$

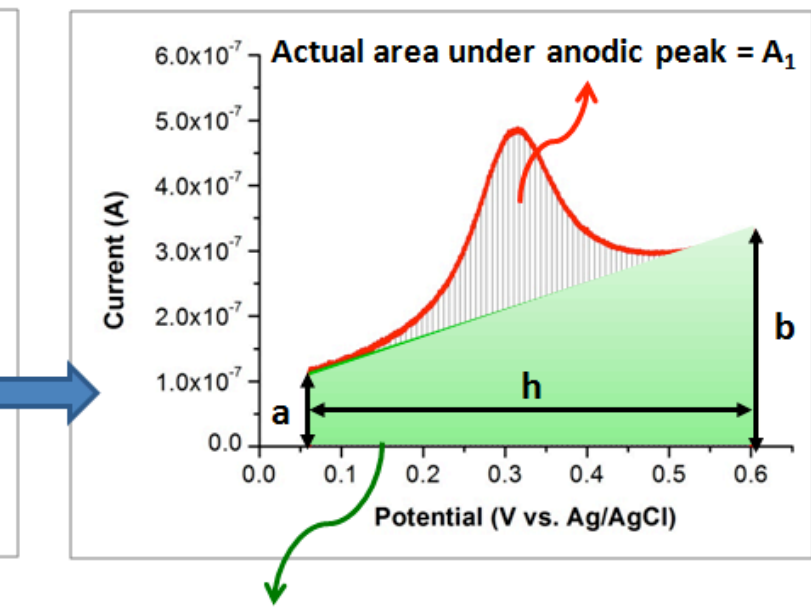

Area of unrequired trapezium: $A_{2}=(a+b) \times h / 2$

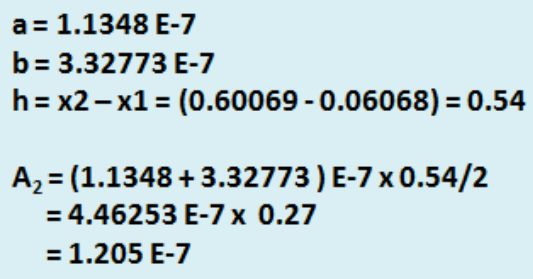

Figure S26. Calculation of area under the anodic peak for Si-Fc@2 (scan rate $=0.1 \mathrm{~V} / \mathrm{s})$. 
From above calculation, $\mathrm{A}_{1}=0.359 \times 10^{-7} \mathrm{AV}$

Therefore, $\mathrm{Q}=\mathrm{A}_{1} / \mathrm{scan}$ rate

$$
\begin{aligned}
& =0.359 \times 10^{-7} \mathrm{AV} / 0.1 \mathrm{~V} / \mathrm{s} \\
& =0.359 \times 10^{-6} \mathrm{As} \\
& =0.359 \times 10^{-6} \text { Coulomb }
\end{aligned}
$$

Hence, surface coverage $\left(\mathrm{mol} / \mathrm{cm}^{2}\right)$ can be determined as:

$$
\begin{aligned}
\Gamma & =\mathrm{Q} / \mathrm{nFA}_{\mathrm{ESA}} \\
& =\left(0.359 \times 10^{-6} \text { Coulomb }\right) /\left\{(96485.3329 \text { Coulomb } / \mathrm{mol}) \times\left(0.5026 \mathrm{~cm}^{2}\right)\right\} \\
& =7.4 \times 10^{-12} \mathrm{~mol} / \mathrm{cm}^{2}
\end{aligned}
$$

Surface coverage (molecules $/ \mathrm{cm}^{2}$ ) can also be expressed as following:

$$
\begin{aligned}
\Gamma & =7.4 \times 10^{-12} \mathrm{~mol} / \mathrm{cm}^{2} \\
& =7.4 \times 10^{-12} \times 6.023 \times 10^{23} \text { molecules } / \mathrm{cm}^{2} \\
& =44.57 \times 10^{11} \text { molecules } / \mathrm{cm}^{2}
\end{aligned}
$$

Thus, the area on the $\mathrm{Si}(111)$ surface which contains one organo-iron unit should be:

$$
\begin{aligned}
\mathrm{A}_{\mathrm{s}} & =\left\{1 /\left(44.57 \times 10^{11}\right)\right\} \mathrm{cm}^{2} \\
& =\left\{10^{14} /\left(44.57 \times 10^{11}\right)\right\} \mathrm{nm}^{2} \\
& =22.44 \mathrm{~nm}^{2}
\end{aligned}
$$

The ratio of Si atoms and organo-iron units on the surface considering the atomic density of $\operatorname{Si}(111)^{5}$ to be $7.8 \times 10^{14}$ atoms $/ \mathrm{cm}^{2}$ should be:

$$
\begin{aligned}
\mathrm{R}_{\mathrm{Si} / \mathrm{Fe}} & =\left(7.8 \times 10^{14}\right) /\left(44.57 \times 10^{11}\right) \\
& =175
\end{aligned}
$$

This means that a single organo-iron unit is present per 175 atoms of Si on the surface. 
Selected only anodic cycle

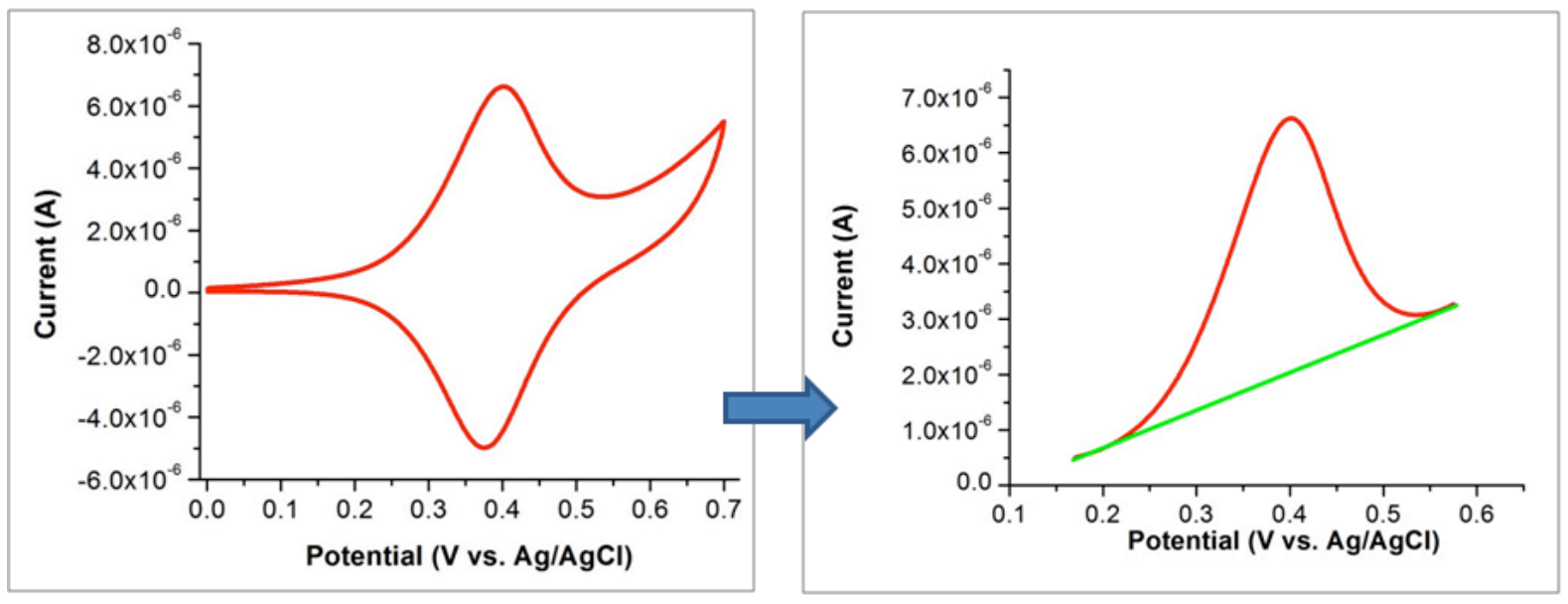

Correct area is under the curve \& bound by the tangent!

Integration: Total Area under the Curve

Correction Employed

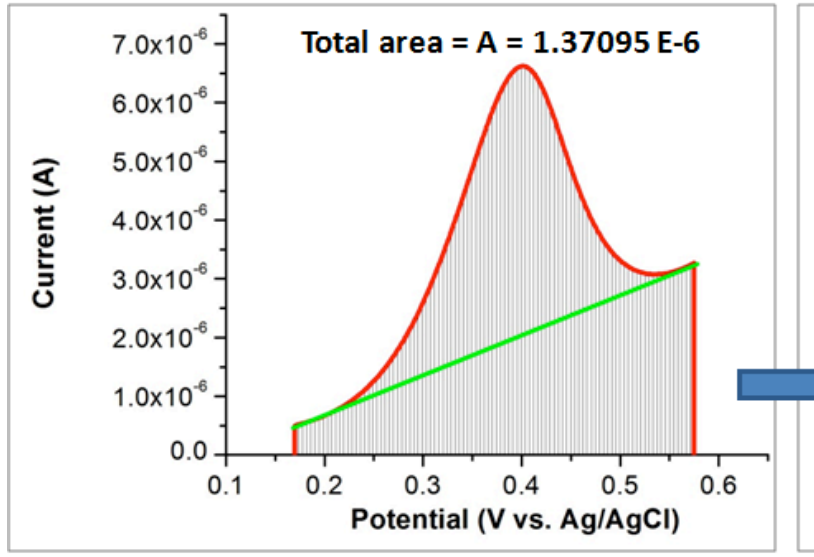

OriginPro:

$\mathrm{x} 1=0.16989 ; \mathrm{x} 2=0.57521$

i1 = 1; i2 = 580

area $=1.37095 \mathrm{E}-6$

y0 = 6.62647 E- $6 ; x 0=0.40167 ; d x=0.18244$

Actual area under anodic peak: $A_{1}=\left(A-A_{2}\right)$

$=(1.37095-0.7643) \mathrm{E}-6$

$=0.6066 \mathrm{E}-6$

Area of unrequired trapezium: $A_{2}=(a+b) \times h / 2$

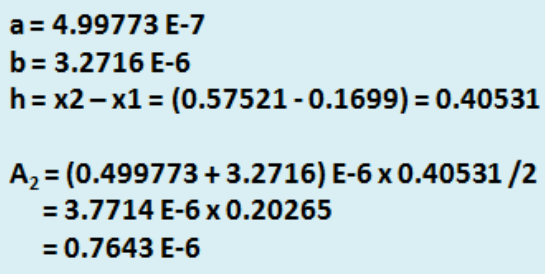

Figure S27. Calculation of area under the anodic peak for Si-Fc@3 $($ scan rate $=0.1 \mathrm{~V} / \mathrm{s})$. 
From above calculation, $\mathrm{A}_{1}=0.6066 \times 10^{-6} \mathrm{AV}$

Therefore, $\mathrm{Q}=\mathrm{A}_{1} /$ scan rate

$$
\begin{aligned}
& =0.6066 \times 10^{-6} \mathrm{AV} / 0.1 \mathrm{~V} / \mathrm{s} \\
& =0.6066 \times 10^{-5} \mathrm{As} \\
& =0.6066 \times 10^{-5} \text { Coulomb }
\end{aligned}
$$

Hence, surface coverage $\left(\mathrm{mol} / \mathrm{cm}^{2}\right)$ can be determined as:

$$
\begin{aligned}
\Gamma & =\mathrm{Q} / \mathrm{nFA}_{\mathrm{ESA}} \\
& =\left(0.6066 \times 10^{-5} \text { Coulomb }\right) /\left\{(96485.3329 \text { Coulomb } / \mathrm{mol}) \times\left(0.5026 \mathrm{~cm}^{2}\right)\right\} \\
& =1.25 \times 10^{-10} \mathrm{~mol} / \mathrm{cm}^{2}
\end{aligned}
$$

Surface coverage (molecules $/ \mathrm{cm}^{2}$ ) can also be expressed as following:

$$
\begin{aligned}
\Gamma & =1.25 \times 10^{-10} \mathrm{~mol} / \mathrm{cm}^{2} \\
& =1.25 \times 10^{-10} \times 6.023 \times 10^{23} \text { molecules } / \mathrm{cm}^{2} \\
& =7.53 \times 10^{13} \text { molecules } / \mathrm{cm}^{2}
\end{aligned}
$$

Thus, the area on the $\mathrm{Si}(111)$ surface which contains one organo-iron unit should be:

$$
\begin{aligned}
\mathrm{A}_{\mathrm{s}} & =\left\{1 /\left(7.53 \times 10^{13}\right)\right\} \mathrm{cm}^{2} \\
& =\left\{10^{14} /\left(7.53 \times 10^{13}\right)\right\} \mathrm{nm}^{2} \\
& =1.33 \mathrm{~nm}^{2}
\end{aligned}
$$

The ratio of Si atoms and organo-iron units on the surface considering the atomic density of $\operatorname{Si}(111)^{5}$ to be $7.8 \times 10^{14}$ atoms $/ \mathrm{cm}^{2}$ should be:

$$
\begin{aligned}
\mathrm{R}_{\mathrm{Si} / \mathrm{Fe}} & =\left(7.8 \times 10^{14}\right) /\left(7.53 \times 10^{13}\right) \\
& =10.36
\end{aligned}
$$

This means that $\sim 1$ organo-iron unit is present per 10.4 atoms of Si on the surface. 
Selected only anodic cycle

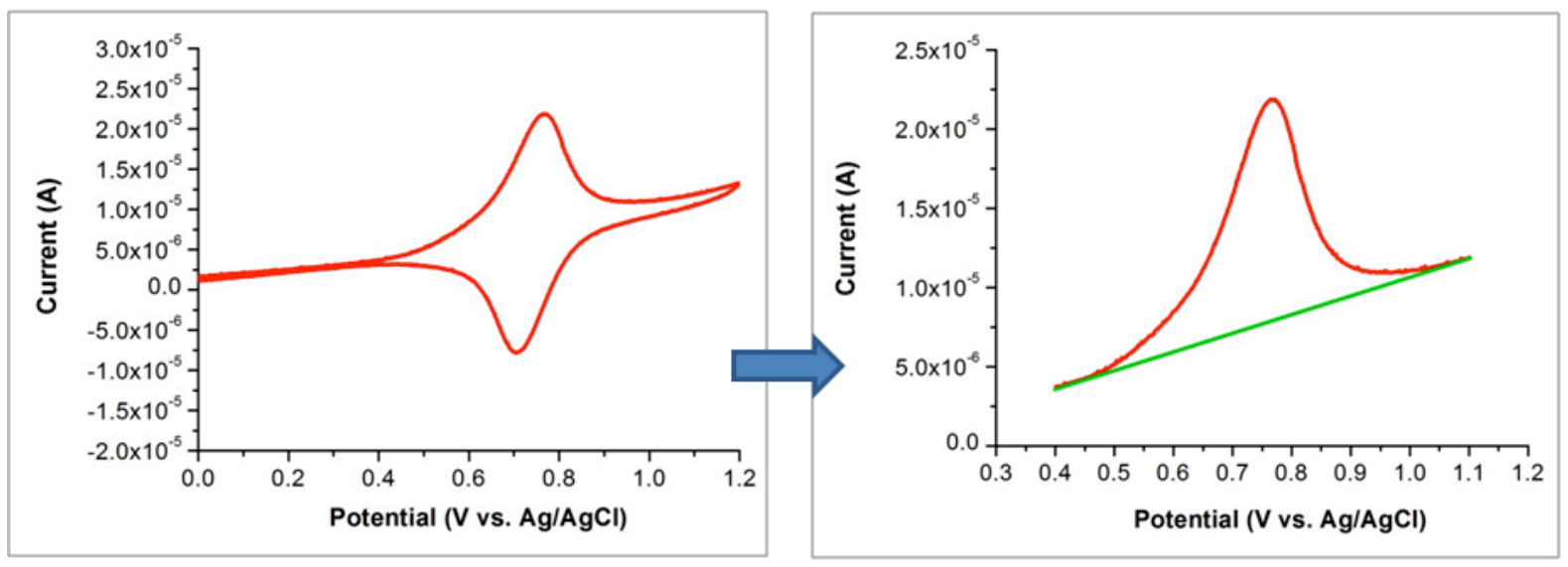

Correct area is under the curve \& bound by the tangent!

Integration: Total Area under the Curve

Correction Employed

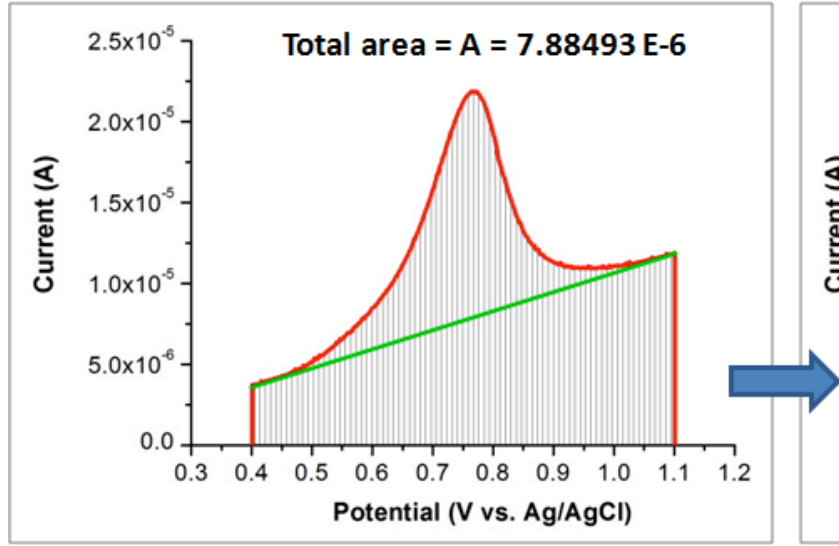

OriginPro:

$\mathrm{x} 1=0.40048 ; \mathrm{x} 2=1.10100$

$\mathrm{i} 1=1 ; \mathrm{i} 2=585$

area $=7.88493 \mathrm{E}-6$

y0 $=2.18741 E-5 ; x 0=0.76397 ; d x=0.29533$

Actual area under anodic peak: $A_{1}=\left(A-A_{2}\right)$

$=(7.88493-5.46693) \mathrm{E}-6$

$=2.418 \mathrm{E}-6$

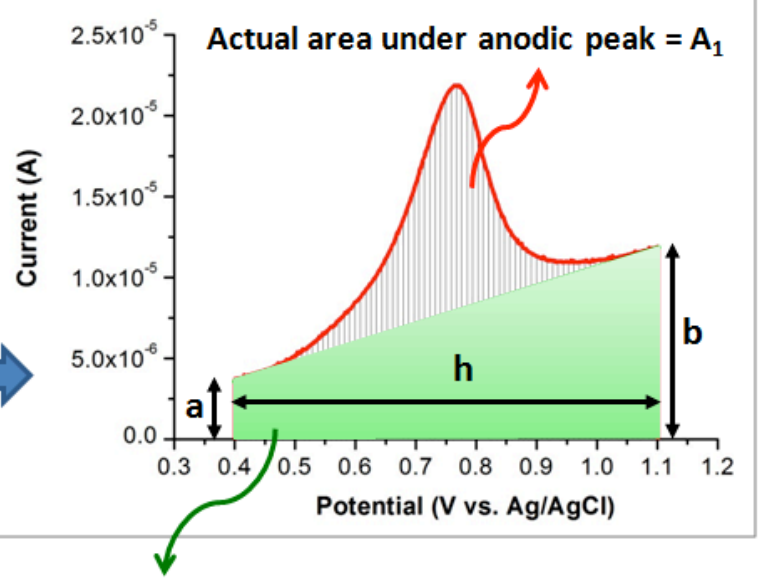

Area of unrequired trapezium: $A_{2}=(a+b) \times h / 2$

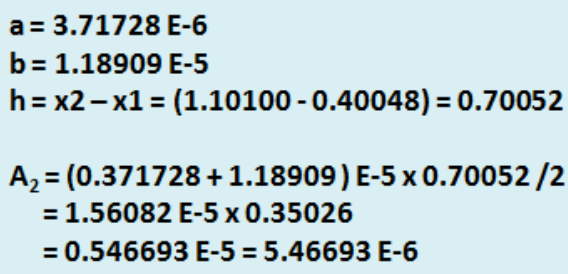

Figure S28. Calculation of area under the anodic peak for Si-Fc@4 (scan rate=0.05 V/s). 
From above calculation, $\mathrm{A}_{1}=2.418 \times 10^{-6} \mathrm{AV}$

Therefore, $\mathrm{Q}=\mathrm{A}_{1} /$ scan rate

$$
\begin{aligned}
& =2.418 \times 10^{-6} \mathrm{AV} / 0.05 \mathrm{~V} / \mathrm{s} \\
& =48.36 \times 10^{-6} \mathrm{As} \\
& =48.36 \times 10^{-6} \mathrm{Coulomb}=4.836 \times 10^{-5} \text { Coulomb }
\end{aligned}
$$

Hence, surface coverage $\left(\mathrm{mol} / \mathrm{cm}^{2}\right)$ can be determined as:

$$
\begin{aligned}
\Gamma & =\mathrm{Q} / \mathrm{nFA} A_{\mathrm{ESA}} \\
& =\left(4.836 \times 10^{-5} \text { Coulomb }\right) /\left\{(96485.3329 \text { Coulomb } / \mathrm{mol}) \times\left(0.5026 \mathrm{~cm}^{2}\right)\right\} \\
& =9.972 \times 10^{-10} \mathrm{~mol} / \mathrm{cm}^{2}
\end{aligned}
$$

Surface coverage (molecules $/ \mathrm{cm}^{2}$ ) can also be expressed as following:

$$
\begin{aligned}
\Gamma & =9.972 \times 10^{-10} \mathrm{~mol} / \mathrm{cm}^{2} \\
& =9.972 \times 10^{-10} \times 6.023 \times 10^{23} \text { molecules } / \mathrm{cm}^{2} \\
& =60.06 \times 10^{13} \text { molecules } / \mathrm{cm}^{2}
\end{aligned}
$$

Thus, the area on the Si(111) surface which contains one organo-iron unit should be:

$$
\begin{aligned}
\mathrm{A}_{\mathrm{s}} & =\left\{1 /\left(60.06 \times 10^{13}\right)\right\} \mathrm{cm}^{2} \\
& =\left\{10^{14} /\left(60.06 \times 10^{13}\right)\right\} \mathrm{nm}^{2} \\
& =0.166 \mathrm{~nm}^{2}
\end{aligned}
$$

The ratio of $\mathrm{Si}$ atoms and organo-iron units on the surface considering the atomic density of $\mathrm{Si}(111)^{5}$ to be $7.8 \times 10^{14}$ atoms $/ \mathrm{cm}^{2}$ should be:

$$
\begin{aligned}
\mathrm{R}_{\mathrm{Si} / \mathrm{Fe}} & =\left(7.8 \times 10^{14}\right) /\left(60.06 \times 10^{13}\right) \\
& =1.3
\end{aligned}
$$

This means that $\sim 1$ organo-iron unit is present per 1.3 atoms of $\mathrm{Si}$ on the surface. 


\section{Determination of the Rate of Electrochemical Oxidation of Organo-Iron}

The rates of electrochemical oxidation $\left(k_{\mathrm{s}}\right.$ in $\left.\mathrm{s}^{-1}\right)$ of the organo-iron units in the ferrocenefunctionalized Si(111) surfaces (namely, Si-Fc@3 and Si-Fc@4, as the two representative cases) were determined using the Laviron's formalism. ${ }^{6}$ The latter correlates the changes in peak current $\left(i_{\mathrm{p}}\right)$ and over-potential $\left(E_{\mathrm{p}}-E_{1 / 2}^{0}\right)$ with increasing scan rate $(v)$. Therefore, when the anodic peak current $\left(i_{\mathrm{pa}}\right)$ and the anodic over-potential $\left(E_{\mathrm{pa}}-E_{1 / 2}^{0}\right)$ are linearly correlated, the Laviron's equation for electrochemical oxidation can be represented as:

$$
i_{p a}=n F A_{E S A} k_{S} \Gamma \exp \left[\frac{\alpha n F\left(E_{p a}-E_{1 / 2}^{0}\right)}{R T}\right]
$$

The symbols in the equation refer to the following:

$\mathrm{n}$ : number of electrons exchanged ( $\mathrm{n}=1$ for ferrocene/ferricenium redox system)

F: Faraday constant $=96485.33$ Coulomb $/ \mathrm{mol}$

$\mathrm{A}_{\mathrm{ESA}}$ : Electro-active surface area $\left(\mathrm{A}_{\mathrm{ESA}}=0.5026 \mathrm{~cm}^{2}\right.$ in this case, as mentioned earlier)

$\Gamma$ : Surface coverage of organo-iron $\left(\mathrm{mol} / \mathrm{cm}^{2}\right)$

$\alpha$ : Transfer coefficient ( $\alpha=0.5$ for a reversible redox system)

$k_{\mathrm{s}}$ : Standard rate constant for electrochemical oxidation $\left(\mathrm{s}^{-1}\right)$

$E_{1 / 2}^{0}: E_{1 / 2}$ at very low scan rate

$E_{\mathrm{pa}}:$ Anodic peak potential at different scan rate

Using $\mathrm{n}=1$ and $\alpha=0.5$, the equation can be represented as:

$$
i_{p a}=F A_{E S A} k_{S} \Gamma \exp \left[\frac{F\left(E_{p a}-E_{1 / 2}^{0}\right)}{2 R T}\right]
$$

Therefore, the logarithm expression of the above equation translates to:

$$
\ln i_{p a}=\ln \left(F A_{E S A} k_{s} \Gamma\right)+\frac{F}{2 R T}\left(E_{p a}-E_{1 / 2}^{0}\right)
$$

Thus a linear plot of $\left(\ln i_{\mathrm{pa}}\right)$ and $\left(E_{\mathrm{pa}}-E_{1 / 2}^{0}\right)$ should give rise to the intercept of ' $\ln \left(\mathrm{FA}_{\mathrm{ESA}} k_{\mathrm{S}} \Gamma\right)$ '. Since the values of $\mathrm{F}, \mathrm{A}_{\mathrm{ESA}}$ and $\Gamma$ (for a system) are already known, one can evaluate ' $k_{\mathrm{s}}$ ' from the intercept. Shown below are the associated data for determination of the rates $\left(k_{\mathrm{s}}\right)$ of electrochemical oxidation of ferrocene units in Si-Fc@3 and Si-Fc@4. 


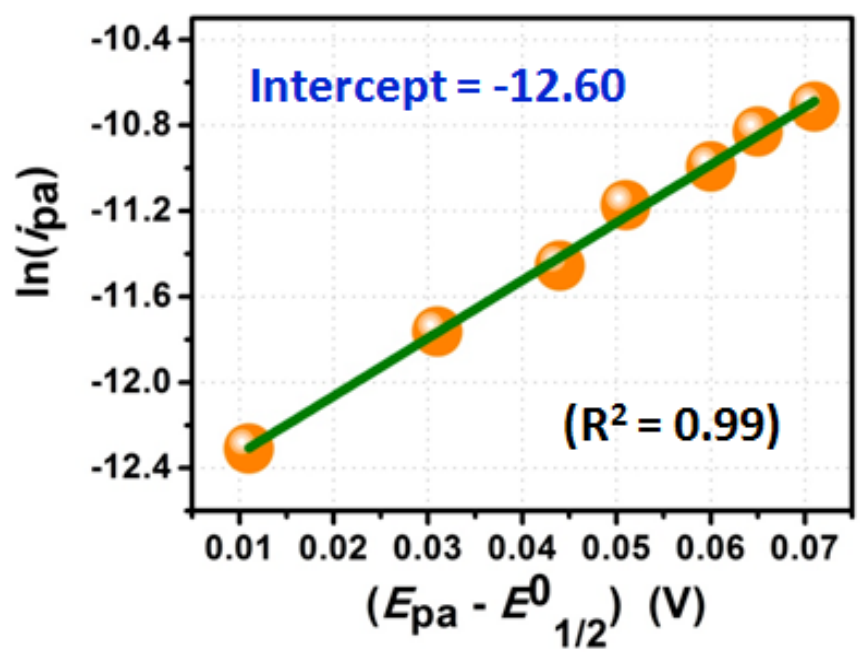

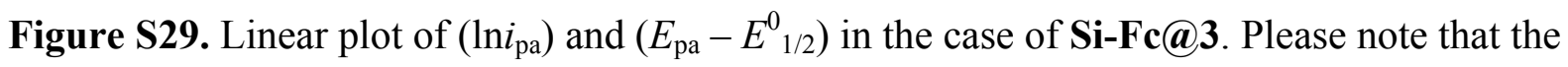
intercept of the line is -12.60 .

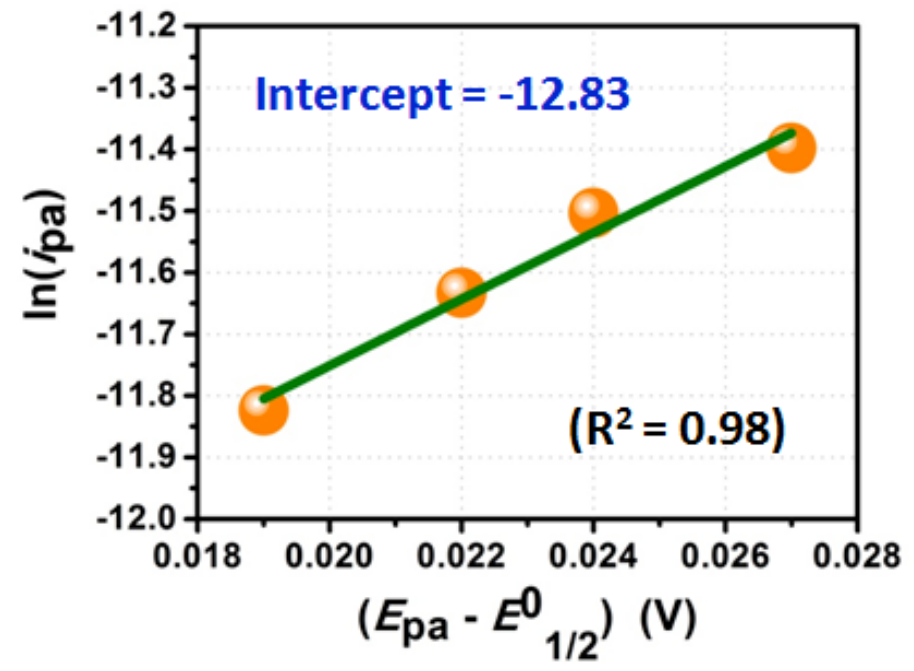

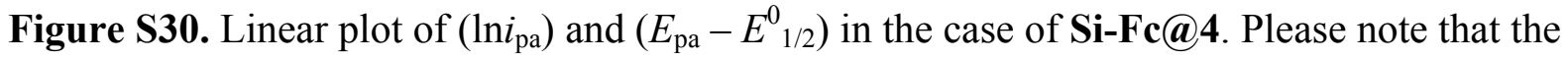
intercept of the line is -12.83 .

Table S1. Determination of the Rates of Electrochemical Oxidation $\left(k_{\mathrm{s}}\right)$ of Organo-Iron Units in Si-Fc@3 and Si-Fc@4.

\begin{tabular}{|l|l|l|l|}
\hline System & $\ln \left(\mathrm{FA}_{\mathrm{ESA}} k_{\mathrm{S}} \Gamma\right)$ & $\Gamma\left(\mathrm{mol} / \mathrm{cm}^{2}\right)$ & $k_{\mathrm{s}}\left(\mathrm{s}^{-1}\right)$ \\
\hline Si-Fc@3 & -12.60 & $1.25 \times 10^{-10}$ & 0.56 \\
\hline Si-Fc@4 & -12.83 & $9.97 \times 10^{-10}$ & 0.052 \\
\hline
\end{tabular}




\section{Electrochemical Properties of Si-NDI@5 and Calculation of Surface Coverage of Immobilized NDI}
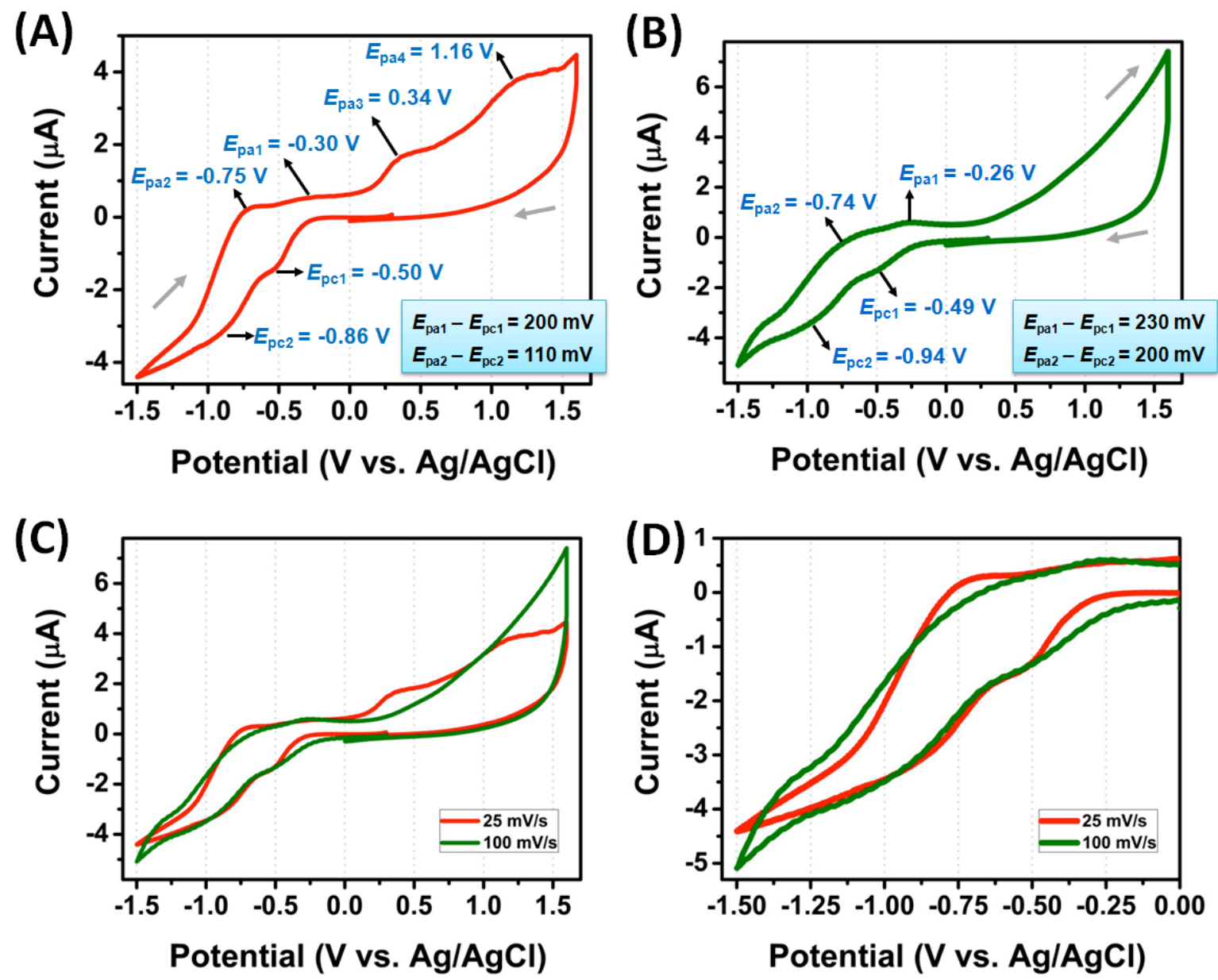

Figure S31. (A) and (B): Representative cyclic voltammograms of Si-NDI@5 at a scan rate of $25 \mathrm{mV} / \mathrm{s}$ (A) and $100 \mathrm{mV} / \mathrm{s} \mathrm{(B).} \mathrm{The} \mathrm{CVs} \mathrm{were} \mathrm{recorded} \mathrm{under} \mathrm{argon} \mathrm{gas} \mathrm{atmosphere} \mathrm{at} 25$ ${ }^{\circ} \mathrm{C}$ in dry acetonitrile using $0.1 \mathrm{M} \mathrm{n}-\mathrm{Bu}_{4} \mathrm{NPF}_{6}$ as the supporting electrolyte, the Si-NDI@5 surface as working electrode, $\mathrm{Ag} / \mathrm{AgCl}(3 \mathrm{M} \mathrm{NaCl})$ as the reference electrode and $\mathrm{Pt}$ as the counter electrode. (C): The CV profiles in (A) and (B) have been shown together in one plot for easy comparison of the electrochemical signatures of Si-NDI@5 at two different scan rates. (D): Expanded region of the CVs in (C) in the range of 0 to $-1.5 \mathrm{~V}$ for a clear observation of the redox processes associated with the NDI chromophores in Si-NDI@5. 


\section{Calculation of Surface Coverage of Immobilized NDI in Si-NDI@5}
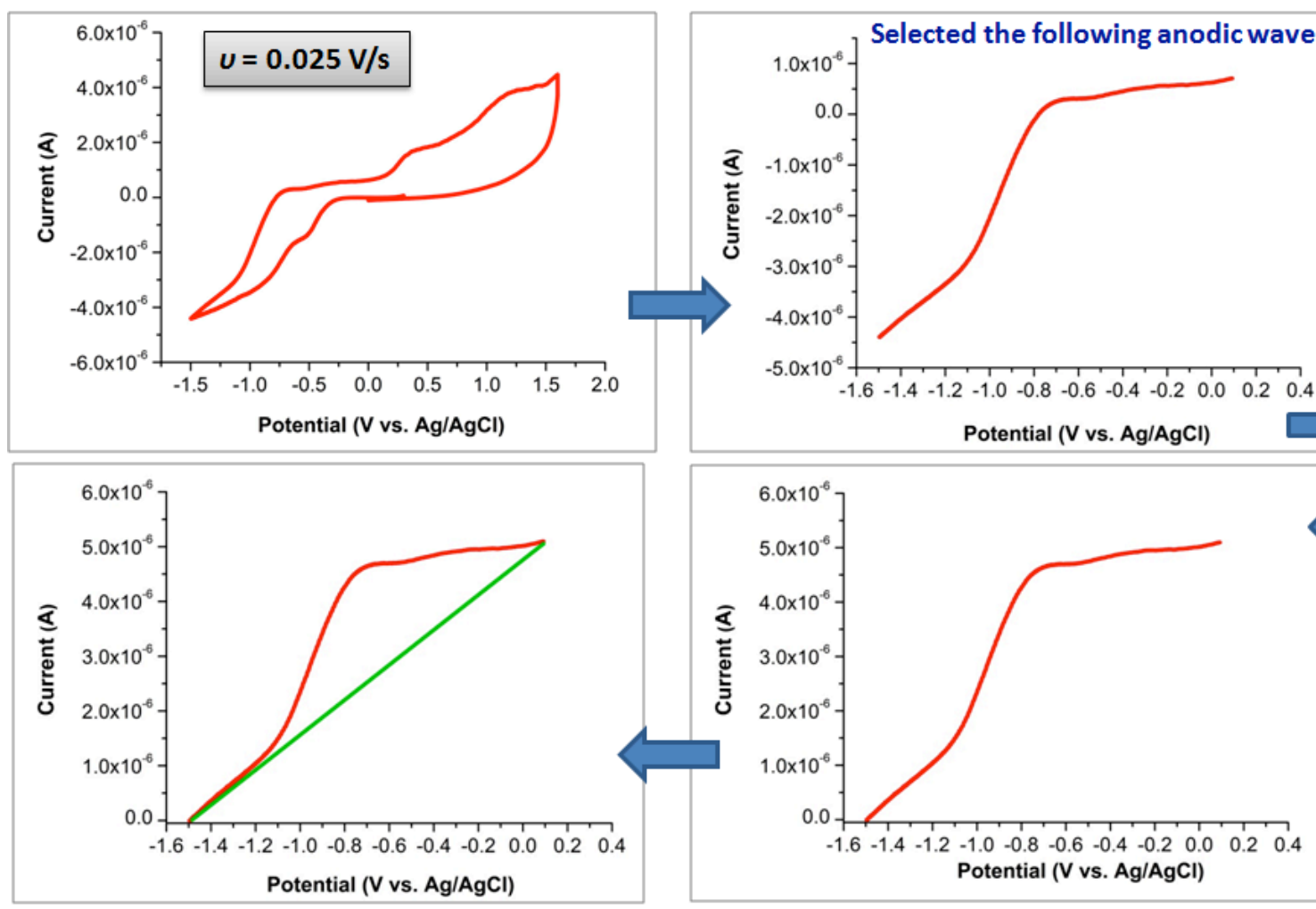

Correct area is under the curve \& bound by the tangent!

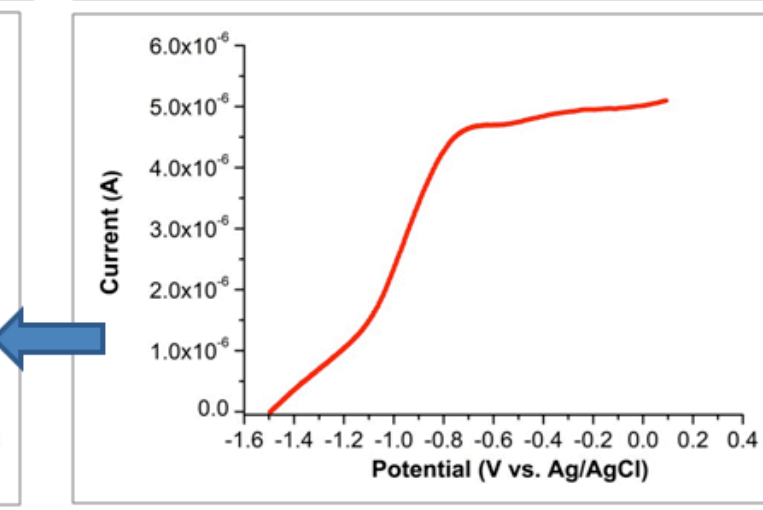

The $\mathrm{Y}$ axis is modified to keep the baseline at zero for calculating mathematical area by integration.

Integration: Total Area under the Curve

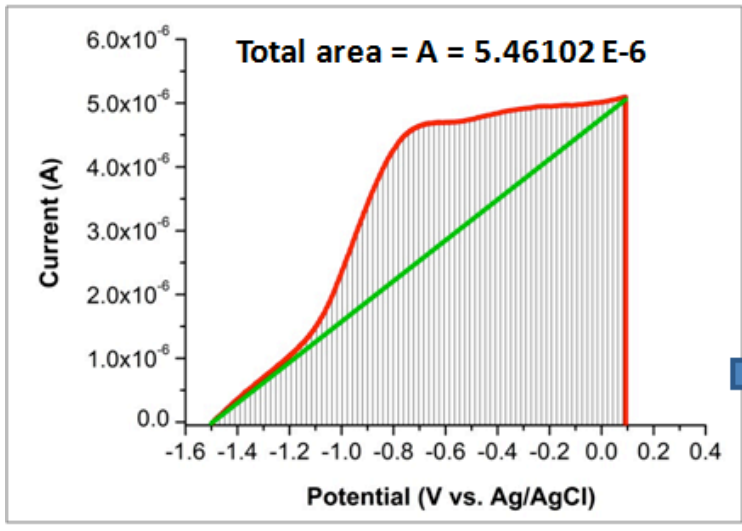

Origin Pro:

$x 1=-1.49702 ; x 2=0.09266$

i1 $=1 ;$ i $2=650$

area $=5.46102 \mathrm{E}-6$

$y 0=5.09740 E-6 ; x 0=0.09026 ; d x=1.07111$

Actual area under anodic peak: $A_{1}=\left(A-A_{2}\right)$

$=(5.46102-4.05125) \mathrm{E}-6=1.40977 \mathrm{E}-6$
Correction Employed

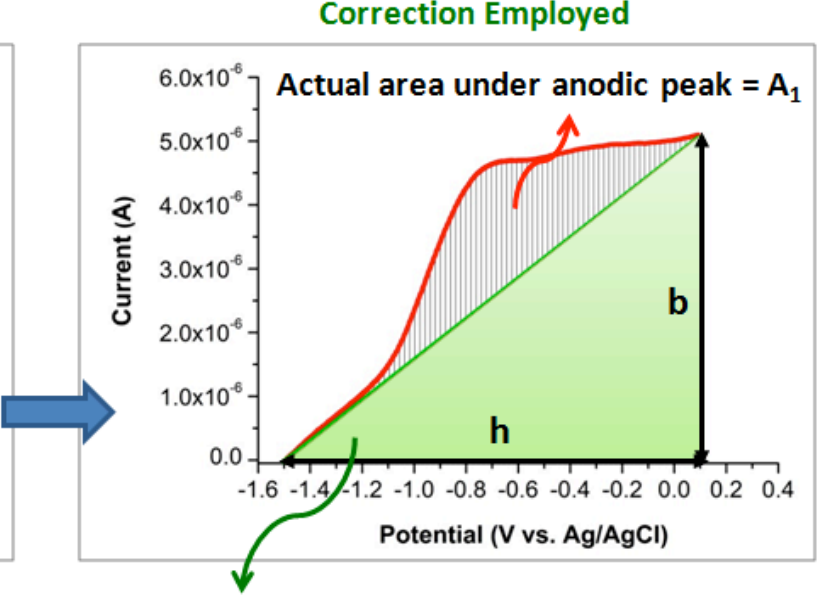

Area of unrequired right-angled triangle:

$$
A_{2}=b \times h / 2
$$

Figure S32. Calculation of area under the anodic oxidation wave for reduced NDI in SiNDI@5 (scan rate $=0.025 \mathrm{~V} / \mathrm{s})$. 
From above calculation, $\mathrm{A}_{1}=1.40977 \mathrm{E}-6 \mathrm{AV}$

Therefore, $\mathrm{Q}=\mathrm{A}_{1} /$ scan rate

$$
\begin{aligned}
& =1.40977 \times 10^{-6} \mathrm{AV} / 0.025 \mathrm{~V} / \mathrm{s} \\
& =56.39 \times 10^{-6} \mathrm{As} \\
& =56.39 \times 10^{-6} \text { Coulomb }
\end{aligned}
$$

Hence, surface coverage $\left(\mathrm{mol} / \mathrm{cm}^{2}\right)$ can be determined as (considering $\left.\mathrm{n}=2\right)$ :

$$
\begin{aligned}
\Gamma & =\mathrm{Q} / \mathrm{nFA} A_{\mathrm{ESA}} \\
& =\left(56.39 \times 10^{-6} \text { Coulomb }\right) /\left\{2 \times(96485.3329 \text { Coulomb } / \mathrm{mol}) \times\left(0.5026 \mathrm{~cm}^{2}\right)\right\} \\
& =5.81 \times 10^{-10} \mathrm{~mol} / \mathrm{cm}^{2}
\end{aligned}
$$

Surface coverage (molecules $/ \mathrm{cm}^{2}$ ) can also be expressed as following:

$\Gamma=5.81 \times 10^{-10} \mathrm{~mol} / \mathrm{cm}^{2}$

$=5.81 \times 10^{-10} \times 6.023 \times 10^{23}$ molecules $/ \mathrm{cm}^{2}$

$=34.99 \times 10^{13}$ molecules $/ \mathrm{cm}^{2}$

Thus, the area on the Si(111) surface which contains one NDI unit should be:

$$
\begin{aligned}
\mathrm{A}_{\mathrm{s}} & =\left\{1 /\left(34.99 \times 10^{13}\right)\right\} \mathrm{cm}^{2} \\
& =\left\{10^{14} /\left(34.99 \times 10^{13}\right)\right\} \mathrm{nm}^{2} \\
& =0.29 \mathrm{~nm}^{2}
\end{aligned}
$$

The ratio of Si atoms and NDI units on the surface considering the atomic density of $\mathrm{Si}(111)^{5}$ to be $7.8 \times 10^{14}$ atoms $/ \mathrm{cm}^{2}$ should be:

$$
\begin{aligned}
\mathrm{R}_{\mathrm{Si} / \mathrm{NDI}} & =\left(7.8 \times 10^{14}\right) /\left(34.99 \times 10^{13}\right) \\
& =2.2
\end{aligned}
$$

This means that $\sim 1$ NDI unit is present per 2.2 atoms of Si on the surface. 


\section{IR, NMR and ESI-Mass Spectra}

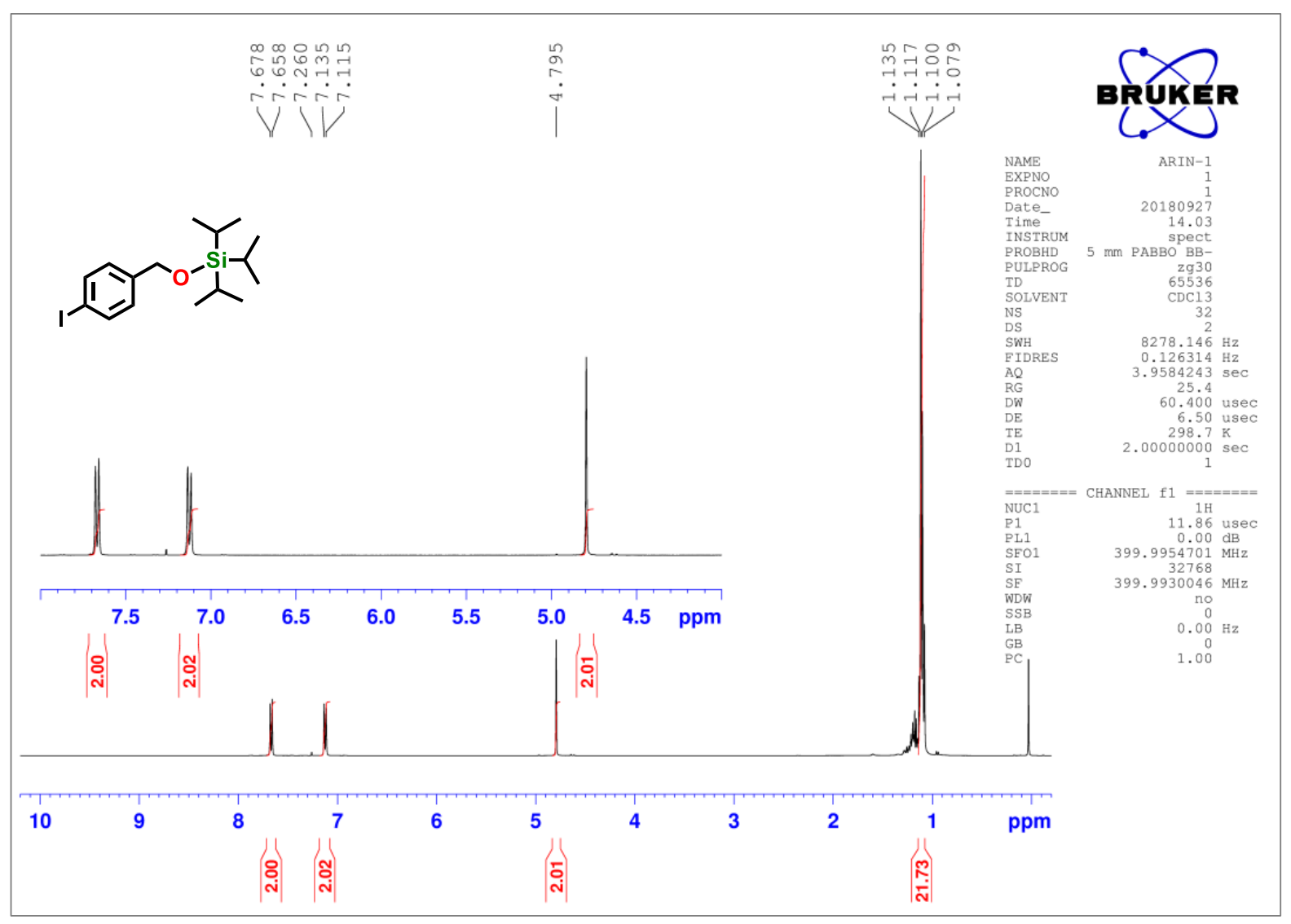

Figure S33. ${ }^{1} \mathrm{H}$ NMR $\left(400 \mathrm{MHz}, \mathrm{CDCl}_{3}\right)$ spectrum of $\mathbf{B}$. Please note that the solvent residual peak is referenced to $7.26 \mathrm{ppm}$. 


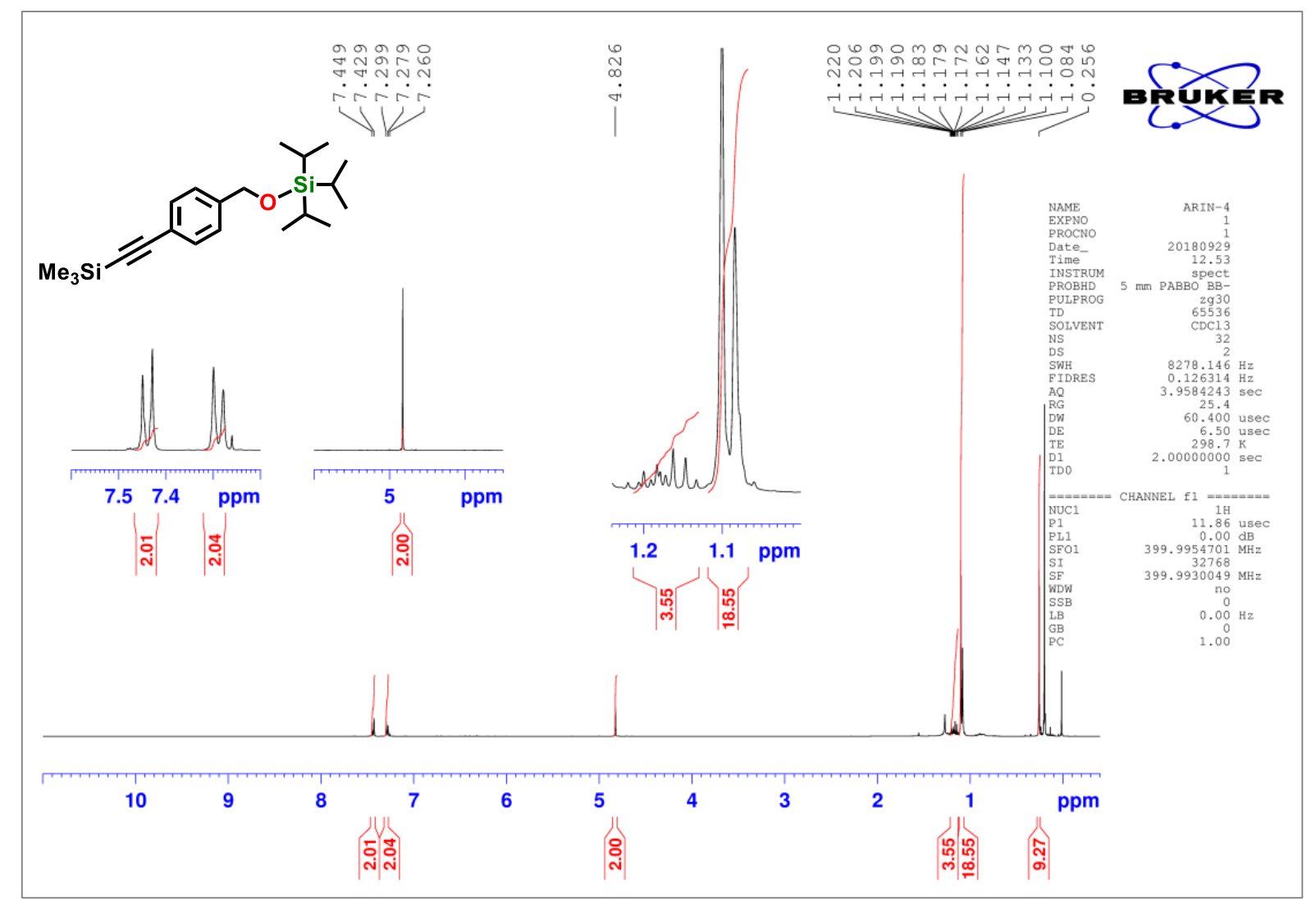

Figure S34. ${ }^{1} \mathrm{H}$ NMR $\left(400 \mathrm{MHz}, \mathrm{CDCl}_{3}\right)$ spectrum of $\mathbf{C}$. Please note that the solvent residual peak is referenced to $7.26 \mathrm{ppm}$. 


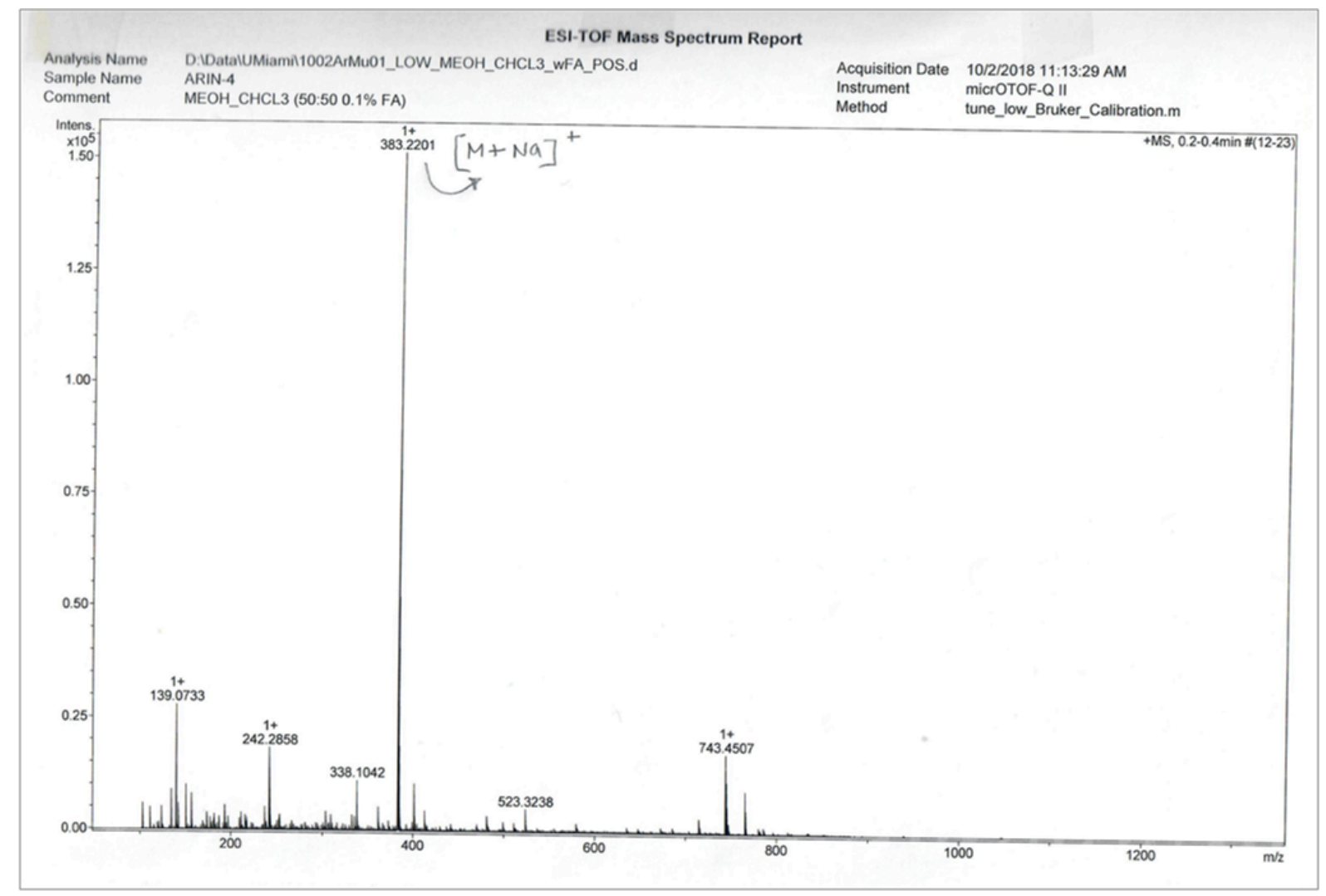

Figure S35. ESI-TOF mass (HRMS) spectrum of $\mathbf{C}$. 


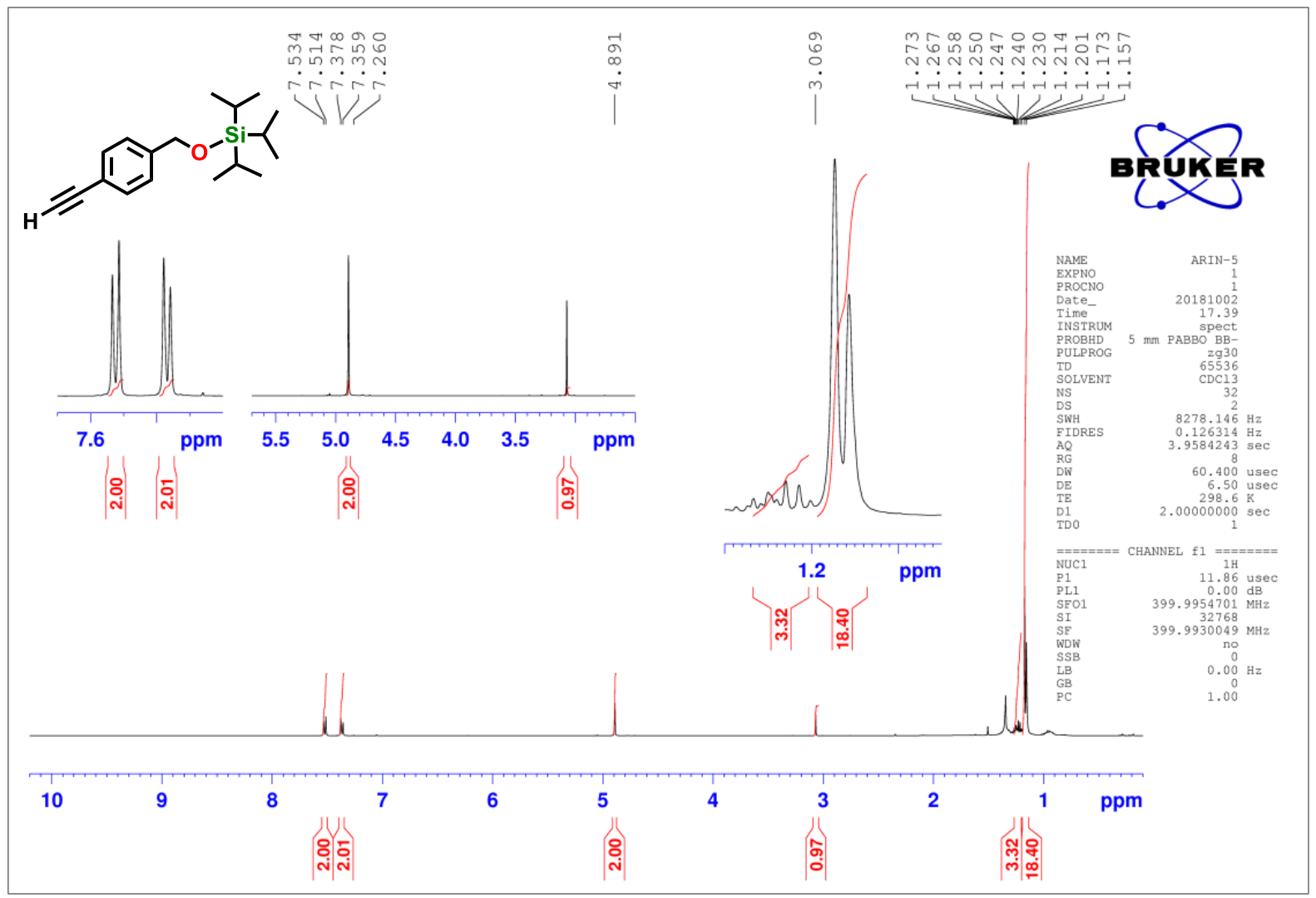

Figure S36. ${ }^{1} \mathrm{H}$ NMR $\left(400 \mathrm{MHz}, \mathrm{CDCl}_{3}\right)$ spectrum of 1 . Please note that the solvent residual peak is referenced to $7.26 \mathrm{ppm}$. 


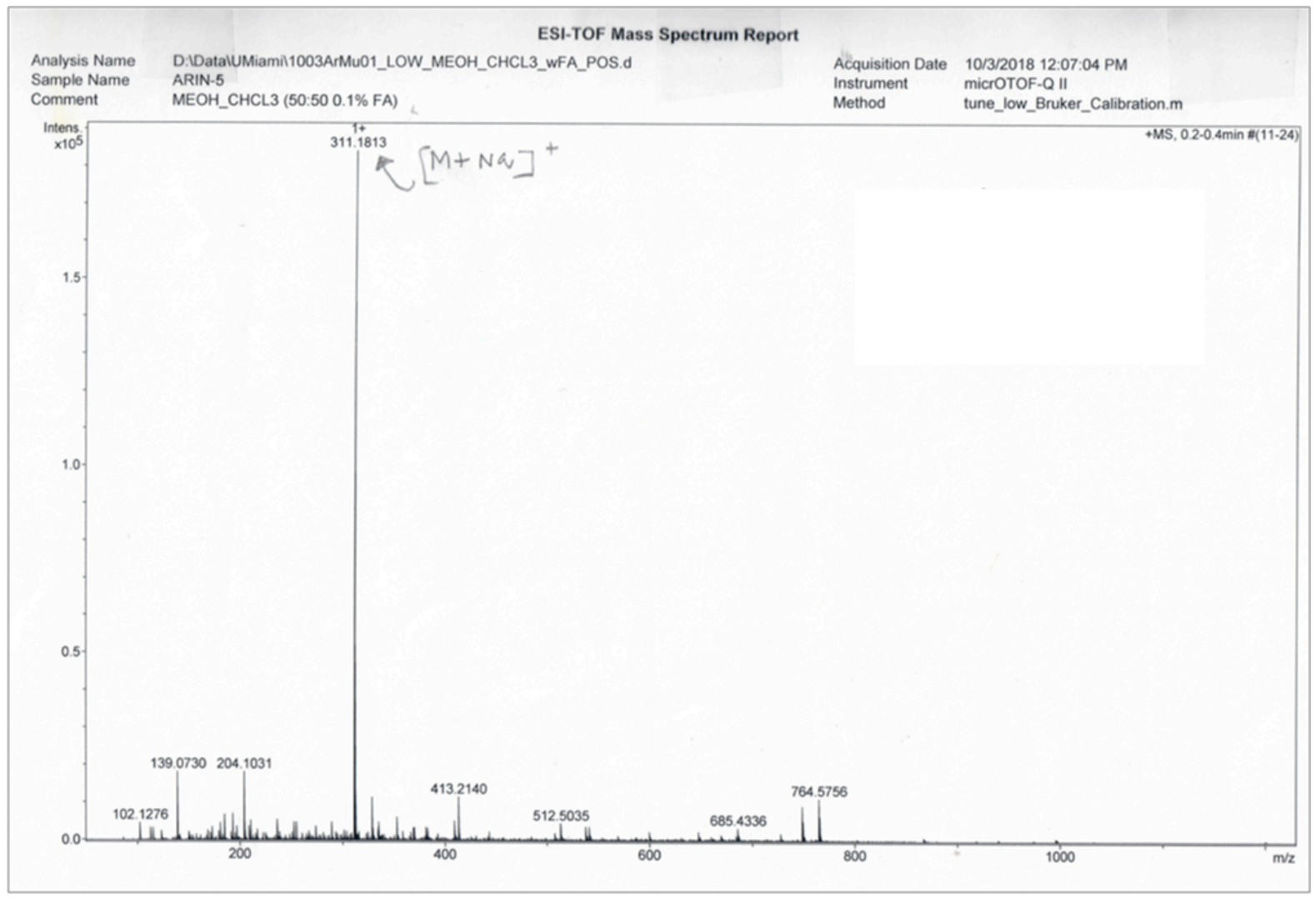

Figure S37. ESI-TOF mass (HRMS) spectrum of 1. 


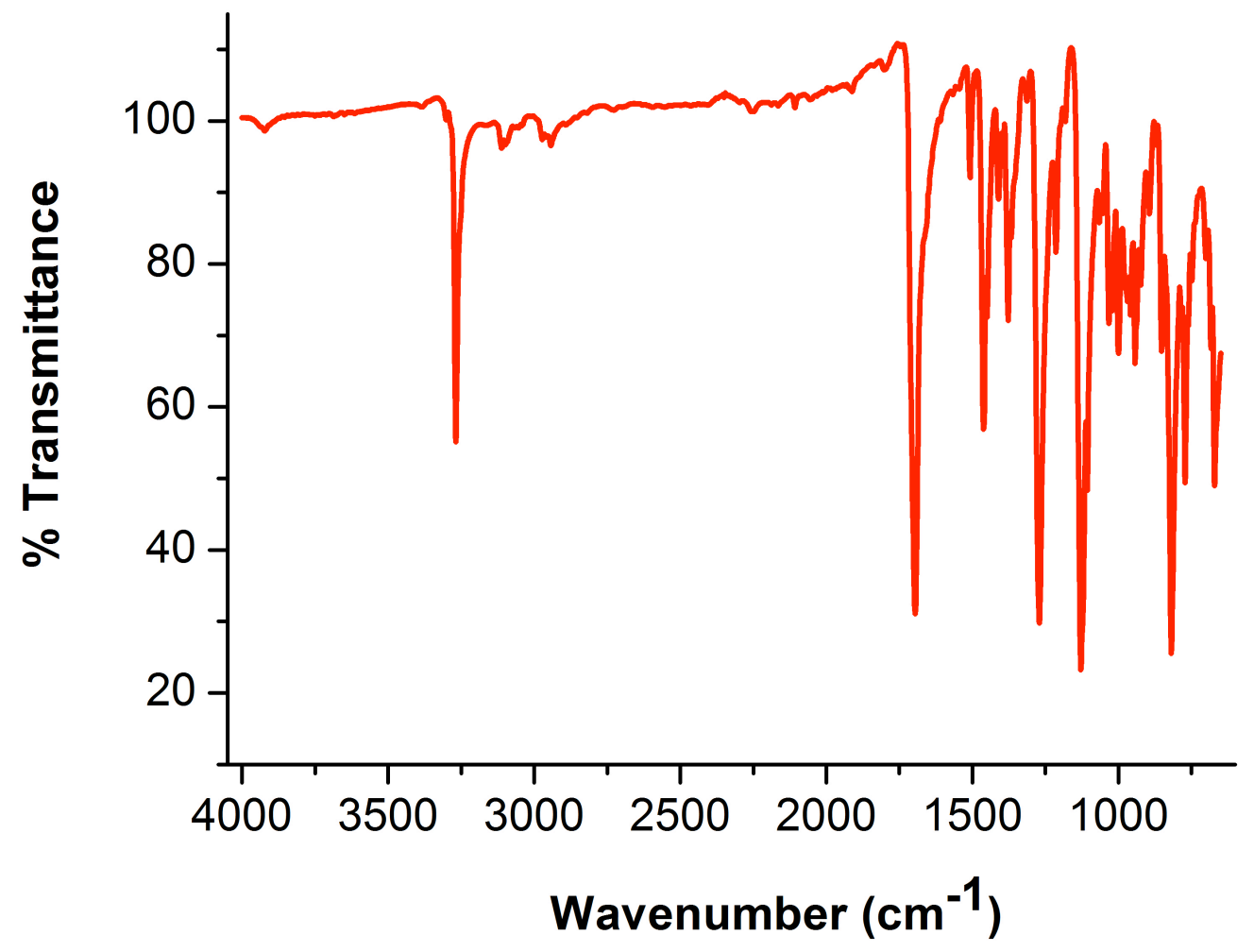

Figure S38. IR (neat solid) spectrum of 2. 


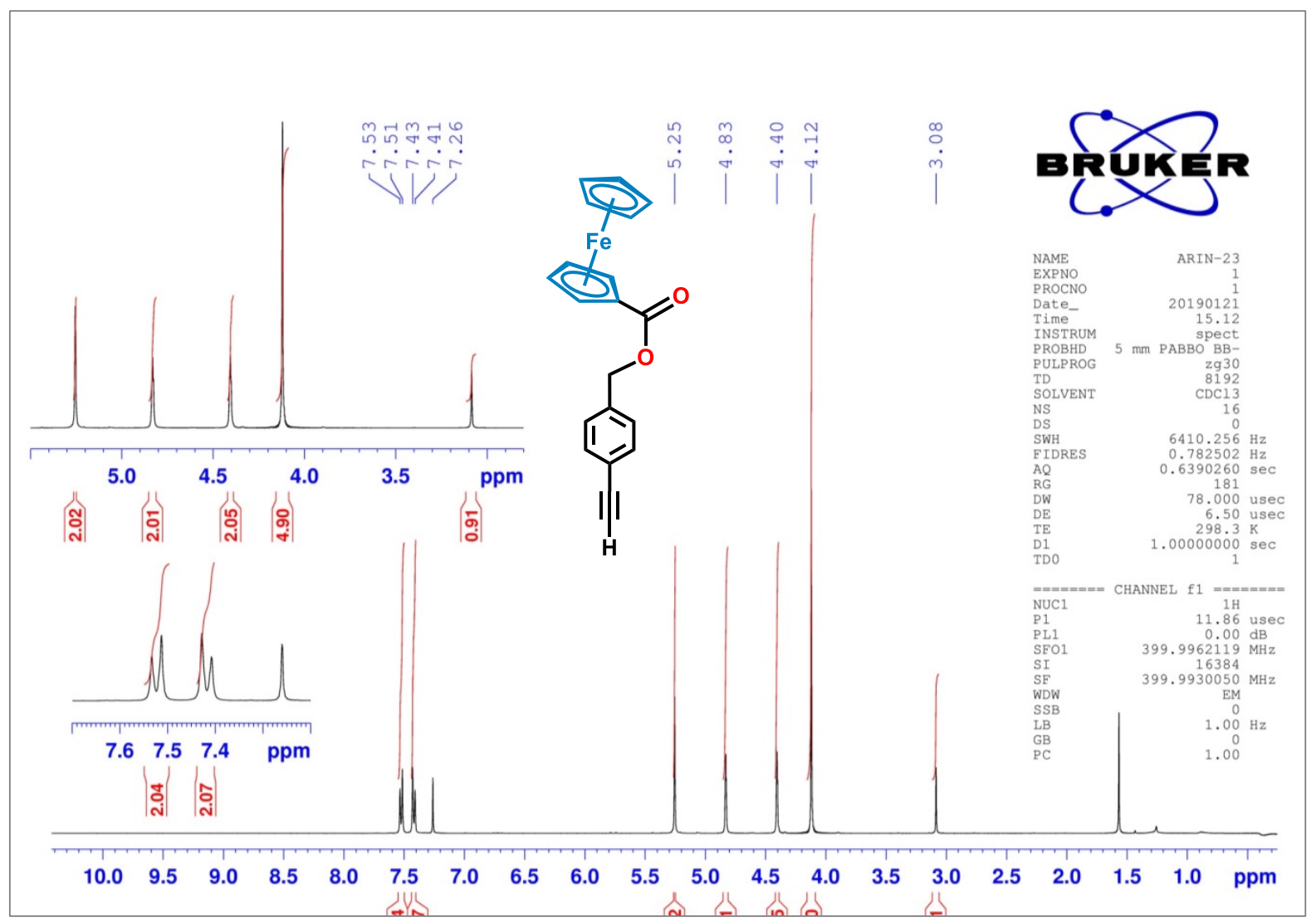

Figure S39. ${ }^{1} \mathrm{H}$ NMR $\left(400 \mathrm{MHz}, \mathrm{CDCl}_{3}\right)$ spectrum of 2. Please note that the solvent residual peak is referenced to $7.26 \mathrm{ppm}$. 


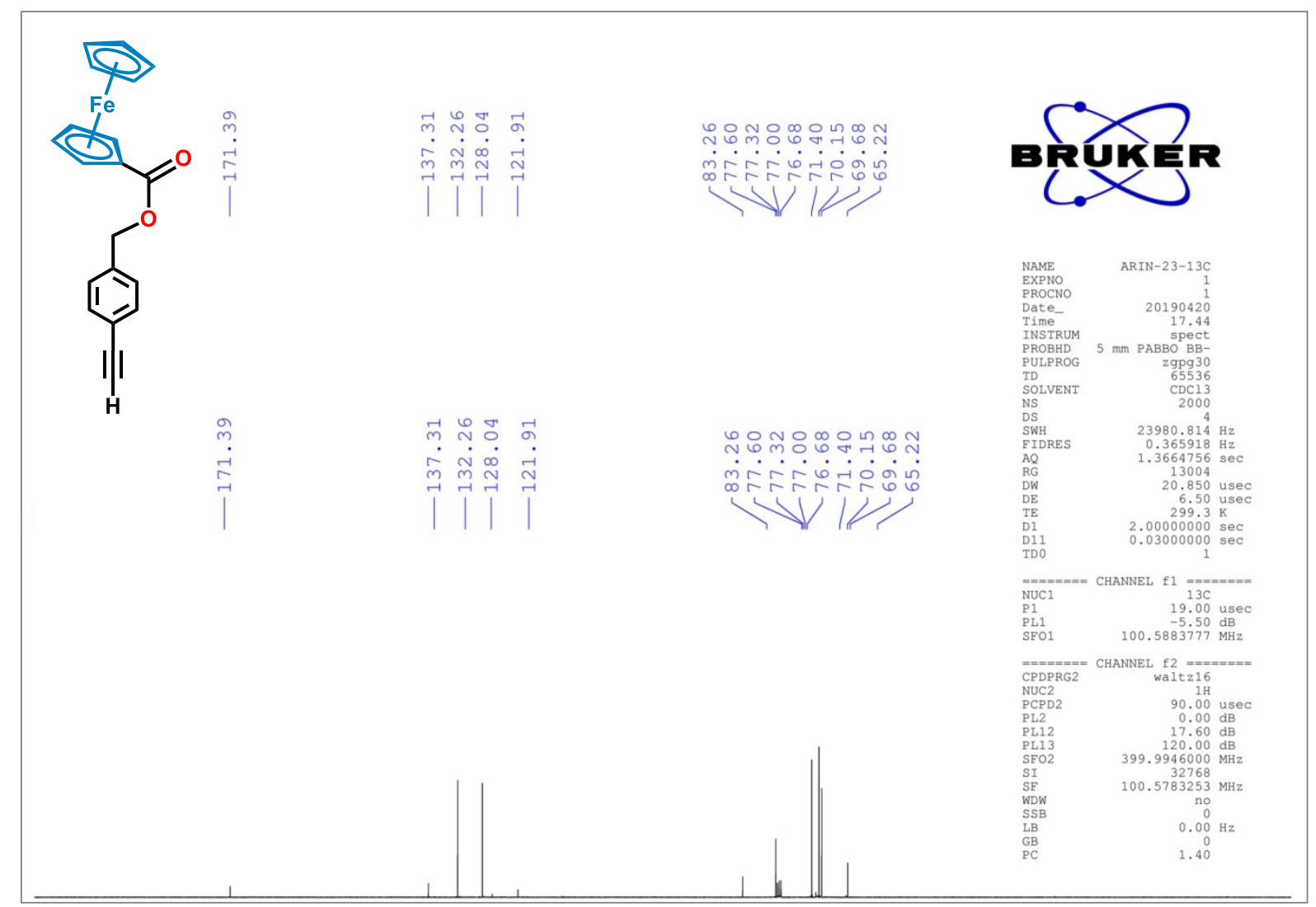

Figure S40. ${ }^{13} \mathrm{C}$ NMR $\left(101 \mathrm{MHz}, \mathrm{CDCl}_{3}\right)$ spectrum of 2. Please note that the triplet at 77.0 ppm is associated with $\mathrm{CDCl}_{3}$. 
ESI-TOF Mass Spectrum Report

$\begin{array}{ll}\begin{array}{l}\text { Analysis Name } \\ \text { Sample Name }\end{array} & \text { D:DatalUMiamil0130ArMu01_LOW_MEOH_CHCL3_WFA_POS.d } \\ \text { ARIN-23 } & \end{array}$

MEOH_CHCL3 $3(50: 500.1 \%$ FA)

Acquisition Date 1/30/2019 1:30:11 PM

microTOF-Q

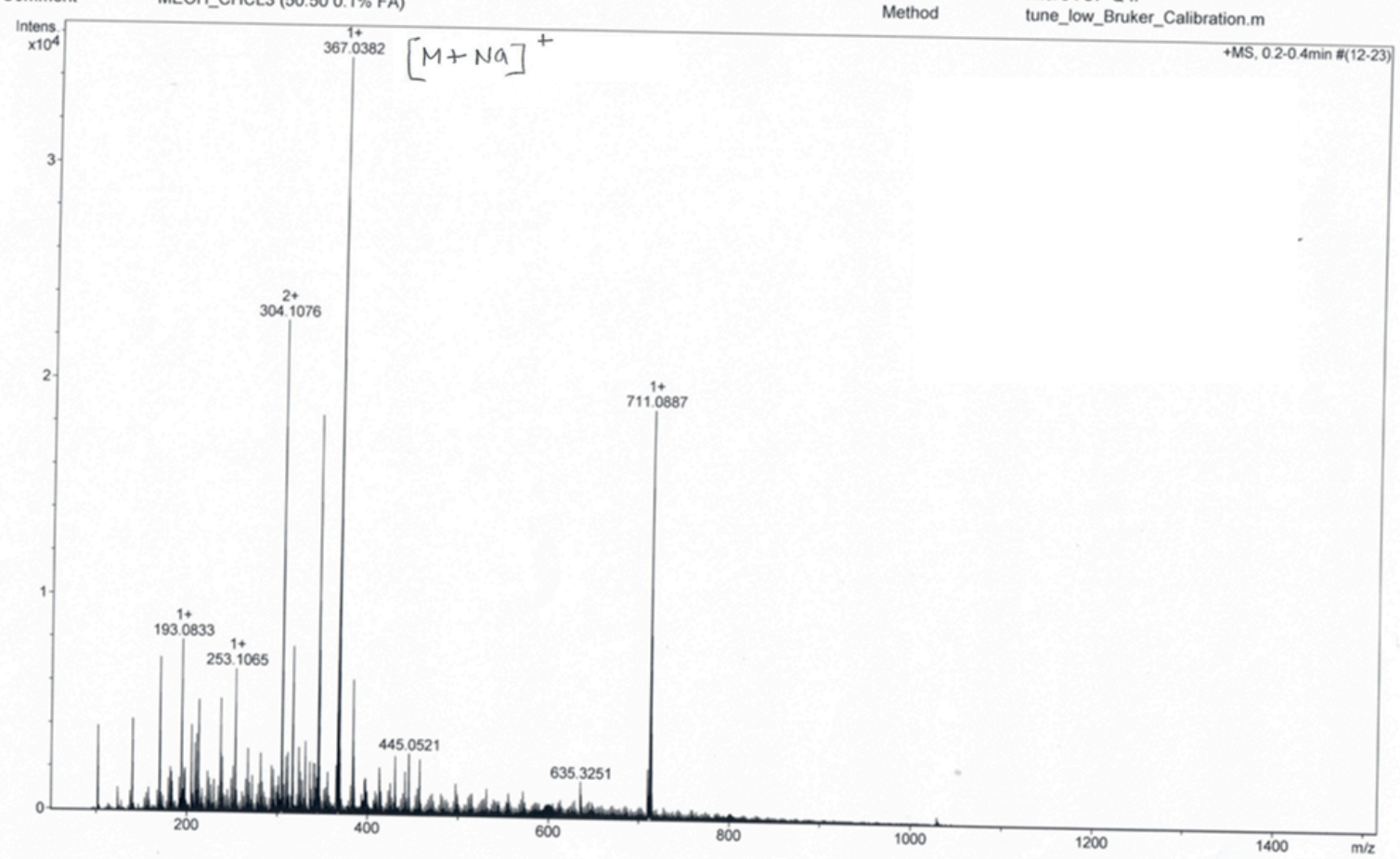

Figure S41. ESI-TOF mass (HRMS) spectrum of 2. 


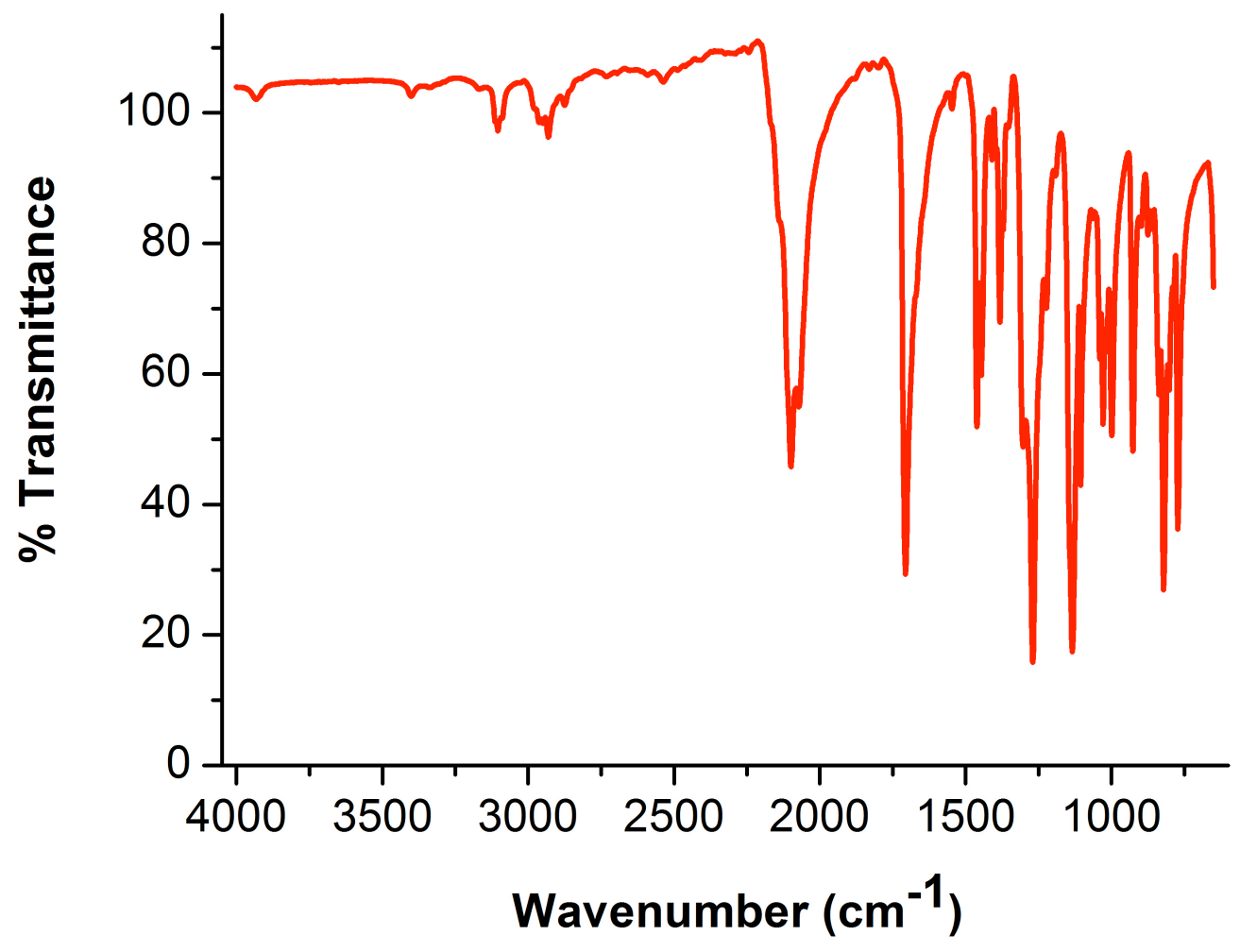

Figure S42. IR (neat solid) spectrum of 3. 


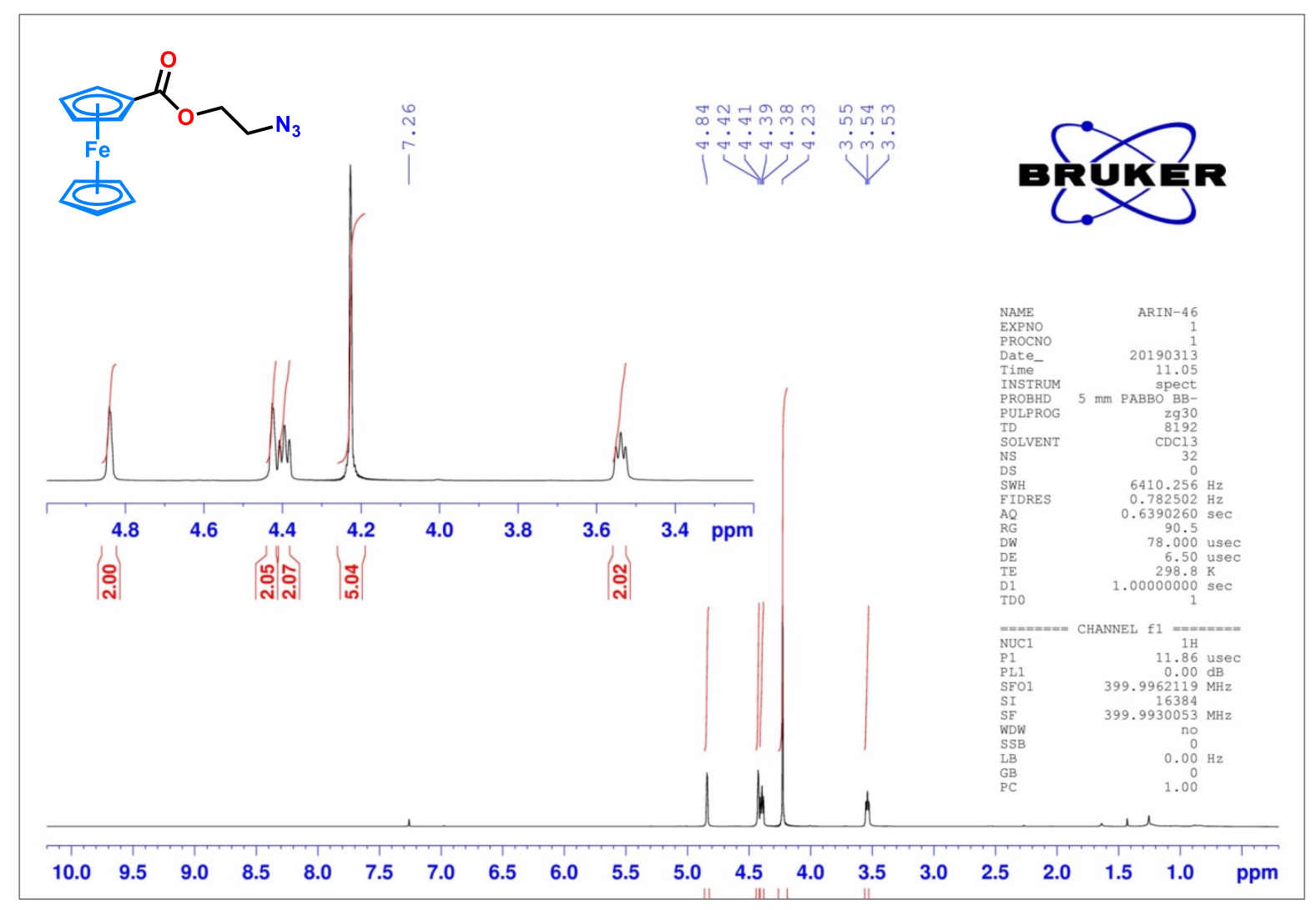

Figure S43. ${ }^{1} \mathrm{H}$ NMR $\left(400 \mathrm{MHz}, \mathrm{CDCl}_{3}\right)$ spectrum of 3. Please note that the solvent residual peak is referenced to $7.26 \mathrm{ppm}$. 


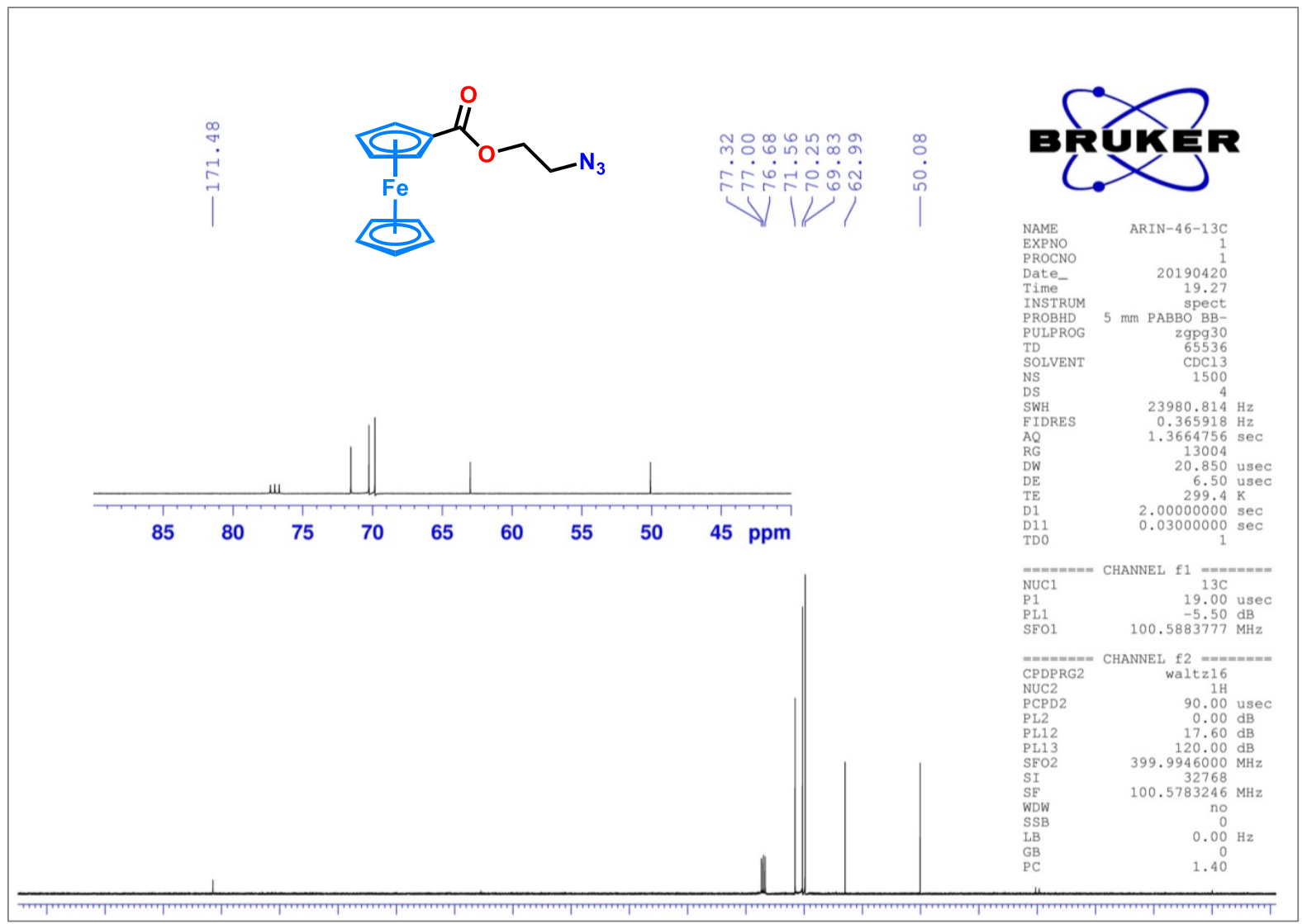

Figure S44. ${ }^{13} \mathrm{C}$ NMR $\left(101 \mathrm{MHz}, \mathrm{CDCl}_{3}\right)$ spectrum of 3. Please note that the triplet at 77.0 ppm is associated with $\mathrm{CDCl}_{3}$. 


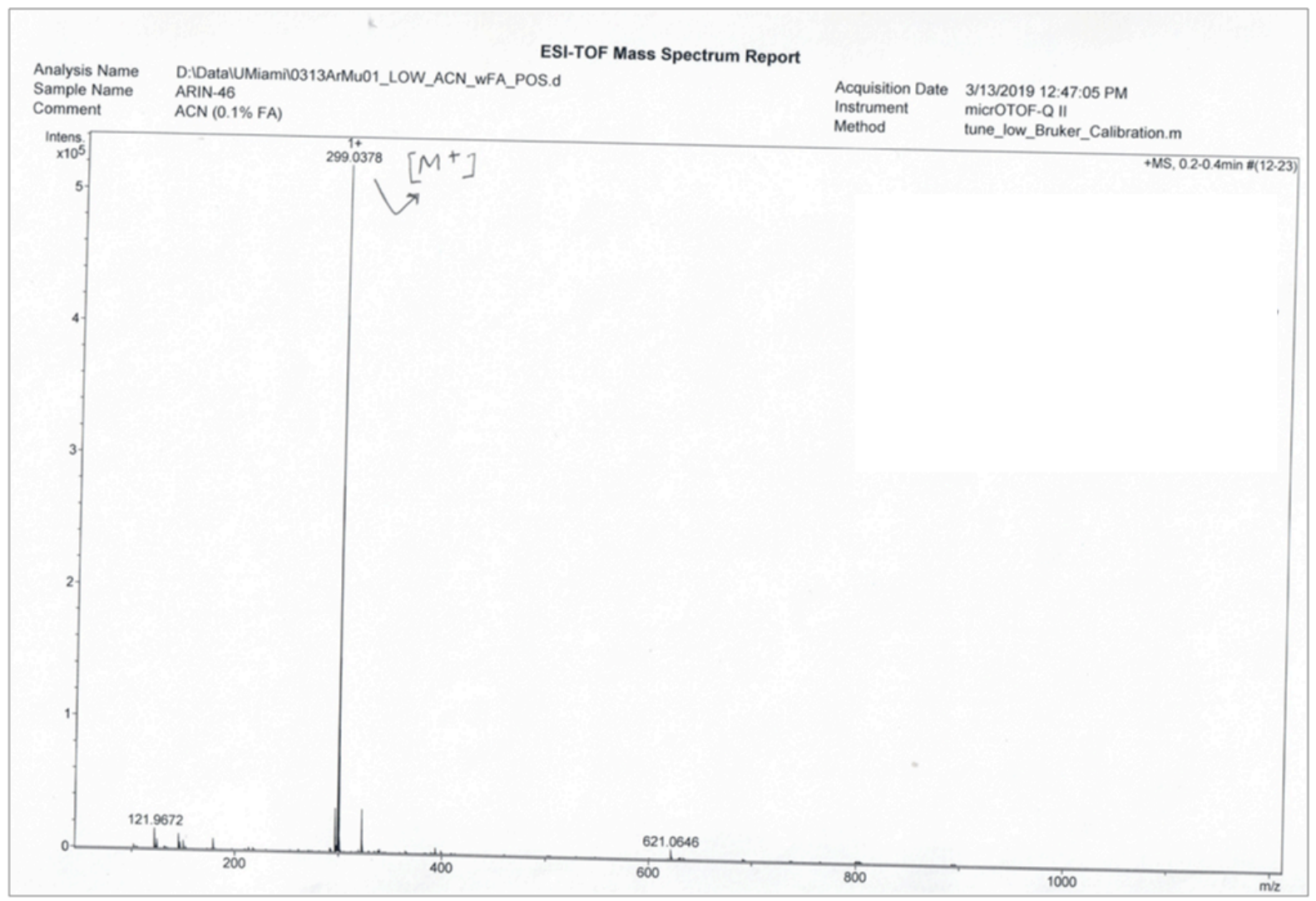

Figure S45. ESI-TOF mass (HRMS) spectrum of 3. 


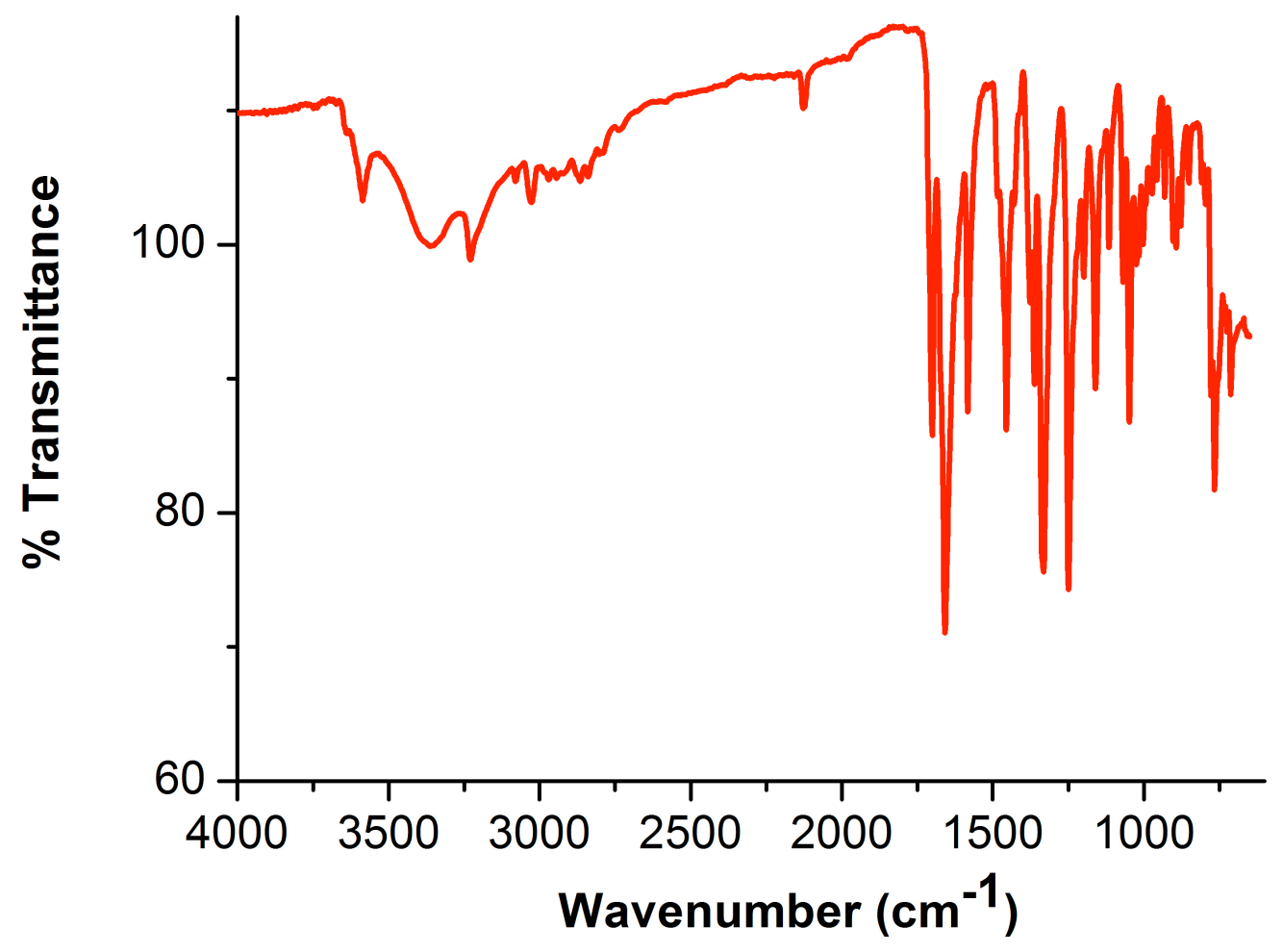

Figure S46. IR (neat solid) spectrum of 5. 


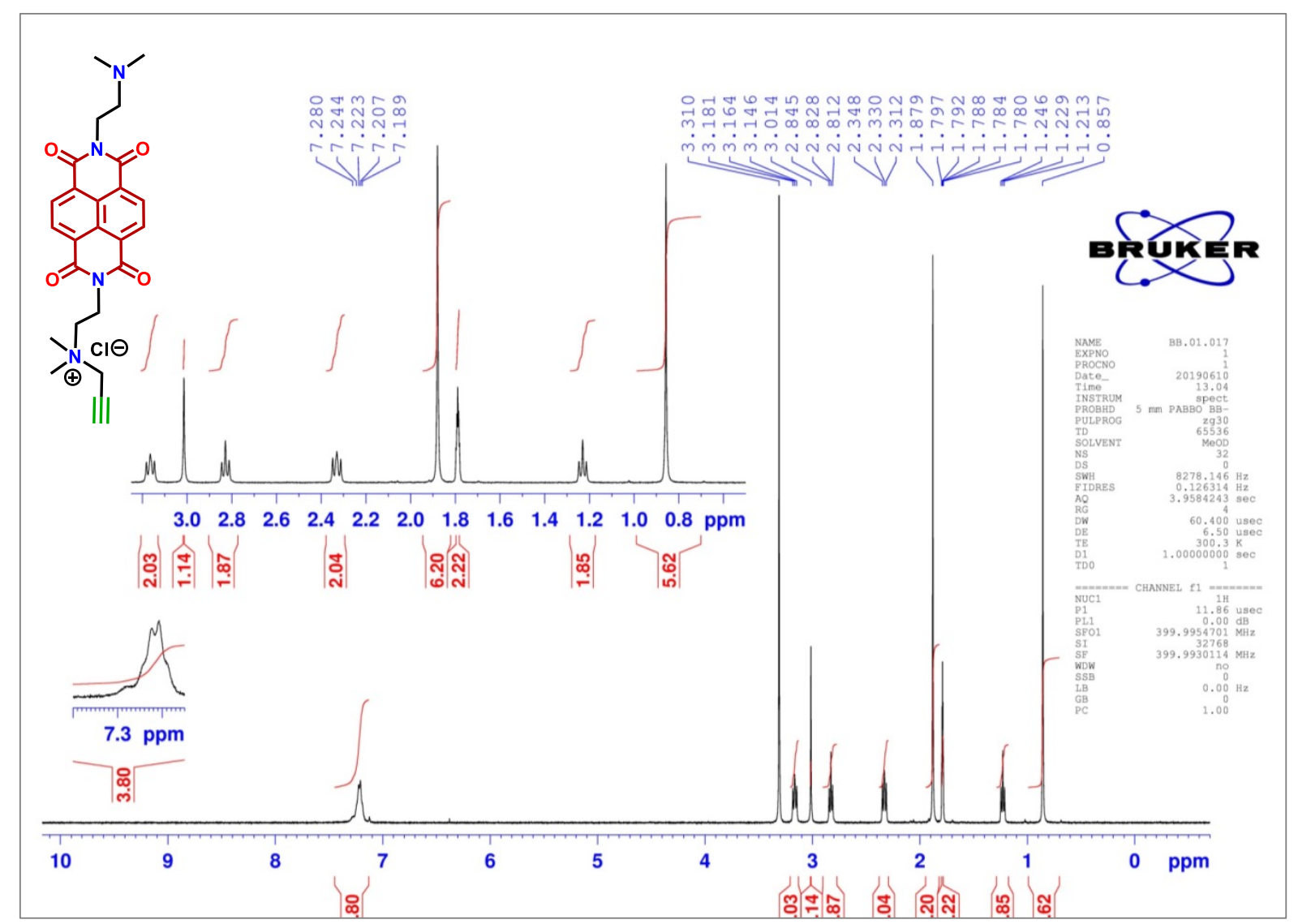

Figure S47. ${ }^{1} \mathrm{H}$ NMR $\left(400 \mathrm{MHz}, \mathrm{CD}_{3} \mathrm{OD}\right)$ spectrum of 5. Please note that the solvent residual peak is referenced to $3.31 \mathrm{ppm}$. 


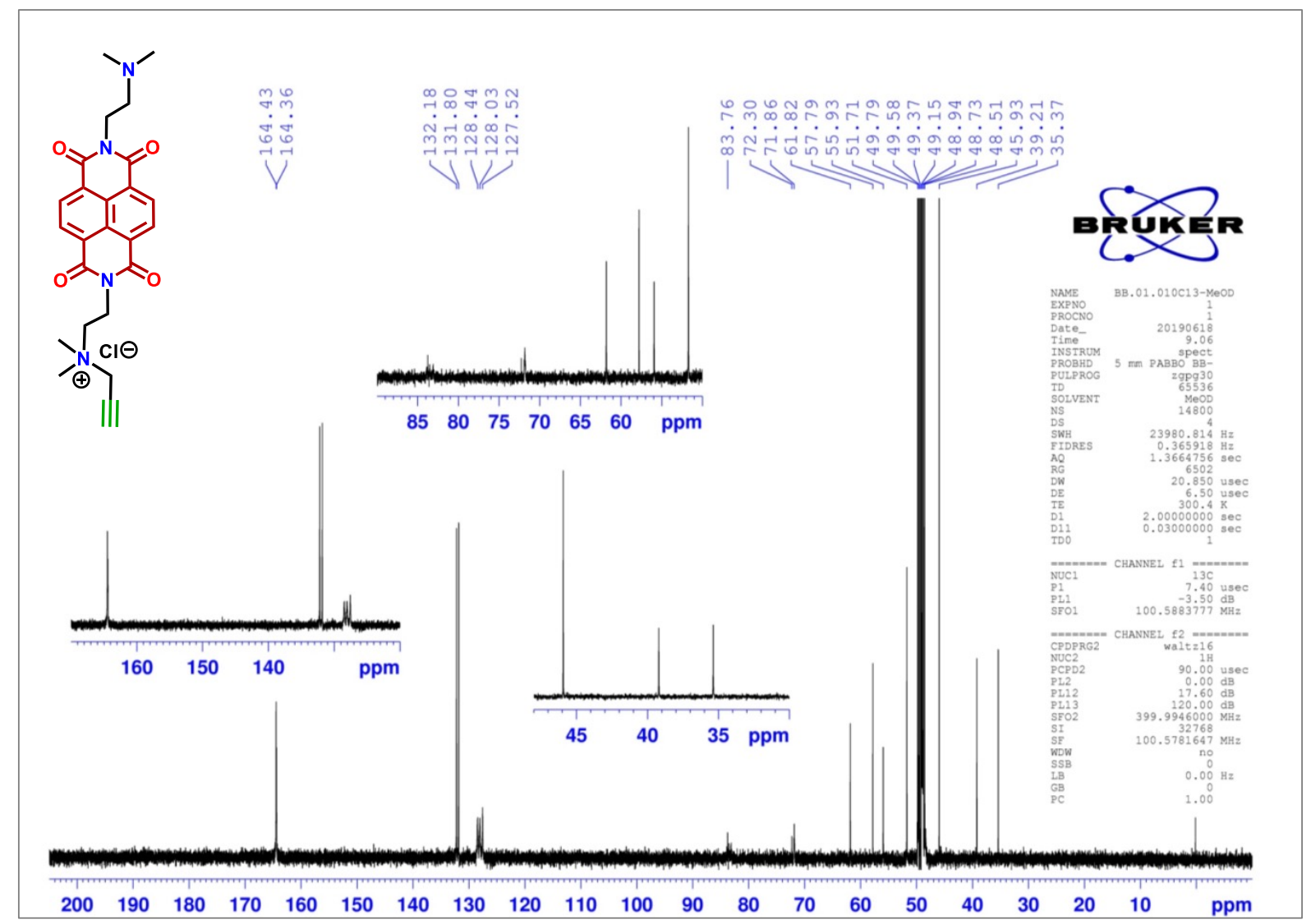

Figure S48. ${ }^{13} \mathrm{C}$ NMR $\left(101 \mathrm{MHz}, \mathrm{CD}_{3} \mathrm{OD}\right)$ spectrum of 5. Please note that the septet at 49.15 ppm is associated with $\mathrm{CD}_{3} \mathrm{OD}$. 


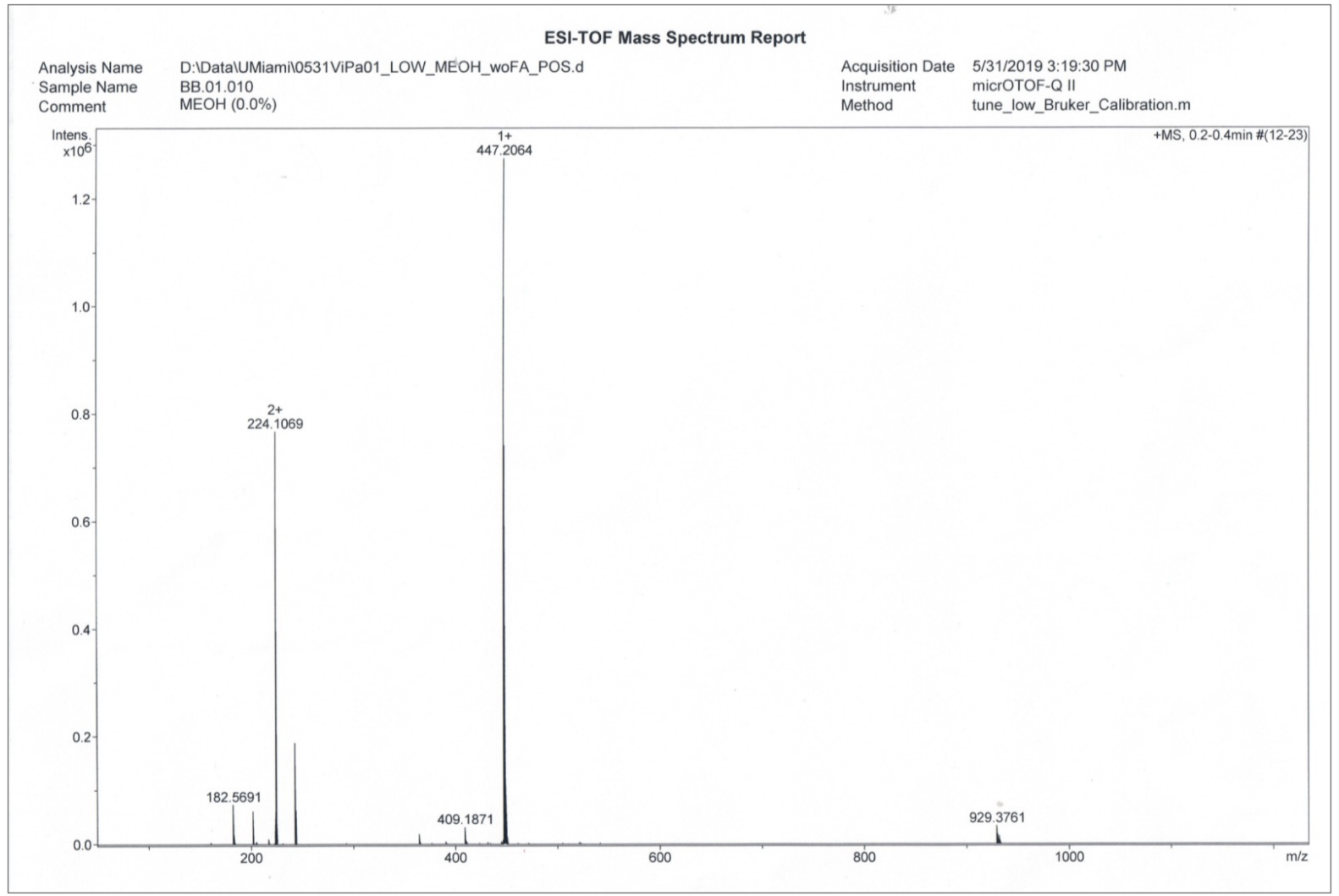

Figure S49. ESI-TOF mass (HRMS) spectrum of 5. 


\section{Key Abbreviations/Acronyms/Symbols Used}

\begin{tabular}{|c|c|}
\hline A & Ampere \\
\hline AFM & Atomic force microscopy \\
\hline anhyd & Anhydrous \\
\hline $\mathrm{Ar}$ & Argon \\
\hline $\mathrm{A}_{\mathrm{ESA}}$ & Electro-active surface area \\
\hline${ }^{\circ} \mathrm{C}$ & Degree Celsius \\
\hline ca. & Circa (from Latin, which means roughly/approximately) \\
\hline Calcd & Calculated \\
\hline cf. & Confer (from Latin, which means compare) \\
\hline $\mathrm{cm}$ & Centimeter \\
\hline Conc. & Concentrated \\
\hline $\mathrm{CV}$ & Cyclic voltammetry/voltammogram \\
\hline$\delta$ & Delta \\
\hline $\mathrm{d}$ & Doublet/Day \\
\hline$\Delta E_{\mathrm{p}}$ & Difference of peak potentials of the anodic and cathodic waves \\
\hline DCM & Dichloromethane \\
\hline DMAP & 4-(Dimethylamino)pyridine \\
\hline DMF & $N, N$-Dimethylformamide \\
\hline $\mathrm{eV}$ & Electron volt \\
\hline$E_{\mathrm{pa}}$ & Anodic peak potential \\
\hline$E_{\mathrm{pc}}$ & Cathodic peak potential \\
\hline$E_{1 / 2}$ & Average of the anodic and cathodic peak potentials \\
\hline EBA & 4-Ethynylbenzyl alcohol \\
\hline EDCI & $\begin{array}{l}N \text {-Ethyl- } N^{\prime} \text {-(3-dimethylaminopropyl)carbodiimide } \\
\text { hydrochloride }\end{array}$ \\
\hline Eq. & Equation \\
\hline ESI-MS & Electrospray ionization mass spectrometry \\
\hline $\mathrm{EtOH}$ & Ethanol \\
\hline $\mathrm{F}$ & Faraday constant \\
\hline Fc & Ferrocene \\
\hline FTIR & Fourier-transform infrared \\
\hline FWHM & Full width at half maximum \\
\hline g & Gram \\
\hline$\Gamma$ & Gamma (refers to surface coverage) \\
\hline $\mathrm{h}$ & Hour \\
\hline HBTU & $\begin{array}{l}N, N, N^{\prime}, N^{\prime} \text {-Tetramethyl- } O \text {-(1H-benzotriazol-1-yl)uronium } \\
\text { hexafluorophosphate }\end{array}$ \\
\hline$h v$ & Photoirradiation \\
\hline $\mathrm{HOMO}$ & Highest occupied molecular orbital \\
\hline HPLC & High performance liquid chromatography \\
\hline HRMS & High resolution mass spectrometry \\
\hline $\mathrm{Hz}$ & Hertz \\
\hline$i_{\mathrm{pa}}$ & Anodic peak current \\
\hline$i_{\mathrm{pc}}$ & Cathodic peak current \\
\hline IR & Infrared \\
\hline
\end{tabular}




\begin{tabular}{|c|c|}
\hline $\mathrm{K}$ & Kelvin \\
\hline$k_{\mathrm{s}}$ & Standard rate constant for electrochemical oxidation \\
\hline$\lambda$ & Wavelength \\
\hline $\mathrm{m}$ & Multiplet \\
\hline $\mathrm{M}$ & Molar \\
\hline$\mu$ & Micro \\
\hline$\mu \mathrm{m}$ & Micrometer \\
\hline $\mathrm{MeCN}$ & Acetonitrile \\
\hline $\mathrm{MeOH}$ & Methanol \\
\hline $\mathrm{MHz}$ & Megahertz \\
\hline $\min$ & Minute(s) \\
\hline $\mathrm{mL}$ & Milliliter \\
\hline $\mathrm{mM}$ & Millimolar \\
\hline $\mathrm{mmol}$ & Millimol \\
\hline mol & Mole(s) \\
\hline $\mathrm{mV}$ & Millivolt \\
\hline $\mathrm{n}$ & Number of electrons exchanged during the redox process \\
\hline$v$ & Scan rate \\
\hline NDI & Naphthalene diimide \\
\hline $\mathrm{nm}$ & Nanometer \\
\hline NMR & Nuclear magnetic resonance \\
\hline ppm & Parts per million \\
\hline PTFE & Polytetrafluoroethylene \\
\hline $\mathrm{Q}$ & Total amount of charge passed (in coulomb) \\
\hline $\mathrm{R}$ & Ideal gas constant \\
\hline $\mathrm{R}^{2}$ & Coefficient of linear regression/fitting \\
\hline $\mathrm{R}_{\mathrm{q}}(\mathrm{RMS})$ & Root-mean-square roughness \\
\hline $\mathrm{rt}$ & Room temperature \\
\hline $\mathrm{s}$ & Singlet/Second \\
\hline $\mathrm{t}$ & Triplet \\
\hline $\mathrm{T}$ & Temperature in $\mathrm{K}$ \\
\hline TBAF & Tetrabutylammonium fluoride \\
\hline TFFH & Tetramethylfluoroformamidinium hexafluorophosphate \\
\hline THF & Tetrahydrofuran \\
\hline TIPS & Triisopropylsilyl \\
\hline TLC & Thin layer chromatography \\
\hline TMS & Tetramethylsilane \\
\hline TOF & Time-of-flight \\
\hline UV & Ultraviolet \\
\hline $\mathrm{V}$ & Volt \\
\hline $\mathrm{W}$ & Watt \\
\hline XPS & X-ray photoelectron spectroscopy \\
\hline
\end{tabular}




\section{References}

1. Betzler, F. M.; Klapötke, T. M.; Sproll, S. M., Synthesis of Glycidyl-5-(carboxyethyl-1H-tetrazole) polymer and 1, 2-Bis (5-carboxyethyl-1H-tetrazolyl) ethane as Polymeric Precursor. Eur. J. Org. Chem. 2013, $509-514$.

2. Matsunaga, Y.; Goto, K.; Kubono, K.; Sako, K.; Shinmyozu, T., Photoinduced color change and photomechanical effect of naphthalene diimides bearing alkylamine moieties in the solid state. Chem. Eur. J. 2014, 20, 7309-7316.

3. Nguyen, N.-H.; Apriletti, J. W.; Baxter, J. D.; Scanlan, T. S., Hammett analysis of selective thyroid hormone receptor modulators reveals structural and electronic requirements for hormone antagonists. J. Am. Chem. Soc. 2005, 127, 4599-4608.

4. Leroux, Y. R.; Fei, H.; Noël, J.-M.; Roux, C.; Hapiot, P., Efficient covalent modification of a carbon surface: use of a silyl protecting group to form an active monolayer. J. Am. Chem. Soc. 2010, 132, 14039-14041.

5. Gauthier, N.; Argouarch, G.; Paul, F.; Humphrey, M. G.; Toupet, L.; Ababou-Girard, S.; Sabbah, H.; Hapiot, P.; Fabre, B., Silicon surface-bound redox-active conjugated wires derived from mono- and dinuclear iron (II) and ruthenium (II) oligo (phenyleneethynylene) complexes. Adv. Mater. 2008, 20, 1952-1956.

6. Laviron, E., General expression of the linear potential sweep voltammogram in the case of diffusionless electrochemical systems. J. Electroanal. Chem. 1979, 101, 19-28. 